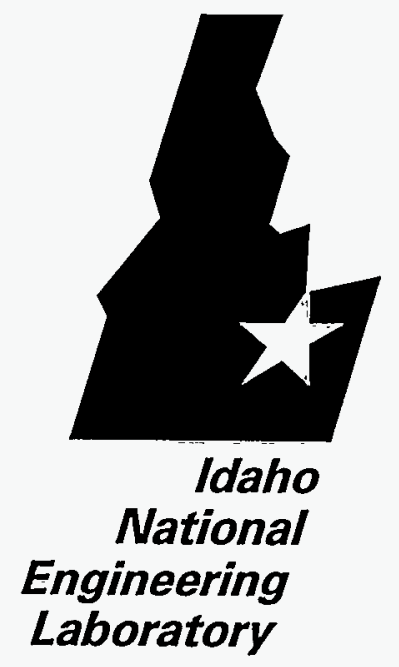

INEL-96/0176

May 1996

The Efficiency Calibration and Development of Environmental

Correction Factors for an In Situ Highresolution Gamma Spectroscopy Well Logging System

John R. Giles

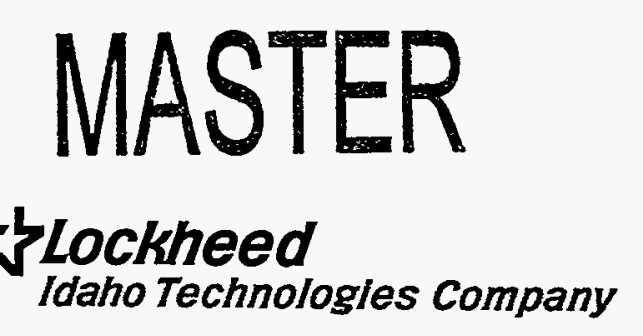





\section{The Efficiency Calibration and Development of Environmental Correction Factors for an In Situ High-resolution Gamma Spectroscopy Well Logging System John R. Giles}

Published May 1996

Idaho National Engineering Laboratory Lockheed Idaho Technologies Company Idaho Falls, Idaho 83415 



\section{DISCLAIMER}

Portions of this document may be illegible in electronic image products. Images are produced from the best available original document. 



\section{ACKNOWLEDGMENTS}

The author wishes to acknowledge the support and opportunity for this thesis project provided by the United States Department of Energy, Associated Western Universities, Inc., and particularly the Environmental Restoration division of Lockheed Martin Idaho Technologies Company. This research was conducted in support of and funded by EM40.

\section{DISCLAIMER}

This report was prepared as an account of work sponsored by an agency of the United States Government. Neither the United States Government nor any agency thereof, nor any of their employees, makes any warranty, express or implied, or assumes any legal liability or responsibility for the accuracy, completeness, or usefulness of any information, apparatus, product, or process disclosed, or represents that its use would not infringe privately owned rights. Reference herein to any specific commercial product, process, or service by trade name, trademark, manufacturer, or otherwise does not necessarily constitute or imply its endorsement, recommendation, or favoring by the United States Government or any agency thereof. The views and opinions of authors expressed herein do not necessarily state or reflect those of the United States Government or any agency thereof. 


\section{CONTENTS}

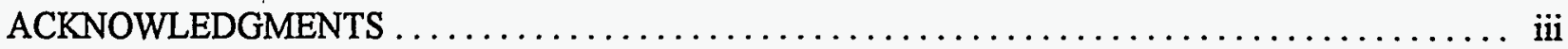

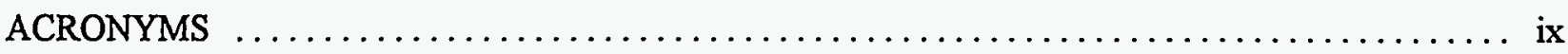

INTRODUCTION $\ldots \ldots \ldots \ldots \ldots \ldots \ldots \ldots \ldots \ldots \ldots \ldots \ldots \ldots \ldots \ldots \ldots \ldots \ldots \ldots \ldots, 1$

LITERATURE REVIEW $\ldots \ldots \ldots \ldots \ldots \ldots \ldots \ldots \ldots \ldots \ldots \ldots \ldots \ldots \ldots \ldots \ldots \ldots \ldots \ldots$

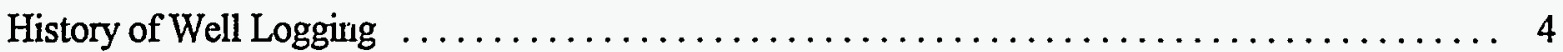

Photon Interactions in the Borehole Environment $\ldots \ldots \ldots \ldots \ldots \ldots \ldots \ldots \ldots \ldots \ldots$

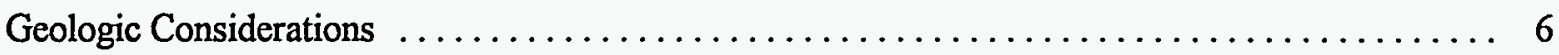

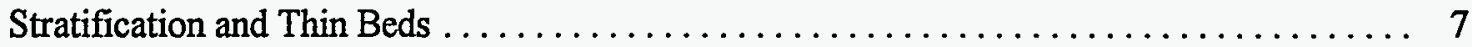

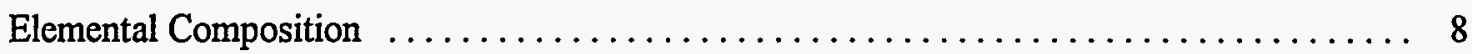

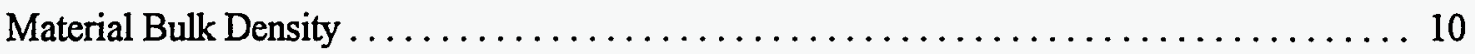

Material Porosity and Moisture Content $\ldots \ldots \ldots \ldots \ldots \ldots \ldots \ldots \ldots \ldots \ldots \ldots \ldots \ldots \ldots \ldots \ldots \ldots \ldots \ldots$

Computer Modeling of Photon Fluence $\ldots \ldots \ldots \ldots \ldots \ldots \ldots \ldots \ldots \ldots \ldots \ldots \ldots \ldots \ldots$

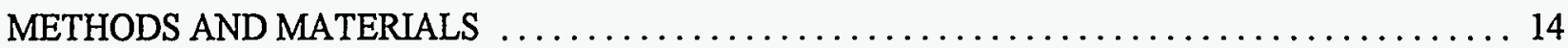

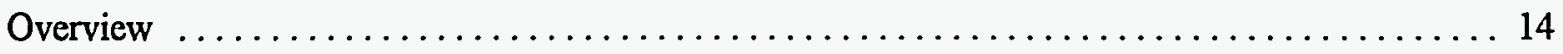

Description of Gamma Spectroscopy Logging System $\ldots \ldots \ldots \ldots \ldots \ldots \ldots \ldots \ldots \ldots$

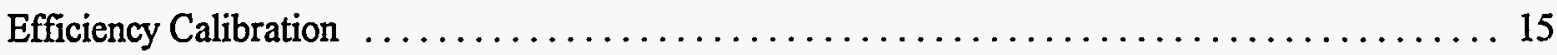

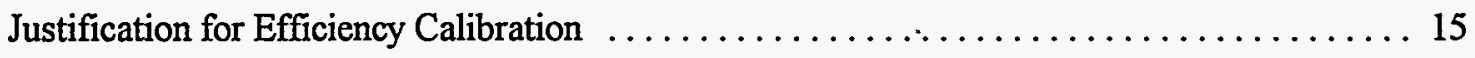

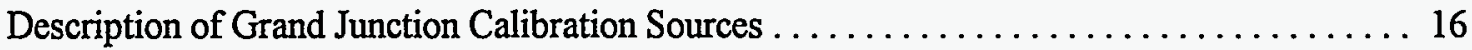

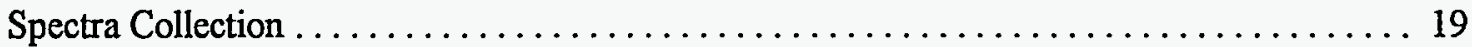

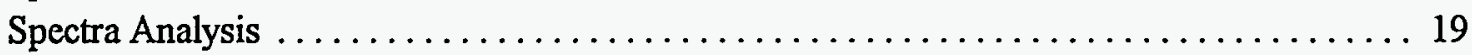

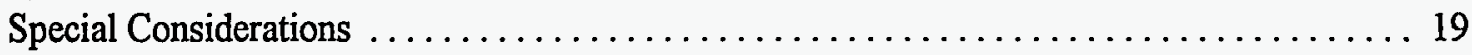

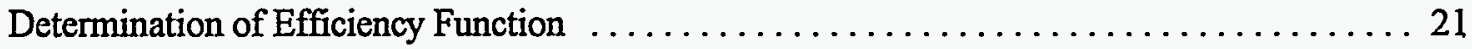

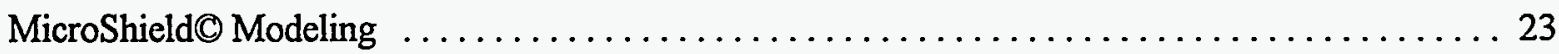

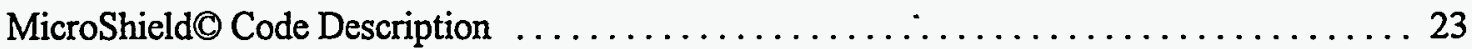

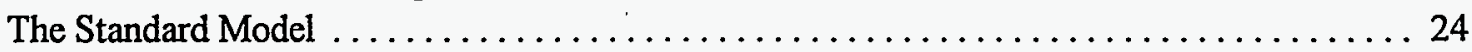

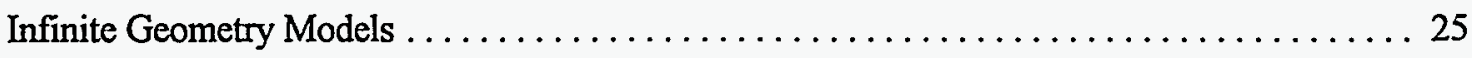

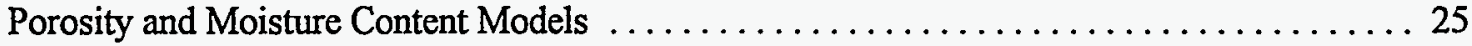

Casing, Annular Fill, and Water-Filled Borehole Models $\ldots \ldots \ldots \ldots \ldots \ldots \ldots \ldots . \ldots 28$ 


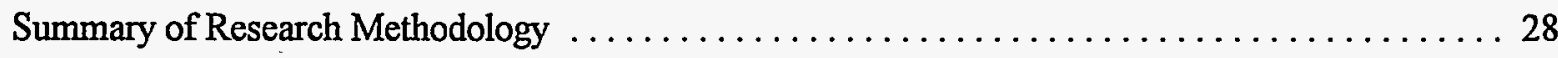

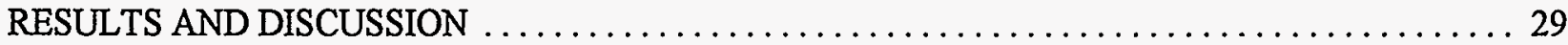

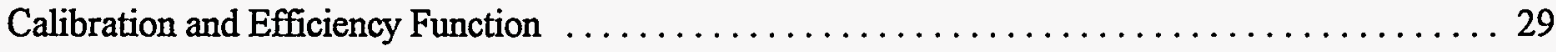

MicroShield $₫$ Modeling $\ldots \ldots \ldots \ldots \ldots \ldots \ldots \ldots \ldots \ldots \ldots \ldots \ldots \ldots \ldots \ldots \ldots \ldots$

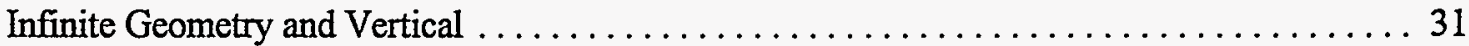

Distribution Study . . . . . . . . . . . . . . . . . . . . . . . . . . 32

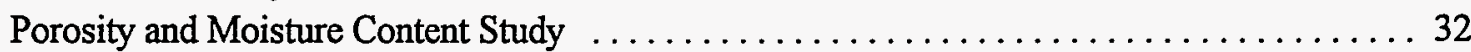

Casing, Annular Fill, and Water-Filled Borehole Correction Factors:

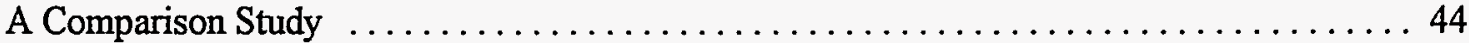

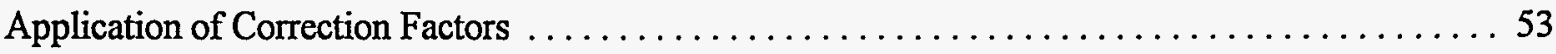

Summary of GSLS Calibration and MicroShieldC Modeling Results $\ldots \ldots \ldots \ldots \ldots \ldots \ldots . \ldots 4$

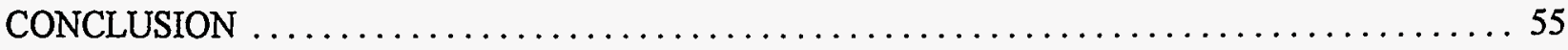

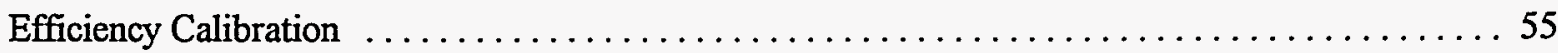

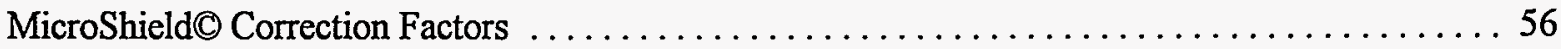

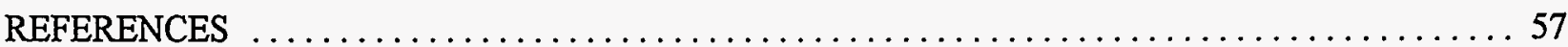

\section{FIGURES}

1. Total attenuation for Earth materials and NBS concrete $\ldots \ldots \ldots \ldots \ldots \ldots \ldots \ldots \ldots \ldots$

2. Gamma Spectroscopy Logging System with logging tool $\ldots \ldots \ldots \ldots \ldots \ldots \ldots \ldots \ldots$

3. Typical cross-section of $\mathrm{K}$, $\mathrm{U}$, and $\mathrm{T}$ calibration sources $\ldots \ldots \ldots \ldots \ldots \ldots \ldots \ldots \ldots \ldots$

4. GSLS Efficiency curve for photons ranging from $186-\mathrm{keV}$ to $2,614-\mathrm{keV} \ldots \ldots \ldots \ldots \ldots$

5. Relative photon fluence rates for annular thicknesses from $1.0-\mathrm{cm}$ to $105.0-\mathrm{cm} \ldots \ldots \ldots \ldots . \ldots 32$

6. Relative photon fluence rates for annular heights from $1.0-\mathrm{cm}$ to $200.0-\mathrm{cm} \ldots \ldots \ldots \ldots \ldots \ldots$

7a. Correction factors for thin beds $15-\mathrm{cm}$ to $50-\mathrm{cm}$ thick for photons from $186-\mathrm{keV}$ to $2,614-\mathrm{keV} \ldots 34$

7b. Correction factors for thin beds $60-\mathrm{cm}$ to $90-\mathrm{cm}$ thick for photons from $186-\mathrm{keV}$ to $2,614-\mathrm{keV} \ldots 35$ 
8. Vadose zone correction factors for formation porosities from $10 \%$ to $60 \%$ and photons from

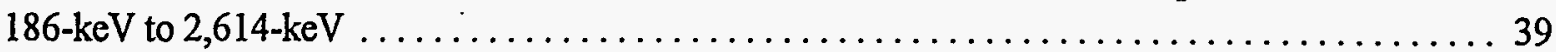

9. Saturated zone correction factors for formation porosities from $10 \%$ to $60 \%$ and photons $\ldots \ldots .40$ from $186-\mathrm{keV}$ to $2,614-\mathrm{keV}$

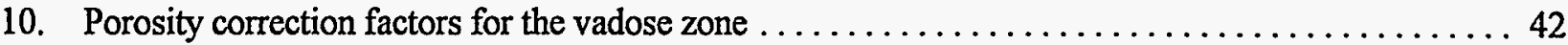

11. Porosity correction factors for the saturated zone $\ldots \ldots \ldots \ldots \ldots \ldots \ldots \ldots \ldots \ldots \ldots \ldots$

12. Saturation ratio correction factors for formation porosities from $10 \%$ to $60 \% \ldots \ldots \ldots \ldots \ldots 45$

13. Three-dimensional representation of the saturation ratio correction factors as a function of

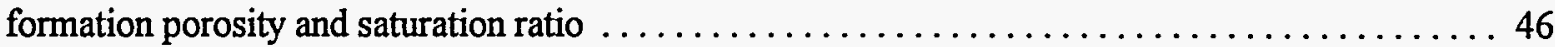

14. Iron casing correction factors, $\mathrm{K}_{\mathrm{I}}$, for casing thicknesses of $0.75-\mathrm{cm}$ and $1.0-\mathrm{cm}$, with and without buildup

15. Water-filled borehole correction factors, $\mathrm{K}_{\mathrm{WF}}$, for water annuli $1.0,4.0,7.0$, and $11.0-\mathrm{cm}$ thick, with and without buildup 48

16. PVC casing correction factors for casing thicknesses of $0.75-\mathrm{cm}$ and $1.0-\mathrm{cm} \ldots \ldots \ldots \ldots \ldots$

17. Concrete annular fill correction factors, $K_{C}$, for fill regions $10.0-\mathrm{cm}$ and $15.0-\mathrm{cm}$ thick 52

\section{TABLES}

1. Photon interaction modes and their dependence upon photon energy, $E_{\gamma}$, and atomic number, $Z$

2. Comparison of average composition and atomic numbers for common Earth material and NBS concrete

3. Sample bulk density comparison between common Earth material and concrete $\ldots \ldots \ldots \ldots \ldots 11$

4. Assigned concentrations for calibration of spectral gamma-ray logging systems $\ldots \ldots \ldots \ldots$

5a. Potassium-40 gamma-ray and absolute peak intensity $\ldots \ldots \ldots \ldots \ldots \ldots \ldots \ldots \ldots \ldots$

5b. Uranium-238 series gamma-rays and absolute peak intensities $\ldots \ldots \ldots \ldots \ldots \ldots \ldots \ldots \ldots$

5c. Thorium-232 series gamma-rays and absolute peak intensities $\ldots \ldots \ldots \ldots \ldots \ldots \ldots \ldots \ldots$ 
6. Comparison of selected absolute gamma-ray intensities for gamma-rays emitted by naturally occurring elements

7. Listing of complex photopeaks used in the GSLS efficiency calibration $\ldots \ldots \ldots \ldots \ldots \ldots \ldots$

8. Photon energies and source strengths used in MicroShield $\mathbb{C}$ modeling $\ldots \ldots \ldots \ldots \ldots \ldots \ldots$

9. Standard model dimension variations for the purpose of infinite geometry verification $\ldots \ldots \ldots 26$

10. Partial densities of materials comprising the cylindrical annular source matrix $\ldots \ldots \ldots \ldots \ldots$

11. Photon fluence rates for Standard model conditions $\ldots \ldots \ldots \ldots \ldots \ldots \ldots \ldots \ldots \ldots \ldots \ldots$

12. Fit parameters for vertical correction factor function $\ldots \ldots \ldots \ldots \ldots \ldots \ldots \ldots \ldots \ldots \ldots$

13. Fit parameters for vadose and saturated zone correction factors $\ldots \ldots \ldots \ldots \ldots \ldots \ldots \ldots \ldots$

14. Fit parameters for saturation ratio correction factors in formations with porosities from

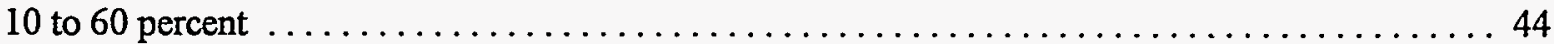

15. Iron casing correction factor fit parameters as determined from MicroShield ${ }^{\circ}$ output . . . . . . 49

16. Iron casing correction factor fit parameters as determined by Koizumi et al. $(1993,1994) \ldots \ldots \ldots 49$

17. Water-filled borehole correction factor fit parameters as determined from MicroShield $\bigcirc$ data .... 50

18. Water-filled borehole correction factor fit parameters as determined by Koizumi et al. (1993, 1994)

19. PVC casing correction factor fit parameters

20. Concrete annular fill correction factor function fit parameters as determined from

MicroShieldC output 52

21. Summary of environmental correction factors 


\section{ACRONYMS}

\begin{tabular}{|c|c|}
\hline $\mathrm{AC}$ & alternating current \\
\hline CASAS & Computer Automated Spectral Acquisition System \\
\hline $\operatorname{CsI}(\mathrm{Tl})$ & thallium-activated cesium iodide \\
\hline $\mathrm{DC}$ & direct current \\
\hline DOE & Department of Energy \\
\hline $\mathrm{Ge}(\mathrm{Li})$ & lithium-drifted germanium \\
\hline GSLS & Gamma Spectroscopy Logging System \\
\hline HPGe & high-purity germanium \\
\hline $\mathrm{HV}$ & high-voltage \\
\hline IAEA & International Atomic Energy Agency \\
\hline ID & inner-diameter \\
\hline INEL & Idaho National Engineering Laboratory \\
\hline $\mathrm{keV}$ & kilo-electron volts \\
\hline LASL & Los Alamos Scientific Laboratory \\
\hline $\mathrm{LN}_{2}$ & liquid nitrogen \\
\hline $\mathrm{MCA}$ & multi-channel analyzer \\
\hline MCNP & Monte Carlo Neutron Photon \\
\hline $\mathrm{MeV}$ & Million-electron volts \\
\hline $\mathrm{mfp}$ & mean-free-path \\
\hline $\mathrm{NaI}(\mathrm{Tl})$ & thallium-activated sodium iodide \\
\hline NBS & National Bureau of Standards \\
\hline NIM & nuclear instrumentation module \\
\hline
\end{tabular}


NORM

NTS

OD

PTO

PVC naturally occurring radioactive material

Nevada Test Site

outer-diameter

power-take-off

poly vinyl chloride 


\begin{abstract}
A Gamma Spectroscopy Logging System (GSLS) has been developed to study sub-surface radionuclide contamination. Absolute efficiency calibration of the GSLS was performed using simple cylindrical borehole geometry. The calibration source incorporated naturally occurring radioactive material (NORM) that emitted photons ranging from $186-\mathrm{keV}$ to $2,614-\mathrm{keV}$. More complex borehole geometries were modeled using commercially available shielding software. A linear relationship was found between increasing source thickness and relative photon fluence rates at the detector. Examination of varying porosity and moisture content showed that as porosity increases, relative photon fluence rates increase linearly for all energies. Attenuation effects due to iron, water, PVC, and concrete cylindrical shields were found to agree with previous studies. Regression analyses produced energy-dependant equations for efficiency corrections applicable to spectral gammaray well logs collected under non-standard borehole conditions.
\end{abstract}

\title{
DISCLAIMER
}

This report was prepared as an account of work sponsored by an agency of the United States Government. Neither the United States Government nor any agency thereof, nor any of their employees, makes any warranty, express or implied, or assumes any legal liability or responsibility for the accuracy, completeness, or usefulness of any information, apparatus, product, or process disclosed, or represents that its use would not infringe privately owned rights. Reference herein to any specific commercial product, process, or service by trade name, trademark, manufacturer, or otherwise does not necessarily constitute or imply its endorsement, recommendation, or favoring by the United States Government or any agency thereof. The views and opinions of authors expressed herein do not necessarily state or reflect those of the United States Government or any agency thereof. 



\section{The Efficiency Calibration and Development of Environmental Correction Factors for an In-situ High-resolution Gamma Spectroscopy Well Logging System}

\section{INTRODUCTION}

Photon detectors were used for uranium ore exploration as early as the 1950's (Hyman et al. 1955; Fertl 1979; Lauber et al. 1972). The first gamma-ray logging tools used sodium-iodide [NaI(Tl)] scintillation detectors. While the $\mathrm{NaI}(\mathrm{Tl})$ detectors allowed for relatively fast logging of the boreholes, the energy resolution was adequate only for total-count and potassium, uranium, and thorium well logs. It has been shown that estimation of uranium concentration using $\mathrm{NaI}(\mathrm{Tl})$ detectors can produce uncertainties as large as a factor of 10 due to the poor resolution of the $\mathrm{NaI}(\mathrm{Tl})$ detection system (Zhao et al. 1990). Although $\mathrm{NaI}(\mathrm{Tl})$ detectors are used for lithology logging, their utility as a tool for radionuclide quantification in the subsurface has diminished.

Semiconductor diode detectors became commercially available in the 1960's. Included in this category of detectors were the lithium-drifted germanium detectors, or $\mathrm{Ge}(\mathrm{Li})$ detectors. By the mid-1980's $\mathrm{Ge}(\mathrm{Li})$ detectors had been replaced by high-purity germanium detectors (HPGe) which are in widespread use today (Knoll 1989).

High-purity $\mathrm{Ge}$ detectors have been used in a number of scientific fields such as nuclear physics, health physics, and geophysics. Perhaps the most innovative application of HPGe detectors has been in environmental monitoring and geophysics where they have been used for the quantification of naturallyoccurring and man-made radionuclides.

A team of French scientists developed and successfully used a borehole probe containing a planar $\mathrm{Ge}(\mathrm{Li})$ detector in 1970. Shortly thereafter, scientists in the United States constructed and tested coaxial $\mathrm{Ge}(\mathrm{Li})$ detectors for borehole geophysics applications (Lauber et al. 1972). As soon as HPGe detectors became available commercially, they replaced the $\mathrm{Ge}(\mathrm{Li})$ detectors in the geophysics industry.

Down-hole gamma detectors are not only important in geophysics and geology. Their usefulness can also be extended to environmental restoration activities such as site characterization, routine environmental monitoring (Koizumi et al. 1994; Killeen et al. 1993), and as a verification tool for pump-and-treat applications (Giles 1995). With a properly calibrated system, source terms can be determined through the logging of selected wells at a site. Additionally, routine in-situ monitoring of both the vadose and saturated zones can be achieved using existing wells. The usefulness of high-resolution gamma spectroscopy logging systems as a verification tool is still under development, but the concept is quite simple: the extraction well can be characterized prior to pumping, then at any point during and/or after the pump-and-treat process, the well can be characterized again. The change in radionuclide concentration(s) (considering decay and counting uncertainties) would demonstrate the effectiveness of the application. It should be noted that this process can be used in conjunction with conventional water sampling and analysis and can be used to determine sorption ratios and partitioning coefficients for specific radionuclides. Additionally, in-situ monitoring can provide 
real-time analysis. These activities require accurate quantitative and qualitative measurements of gammaemitting radionuclides that can only be achieved through a very detailed calibration process.

The calibration process is generally performed in a set of calibration sources constructed of a homogenous radioactive source matrix with an access hole penetrating the model center to accommodate logging tools. Calibration sources are composed of dry, uncased holes surrounded by an enriched, naturally radioactive, source matrix (Leino 1994). This calibration environment is simple compared to the environments surrounding boreholes encountered during logging operations (Koizumi et al. 1993). Typical monitoring wells are generally constructed in a manner such that the detector-source geometry varies greatly from that of the calibration standards throughout the depth of the well. Geometry departures result from well casing material, annular fill, and water-filled wells.

Schedule 40 iron and PVC casings are the most common materials; however, stainless steel is used in special cases. The annular space between the borehole wall and the casing is commonly filled with cement grout. These well construction materials will attenuate photons emitted in the formation before they reach the detector. When logging below the water table, water inside the well will further attenuate photons. Unless accounted for, well construction materials and water-filled wells may result in estimations of radionuclide concentrations that are much lower than the true values. This inaccuracy may be resolved by applying appropriate correction factors.

In addition to the well completion characteristics, variations in the physical parameters of the subsurface environment must be considered (Rhodes et al. 1966; Wilson et al. 1981). These parameters include formation porosity, relative moisture content, vertical extent of lithologic layers, chemical composition of the formation matrix, and particle and bulk densities. All of these factors influence the transport of photons from the source-bearing formation matrix to the HPGe detector positioned in the well bore and they must be accounted for prior to quantification of naturally occurring or man-made, gammaemitting radionuclides (Koizumi et al. 1993).

The borehole environments that may be encountered in the field are almost infinite, and simulation with physical calibration sources for all conditions would be impractical. Fortunately, computer models can be designed to simulate photon fluence rates from a source of gamma rays in the complex environment surrounding a borehole.

The goal of this calibration and subsequent study of photon transport was to produce a methodology for quantifying radionuclides in the subsurface. This was attempted through the following objectives:

- Perform an efficiency calibration of the Gamma Spectroscopy Logging System (GSLS) at the field calibration facilities in Grand Junction, Colorado

- Study the well characteristics which were thought to modify the detected photon fluence rates, and develop and test hypotheses about these characteristics

- Model the photon fluence rates ranging in energy from $186 \mathrm{keV}$ to $2,614 \mathrm{keV}$ at the detector position using the MicroShield $^{\circ}$ computer code 
- Develop curves for correction factors based on the modeling efforts, applicable to conditions encountered in the field.

The modeled field conditions include infinite cylindrical annular sources in wells cased with different thicknesses of iron and PVC, and in various diameter uncased wells filled with water. Relative photon fluence rates from thin beds and formations with porosities ranging from zero to 60 percent, and moisture contents ranging from zero to 100 percent were also evaluated.

Correction factors determined from relative photon fluence rates can be used in logging operations to obtain more accurate estimates of radionuclide concentrations collected under various field conditions. This thesis describes the methods, materials, and philosophy used to calibrate the GSLS, model the various field conditions, and develop well logging environment correction factors. 


\section{LITERATURE REVIEIN}

\section{History of Well Logging}

Gamma-ray well logging has been used for hydrocarbon exploration in the subsurface for nearly 50 years (Gadeken et al. 1988; Fertl 1979). Gamma-ray well logging has also been used to locate mineral and uranium deposits (IAEA 1976). Initially, sodium-iodide (NaI(TI)) scintillation crystals were used for borehole explorations, and in some cases they are still used today. However, as the demand for uranium ore decreased, the necessity for spectrometric measurements also declined. Consequently, borehole gamma-ray measurements have been used to aid in lithology studies.

Early application of in-situ gamma-ray spectroscopy data assisted in both the qualitative and quantitative estimation of subsurface lithology (Fertl 1979). The spectrometric measurements made with $\mathrm{NaI}(\mathrm{Tl})$ scintillators usually separated the naturally occurring radioactive elements into three energy ranges called "windows." A typical window arrangement would be as follows: ${ }^{40} \mathrm{~K}$ at $1.46-\mathrm{MeV}$ with a window from 1.24 to $1.70-\mathrm{MeV},{ }^{238} \mathrm{U}$-series radionuclides at $1.76-\mathrm{MeV}$ with a window from 1.52 to $2.04-\mathrm{MeV}$, and ${ }^{232} \mathrm{Th}$-series radionuclides at 2.61-MeV with a window from 2.22 to 3.08- $\mathrm{MeV}$ (Mathews et al. 1986). Due to spectral degradation from multiple Compton interactions in the formation and the low penetration capability of low energy gamma-rays, lower energy gamma-rays were not used. Fưther, poor energy resolution of $\mathrm{NaI}(\mathrm{Tl})$ logging tools $(\sim 10 \%)$ does not allow for accurate radionuclide concentration calculations for many of the naturally occurring radionuclides (Zhao et al. 1991; Wilson et al. 1981). These short-comings limited the usefulness of $\mathrm{NaI}(\mathrm{Tl})$ detectors in quantitative borehole logging operations.

Lithium-drifted germanium (Ge(Li)) detectors became commercially available in the 1960's. Lithiumdrifted germanium detectors and cryostat assemblies were being developed for well logging applications in the early 1970's. The detector and associated electronics are housed in some type of cylindrical casing and referred to as the "logging tool" or "logging sonde." Initially, planar $\mathrm{Ge}(\mathrm{Li})$ detectors were developed and used by a team of French scientists, while scientists in the United States were constructing and testing coaxial $\mathrm{Ge}(\mathrm{Li})$ borehole tools (Lauber et al. 1972; Dumesnil et al. 1970; Tanner et al. 1971). Recently, the Institute of Atomic Energy, Beijing, China has reported development of borehole logging tools using $\mathrm{Ge}(\mathrm{Li})$ and HPGe germanium detectors (Zhao et al. 1991).

Even though logging tools equipped with $\mathrm{Ge}(\mathrm{Li})$ detectors provided excellent resolution and accurate concentration measurements for multiple radionuclides, the requirement of keeping the $\mathrm{Ge}(\mathrm{Li})$ detectors cool on a continuous basis posed a large problem and inconvenience. Ultra-pure germanium detectors developed in the early 1980's alleviated the cooling problem associated with $\mathrm{Ge}(\mathrm{Li})$ detectors; the requirement to continuously maintain the detector in a cryogenic state is no longer applicable as long as high-voltage (HV) is not applied to the detector if it is at greater than cryogenic temperature.

Another application of high-resolution detectors is that logging tools containing HPGe detectors can be fitted with either pulsed neutron generators or sealed neutron sources and used for neutron activation analysis. This borehole logging technique was originally developed for mineral and petroleum exploration; however, a new application is being developed for site characterization activities in the identification of hazardous organic compounds. 
The utility of HPGe detectors has allowed for their application in the geophysics and petroleum industry and, more recently, in environmental restoration projects at Department of Energy (DOE) and commercial sites.

\section{Photon Interactions in the Borehole Environment}

Detailed investigations have been conducted to verify the predominant mode(s) of photon interactions (NSRDS-NBS 1969). Photons interact via three primary mechanisms: photoelectric absorption, Compton scattering, and pair-production (Knoll 1989; Quittner 1972). Photoelectric absorption occurs when a photon interacts with an atom and disappears. The excess energy added to the atom is transferred to an orbital electron, usually in the K-shell. In turn, the photoelectron is ejected from the orbit of the atom, and an ion pair is created. The energy of the photoelectron, $E_{e-,}$ is equal to the kinetic energy, $E_{\gamma}$, of the photo-absorbed photon minus the binding energy, $E_{b}$, of the electron:

$\mathrm{E}_{\mathrm{e}^{-}}=\mathrm{E}_{\gamma}-\mathrm{E}_{\mathrm{b}}$

Photoelectric absorption is the primary interaction mechanism for low energy photons $\left(\mathrm{E}_{\gamma}<100 \mathrm{keV}\right)$. Compton scattering occurs when an incident photon collides with an electron (considered to be at rest), transferring kinetic energy to that electron. The quantity of energy transferred is a function of both the incident photon's initial kinetic energy, $\mathrm{E}_{\gamma}$, and the angle $\theta$ at which the photon is scattered. Equation 2 shows the angular dependence of the scattered photon's kinetic energy, where $m_{0} c^{2}$ is the rest-mass energy of the electron $(0.511-\mathrm{MeV})$ :

$\mathrm{E}_{\gamma}^{\prime}=\frac{\mathrm{E}_{\gamma}}{1+\frac{\mathrm{E}_{\gamma}}{\mathrm{m}_{\mathrm{O}} \mathrm{c}^{2}} \cdot(1-\cos \theta)}$.

Due to the nature of this phenomenon, the scattered photon may be deflected at any angle from $0^{\circ}$ to $180^{\circ}$ resulting in recoil electrons with a wide range of kinetic energies. Compton interactions dominate the energy region from approximately $100-\mathrm{keV}$ to $3-\mathrm{MeV}$ (Gadeken 1988; Bertozzi et al. 1981). The third major mechanism of photon interaction is pair production. This is the predominant mode of interaction for photons with energies of several $\mathrm{MeV}$. During pair production, an incident photon penetrates the coulomb field of a charged particle and disappears. In its place an electron/positron pair is created, each with equivalent kinetic energies. Conservation of mass and energy set a threshold on the minimum photon energy required for pair production to occur at 1.022-MeV; twice the rest mass of an electron (Cember 1989; Knoll 1989; Turner 1986; IAEA 1976; NSRDS-NBS 1969). Any given photon may interact via the above mentioned modes, provided the photon energy is at least $1.022-\mathrm{MeV}$ for pair production; however, the probability of the photon undergoing a specific interaction is dependent upon the energy of the incident photon and the density of the absorber.

The probability of interaction of a photon in any media is not only a function of the photon energy, but also of the target material $Z$. The total interaction probability can be approximated by summing the three primary interaction probabilities; specifically, $\tau_{p e}+\sigma_{C}+\kappa_{n}$, where $\tau_{p e}, \sigma_{C}$, and $\kappa_{n}$ are the probabilities of interaction for photoelectric absorption, Compton scattering, and pair production, respectively, in units of 
barns per atom (b/atom). The probability of photoelectric absorption can be approximated with the following (Knoll 1989; Gadeken et al. 1988):

$$
\tau_{p e} \cong K \cdot \frac{Z^{n}}{E_{\gamma}^{3.5}}
$$

where

$$
\begin{aligned}
& \tau_{\mathrm{pe}}=\text { the probability of photoelectric absorption (b/atom) } \\
& \mathrm{K}=\text { a constant } \\
& \mathrm{Z}=\text { the atomic number } \\
& \mathrm{n}=\text { exponent with a value between } 4 \text { and } 5 \\
& \mathrm{E}_{\mathrm{\gamma}}=\text { photon energy }(\mathrm{MeV})
\end{aligned}
$$

Compton interactions are dependent upon the number of electrons present in the absorber or target material; therefore, the probability increases linearly with $Z$ and inversely to $E$ (Knoll 1989; Wilson et al. 1981; NSRDS-NBS 29; Glasstone et al. 1981):

$$
\sigma_{\mathrm{C}} \propto \frac{Z}{\mathrm{E}}
$$

The probability of pair production, like photoelectric absorption, cannot be well defined by a single expression; however, it can be approximated by (Knoll 1989; Wilson et al. 1981; Glasstone et al. 1981):

$$
\kappa_{n} \propto Z^{2} \cdot(E-1.02)
$$

Table 1 summarizes the energy and $Z$ dependence of the various photon interactions. As can be seen from Table 1, the predominant mode of interaction for photons ranging in energy from 200 to $2,600 \mathrm{keV}$ is Compton scattering (Gadeken 1988; Bertozzi et al. 1981).

The average distance a photon travels before interacting is the mean-free-path (mfp) and is defined by: $\mathrm{mfp}=\frac{1}{1}$, where $\mu$ is the linear attenuation coefficient (Shleien 1992). This distance is proportional to photon ehergy and inversely proportional to absorber density; therefore, a photon in air will have a mfp several orders of magnitude greater than the mfp for the same photon in concrete (IAEA 1979).

\section{Geologic Considerations}

Geometry and other physical conditions encountered in the field usually differ from those of the calibration geometry and conditions. Stratification, elemental composition, density, porosity, and moisture 
Table 1. Photon interaction modes and their dependence upon photon energy, $E_{\gamma}$, and atomic number, $Z$. $^{a}$

\begin{tabular}{|c|c|c|c|}
\hline Mode of interaction & Energy dependence & Z Dependence & $\begin{array}{c}\text { Energy at which } \\
21 / 2 \text { of interactions } \\
\text { are by this type } \\
(\mathrm{Z}=13)\end{array}$ \\
\hline Photoelectric absorption & $\frac{1}{E^{3}}$ & $\begin{array}{l}\mathrm{Z}^{\mathrm{n}} \\
\mathrm{n}=4 \text { at } 0.1 \mathrm{MeV} \\
\mathrm{n}=4.6 \text { at } 3 \mathrm{MeV}\end{array}$ & $0.046 \mathrm{MeV}$ \\
\hline Compton scattering & $\begin{array}{l}\frac{1+E}{E^{3}}\left(\frac{2 E(1+E)}{1+2 E}-\ln (1+2 E)\right) \\
+\frac{1}{2 E} \ln (1+2 E)-\frac{1+3 E}{(1+2 E)^{2}}\end{array}$ & $Z$ & $0.1 \leq \mathrm{E}_{\gamma}<10 \mathrm{MeV}$ \\
\hline Pair production & $\begin{array}{l}\text { Threshold at } 1.022-\mathrm{MeV} \text { and } \\
\text { weakly increasing with increasing } \mathrm{E}\end{array}$ & $Z^{2}$ & $15 \mathrm{MeV}$ \\
\hline
\end{tabular}

content are the more prominent and important geological and hydrogeological aspects of the surrounding formation that influence the transport of photons through the subsurface materials to the logging tool location.

\section{Stratification and Thin Beds}

It is conceivable and practical to expect stratification of sediments, rock, and minerals in the subsurface. This is an important factor for both natural gamma logging, and contamination assessment. When considering natural gamma radiation, different strata in the subsurface can contain varying quantities of the naturally occurring radionuclides. Radionuclide concentrations at or near transition zones between adjacent strata can have uncertainties associated with them due to the different compositions of adjacent layers (Wilson et al. 1979; Wilson et al. 1981). Similar variances in man-made radionuclide concentrations may be observed between adjacent strata due to geochemical parameters of the individual strata and radionuclides including sorption ratios and partitioning coefficients. Measured spectra in thin beds do not seem to follow mathematical predictions. However, empirical evidence demonstrates that detector size and shape seem to play a very important role in the detector response to thin bed formations. As a result, there can be a large amount of variation associated with the actual and measured concentrations of man-made radionuclides in adjacent strata and thin beds (Wilson et al. 1979). 


\section{Elemental Composition}

The chemical (elemental) composition of soils, rock, and unconsolidated sediments in the subsurface vary within and among geologic regions. Adjacent strata in the subsurface can be composed of materials with different grain densities and/or different effective atomic numbers. These differences can affect the attenuation of photons in the subsurface.

The effective $Z$ of a material becomes extremely important when there is a substantial amount of high $Z$ material such as uranium $(Z=92)$ present. It has been demonstrated that in uranium grades of $0.6 \%$ by weight, the flux ratio (photon flux in the presence of uranium divided by the photon flux without uranium) is decreased to less than $95 \%$ for photon energies less than $0.3 \mathrm{MeV}$. Increasing the uranium grade above $0.6 \%$ causes a further decrease in the flux ratio for all photon energies; in fact, the flux ratio for $6.0 \%$ uranium grade never reaches a constant value for photon energies above $0.3 \mathrm{MeV}$, suggesting that photoelectric absorption and pair production interactions become increasingly important in high- $Z$ material. It was consequently predicted that a logging tool calibrated in a formations with low concentrations of high- $Z$ materials will systematically predict lower concentrations of radionuclides in formations with several percent by weight, high-Z materials (Wilson et al. 1979; Wilson et al. 1981).

Although it would be a very formidable task to generate chemical composition tables for all known soils, rocks, and sediments, it is perhaps more practical to develop an average chemical composition of the Earth's crust, giving an estimate for the average $Z$ of earth materials. The average atomic number for most Earth materials encountered during logging activities ranges from 13 to 20 (Koizumi et al. 1991; Wilson et al. 1979; Paton 1978). Table 2 lists the eight most common constituents of Earth materials and their associated abundances, and compares them with the composition of NBS concrete. This comparison is necessary to show that the calibration sources in Grand Junction is valid in terms of effective $Z$ of the material, since it is this property that is most important to the mechanisms of photon energy loss for photon energies ranging from $100 \mathrm{keV}$ to $2,600 \mathrm{keV}$.

A closer look at how average $Z$ and effective $Z$ are computed is necessary to understand why the effective $\mathrm{Z}$ is the more important of the two. The average $\mathrm{Z}$ of a material is given by the following (Worku et al. 1992,1993):

$Z_{A V E}=\frac{\sum_{i}\left(N_{i} \cdot Z_{i}\right)}{\sum_{i} N_{i}}$

where

$$
\begin{aligned}
& N_{i}=\text { the number of elements with atomic number } Z_{i} \\
& Z_{i}=\text { the atomic number of the } i^{\text {th }} \text { element. }
\end{aligned}
$$


Table 2. Comparison of average composition and atomic numbers for common Earth material and NBS concrete.

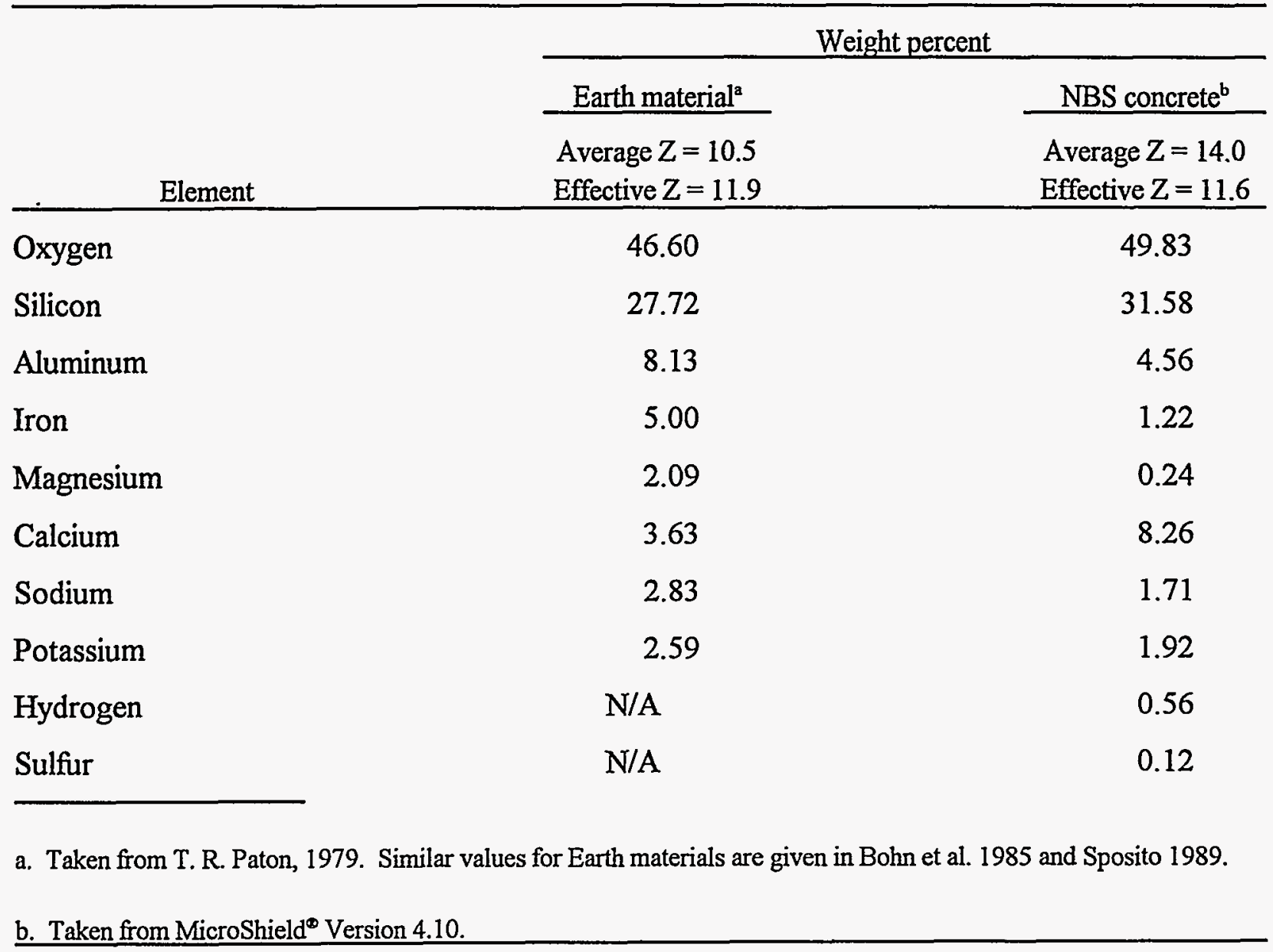

The effective $Z$ ( $Z_{\text {RFF }}$ ) of a material differs from the average $Z$ by including the ratio of atomic density $\left(\mathrm{d}_{i}\right)$ of each element to the effective atomic weight $\left(\mathrm{EAW}_{\mathfrak{i}}\right)$ (Worku et al. 1992,1993):

$$
\mathrm{Z}_{\mathrm{EFF}}=\frac{\sum_{i}\left(\frac{\mathrm{d}_{\mathrm{i}}}{\mathrm{EAW}_{\mathrm{i}}} \cdot \mathrm{Z}_{\mathrm{i}}\right)}{\sum_{\mathrm{i}}\left(\frac{\mathrm{d}_{\mathrm{i}}}{\mathrm{EAW}_{\mathrm{i}}}\right)}
$$

where

$$
\begin{aligned}
& d_{i}=\text { the atomic density of the } i^{\text {th }} \text { element }\left(\text { atoms } / \mathrm{cm}^{3}\right) \\
& \text { EAW }_{i}=\text { the effective atomic weight } \\
& Z_{i} \quad=\text { the effective atomic number of the } i^{\text {th }} \text { element. }
\end{aligned}
$$


As can be seen from Equation 4, calculation of the average $Z$ is a weighted average $Z$ for the material. Calculation of $Z_{\mathrm{FFF}}$ in Equation 5 is also a weighted average; however, it substitutes the ratio of atomic density to effective atomic weight for the number of individual atoms. This gives more credence to constituents with higher atomic numbers.

To further demonstrate the similarities of photon transport through Earth material and concrete, Figure 1 displays total attenuation curves for the two materials for photon energies from $0.01 \mathrm{MeV}$ to $100 \mathrm{MeV}$. Figure 1 demonstrates that the attenuation coefficients for the two materials are identical. This demonstrates that small differences in the effective $Z$ of materials does not significantly affect the transport of photons.

\section{Material Bulk Density}

The density of a material is simply the mass of the material divided by its volume. When dealing with geologic media, the density of a material may be broken into different components; namely particle density, dry bulk density, and material density. Particle density is the mass of a sample after oven-drying divided by the volume of the solid, mineral matter in the sample. Bulk density is the mass of the sample after drying

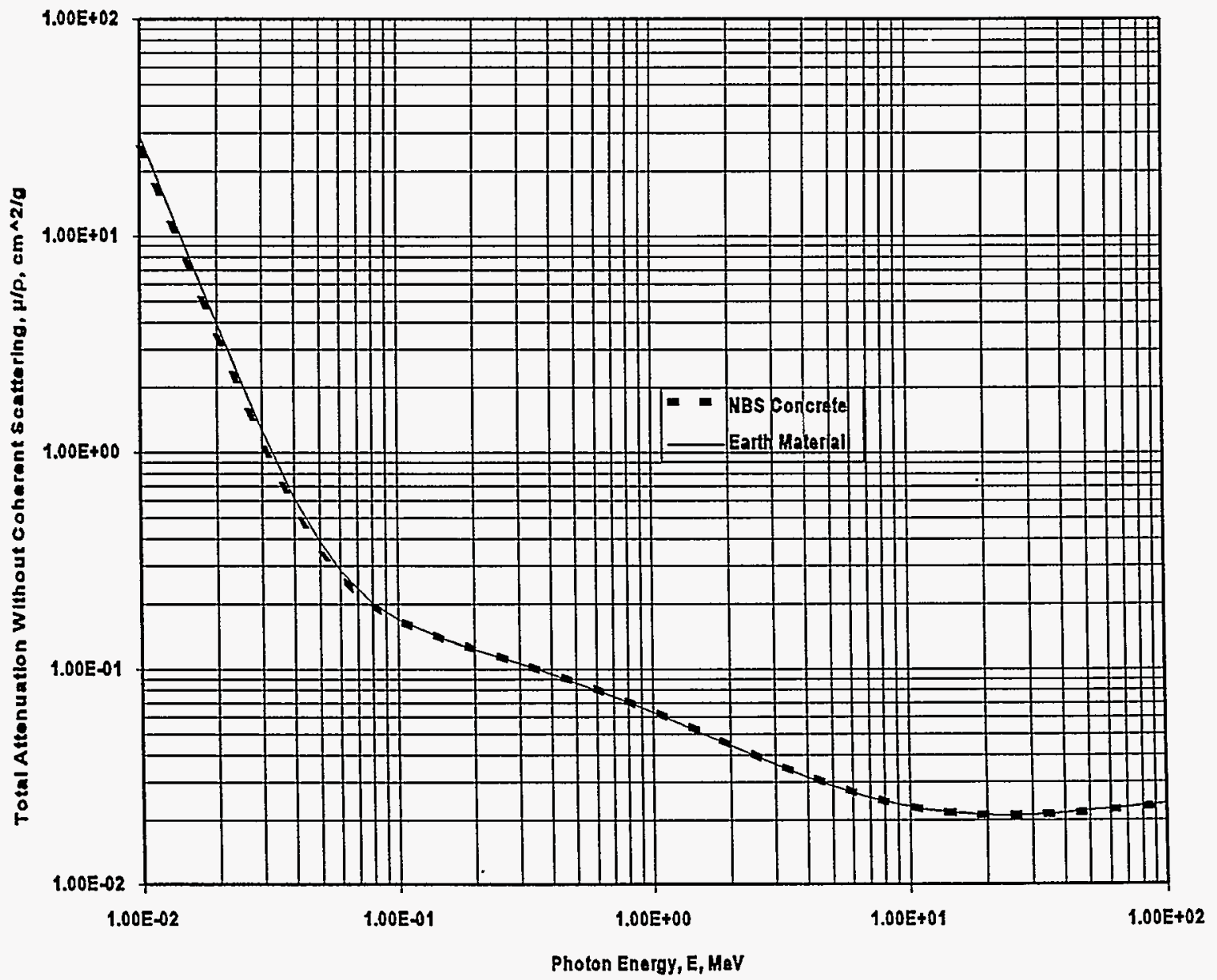

Figure 1. Total attenuation for Earth materials and NBS concrete. 
divided by the original volume of the sample, including all pore spaces (Fetter 1994). It is quite obvious that the particle density of any given sample will be greater than the dry bulk density; however, for any given sample, the ratio of the particle density to dry bulk density will approach unity as the porosity of the material approaches zero.

The particle density of most earth materials averages about $2.65-\mathrm{g} / \mathrm{cm}^{3}$, whereas the particle density of the concrete calibration sources averages $2.58-\mathrm{g} / \mathrm{cm}^{3}$. To demonstrate how the bulk density of a material can vary with porosity, consider the following example: a sample of rock with average grain density and zero porosity has a bulk density of $2.65-\mathrm{g} / \mathrm{cm}^{3}$. As the porosity is increased, the bulk density, $\rho$, decreases proportionally following Equation 6 (Fetter 1994):

$\rho_{\mathrm{i}}=2.65 \frac{\mathrm{g}}{\mathrm{cm}^{3}} \cdot\left(1-\frac{\mathrm{i}}{100}\right)$

where $i$ is the index for the sample porosity varying from 0 to 60 in increments of 5 . Table 3 displays the results from the evaluation of Equation 6, in addition to comparing the results of substituting the value of $2.58 \mathrm{~g} / \mathrm{cm}^{3}$ into Equation 6 . Because bulk density differences between concrete and Earth material are small and the effective $Z$ of concrete and Earth materials do not vary greatly, it is appropriate to use concrete as the mineral containing material for both the calibration sources and computer modeling of an Earth-like source matrix.

Table 3. Sample bulk density comparison between common Earth material and concrete.

\begin{tabular}{cccc}
\hline & \multicolumn{2}{c}{ Sample bulk density } \\
$\left(\mathrm{g} / \mathrm{cm}^{3}\right)$ & & Difference, \\
\cline { 2 - 3 } $\begin{array}{c}\text { Sample porosity } \\
\text { (percent) }\end{array}$ & Earth material & Concrete & 0.07 \\
\hline 0 & 2.65 & 2.58 & 0.07 \\
5 & 2.52 & 2.45 & 0.07 \\
10 & 2.39 & 2.32 & 0.06 \\
15 & 2.25 & 2.19 & 0.06 \\
20 & 2.12 & 2.06 & 0.05 \\
25 & 1.99 & 1.94 & 0.05 \\
30 & 1.86 & 1.81 & 0.04 \\
35 & 1.72 & 1.68 & 0.04 \\
40 & 1.59 & 1.55 & 0.04 \\
45 & 1.46 & 1.42 & 0.04 \\
50 & 1.33 & 1.29 & 0.03 \\
55 & 1.19 & 1.16 & 0.03 \\
60 & 1.06 & 1.03 &
\end{tabular}




\section{Material Porosity and Moisture Content}

The amount of water in a sample is described as the saturation ratio. The saturation ratio is a dimensionless number given by the volume of water in a sample divided by the total volume of void space (Fetter 1994). The partial densities of air and/or water are calculated by multiplying the density of air or water by the percent total volume occupied by the air or water. In conjunction with the particle density of the sample, the partial densities of the air and/or water contribute to the overall effective density of the sample. It is the overall effective density and effective $\mathrm{Z}$ of the material that will govern the transport and interactions of photons through the medium (Wilson et al. 1981; Wilson et al. 1979).

The pore spaces of a given sample are usually filled by air and/or water. In this study, it is assumed that the concrete, air, water mixture appears as a homogeneously distributed source matrix. This assumption is necessary for input parameters into the modeling software.

\section{Computer Modeling of Photon Fluence}

Computer models provide convenient and practical methods for conducting experiments and predicting outcomes. Several attempts have been made to model various borehole conditions and theoretical tool responses using a variety of computer codes.

The initial studies by Koizumi (Koizumi 1988) and Wilson and Evans (Wilson et al. 1979A), were performed to determine the effects of borehole fluid and casing material and thickness on photon intensity inside the borehole at the detector. Koizumi used four different computer codes: DINT, ANISN, GAMRES, and ENFOLD, to model the response of CsI(Tl) detectors in both cased and uncased boreholes containing various mud types. DINT compiled photon cross section data for user-defined materials using the KleinNishina formula. ANISN used discrete ordinates method on the one-dimensional Boltzmann transport equation to calculate gamma-ray intensities at selected points. GAMRES is a Monte Carlo code used to determine detector response functions and to assimilate a pulse height distribution in a multichannel analyzer. ENFOLD was used to compile the information from ANISN and GAMRES to construct pulse height spectra. Energy and source dependent spectral correction factors were determined through computer modeling that could not have been determined otherwise (Koizumi 1988). The study conducted by Wilson and Evans also involved the determination of environmental correction factors for scintillation detectors. Wilson performed experiments with different casing materials and different diameter, water-filled boreholes while Evans and a team of scientists from Los Alamos Scientific Laboratory (LASL) performed the same experiments using a discrete ordinates transport code ONETRAN. The results of the two separate experiments were then compared to each other and compiled into one report. The gamma-ray transport calculations in this study were consistently lower than the experimental values; however, the detector response was not included in the calculations (Wilson et al. 1979B). In addition, Wilson (Wilson et al. 1979A) conducted a study on the formation effects on photon transport. Included in this portion of the study was an investigation of the effects of thin beds containing homogeneously distributed sources of uranium, and the effects of formation $\mathrm{Z}$ on the transport of photons. They obtained data which supported the hypothesis that photon fluence scales as the inverse of the formation bulk density (Wilson et al. 1979A). Recent studies have been conducted to help with the identification of man-made radionuclides and to determine the effects of potassium bearing mud-cake on borehole walls (Wilson et al. 1993) and plate-out of radon decay products on casing (Killeen et al. 1993). Conaway conducted a study involving the fabrication of natural background spectra, typical of the geologic 
environment around the Nevada Test Site (NTS). These background spectra of ${ }^{40} \mathrm{~K}$, natural uranium and thorium were then used to strip actual spectra collected in boreholes at NTS. Once the natural background was subtracted, only peaks from man-made radionuclides remained (Conaway 1991). Another study performed by Wilson (Wilson et al. 1993) utilized a Monte Carlo code, MCNP, to model spectra produced by gamma-ray sources in the form of thin layers on the borehole wall. The Monte Carlo technique was used because discrete ordinate calculations for this geometry suffered from convergence problems. Gadeken (Gadeken et al. 1991) confirmed that very good agreement can be obtained between laboratory and computational experiments determining spectroscopy logging tool sensitivities for various energy gamma rays emitted in the borehole environment.

Often it is physically and monetarily prohibitive to conduct field experiments to obtain information about photon fluence rates and detector response. Computer modeling techniques can be used as a viable substitute for field data. However, useful modeling requires both careful code selection and careful input parameter selection. The software must be adequate to perform all necessary tasks without any difficulties in precision or accuracy errors (Wilson et al. 1993). In addition, the input parameters used must accurately represent field conditions.

This study is based on computer models generated using the MicroShield ${ }^{\circ}$ computer code by Grove Engineering. MicroShield ${ }^{\circ}$ uses numerical integration to predict photon fluence rates for a variety of source/shield configurations. 


\section{METHODS AND MATERIALS}

\section{Overview}

High-resolution gamma spectroscopy well-logging involves not only data acquisition, but data correction due to inconsistencies of the logging environment compared to the system calibration conditions. Several items must be considered when performing quantitative in-situ measurements of natural or manmade radionuclides. These include well completion properties such as casing, annular fill, and the effects of water within the boreholes, and formation properties such as density, effective $\mathrm{Z}$, porosity and moisture content. One effective method of accounting for these various conditions is through the aid of computer modeling. The following is a description of a high-resolution logging system, system calibration, and computer modeling efforts to account for deviations from the calibration standards.

\section{Description of Gamma Spectroscopy Logging System}

The INEL Gamma Spectroscopy Logging System (GSLS) consists of hardware and software designed to record the distribution of gamma emitting radionuclides present in the subsurface. The GSLS utilizes a HPGe crystal which provides high resolution spectra for gamma radiation measurements in the subsurface. The system consists of a logging tool, nuclear signal monitoring equipment, hydraulic winch and boom. All of the equipment is contained in a one-ton, 4-wheel drive van. Greenspan, Inc. of Houston, Texas designed and manufactured the GSLS. Figure 2 is a picture of the GSLS with the logging tool hanging from the boom.

The data acquisition system is comprised of EG\&G ORTEC electronics; namely, an 18\% GEM Plus PopTop ${ }^{\mathrm{TM}}$, bulletized, p-type, coaxial HPGe detector, a Model 232 transistor reset preamplifier, a Model 973 High-Rate Spectroscopy Amplifier, a Model 921 Spectrum Master multi-channel analyzer (MCA), and a

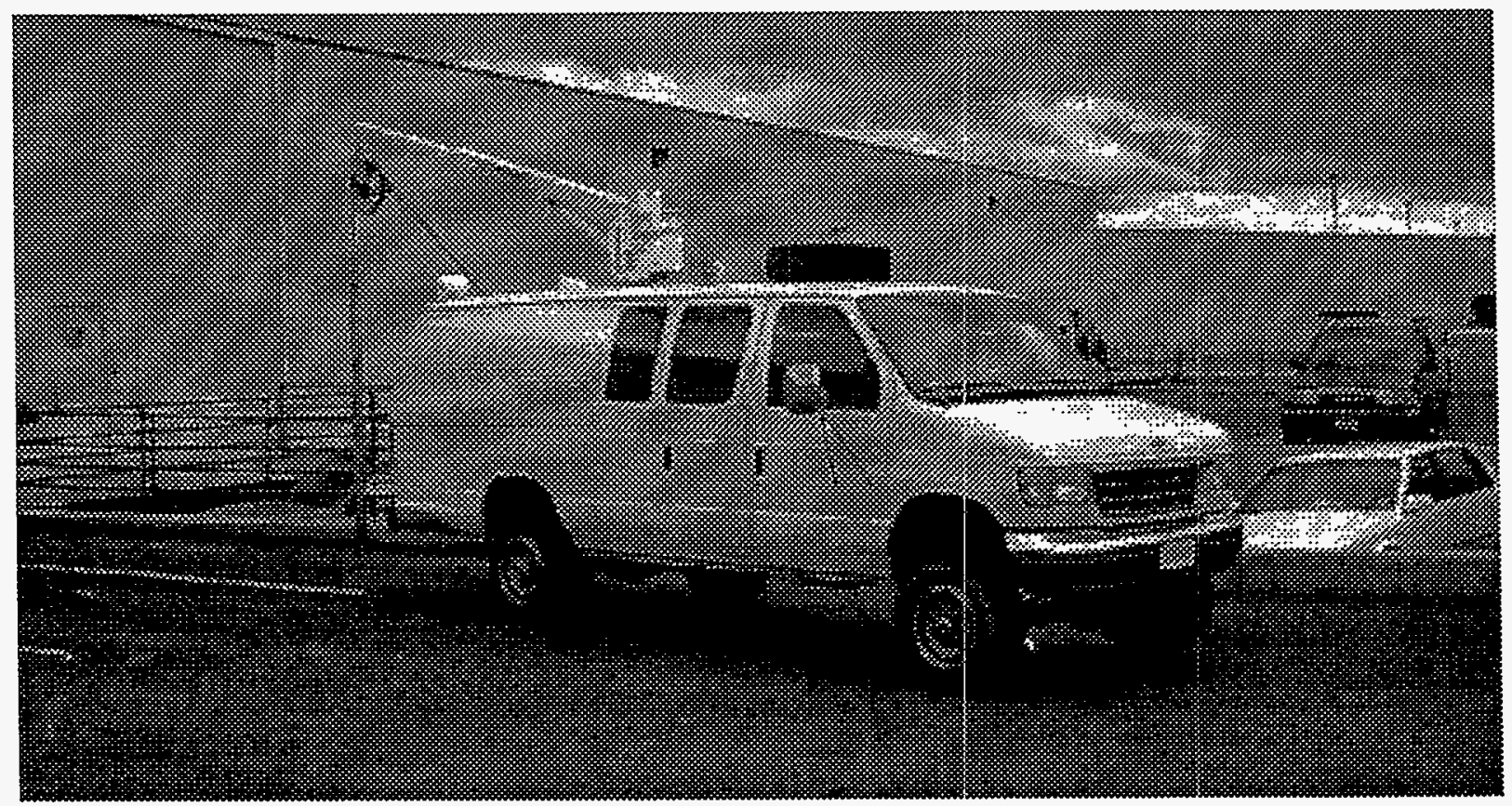

Figure 2. Gamma Spectroscopy Logging System with logging tool. 
high-voltage (HV) power supply. The 973 amplifier and 921 MCA are housed in a Model 4001C NIM (nuclear instrumentation module) bin. Bin power is provided by an EG\&G ORTEC BLACK MAXTM 300 Watt power supply with six output voltages: $\pm 6 \mathrm{~V}, \pm 12 \mathrm{~V}, \pm 24 \mathrm{~V} \mathrm{DC}$. The $\mathrm{HV}$ maintains a positive $3,500-\mathrm{V}$ potential across the detector contacts. The Model 973 amplifier is a gated integrator with a pulse shaping time set at 5- $\mu \mathrm{s}$. The signal from the 973 is sent to the $921 \mathrm{MCA}$ which is set up to collect pulses in 8,192 channels. The spectroscopy software selected to run the NIM electronics is based on EG\&G ORTEC Maestro ${ }^{\mathrm{TM}}$ II MCA Emulation Software and is incorporated into the GSLS System software package titled CASASI $^{\circ}$, written by Greenspan, Inc.

The logging tool contains the HPGe detector, high-voltage power supply, and pre-amplifier. This equipment along with a liquid nitrogen dewar are housed in a water-tight, stainless steel casing. This tool has an outer-diameter (OD) of 3.65-in. and can be used in any cased well or borehole with an inner-diameter (ID) of 4.0 -in. or larger. The detector requires a $6-\mathrm{hr}$. cooling period, after which the detector can remain in a borehole for approximately 12-hrs. before the $\mathrm{LN}_{2}$ dewar needs refilling.

The system is equipped with a sufficient length of cable to log to a depth of 760 -ft. The cable consists of the electronic wiring required to send the detector pulses, a vent hose for the nitrogen, and two concentric kevlar braids to support the weight of the logging tool.

The entire system is computer controlled using a Texas Micro personal computer. CASASI ${ }^{\circ}$ logging software controls the movement of the tool ana operation of spectroscopy electronics. The software and hardware are configured to allow almost complete system automation. Additionally, there are manual controls that allow the user to override computer controlled tool movement and data acquisition in the event of computer malfunction. The safety shutdown features include a smoke detector, and a load-cell that senses the amount of weight on the end of the boom. If the tool becomes lodged in the well as indicated by the loadcell, the hoist shuts down so the cable is not disconnected from the tool.

The system is self-contained, and does not require external power. Power requirements for the system are produced using a Ford 7.3-liter diesel engine. A power-take-off (PTO) connected to the vehicle transmission operates a hydraulic pump which provides the hydraulic pressures needed to operate the cable hoisting system. A 120-V AC generator operates in place of the engine alternator and provides the power for the computer, NIM bin, and other electronics. The generator also provides power to a DC generator/regulator system that supplies the DC current required for the top mounted crane, and the rest of the vehicle.

\section{Efficiency Calibration}

\section{Justification for Efficiency Calibration}

"To provide consistent quantitative radiometric field measurements which achieve adequate precision and accuracy it is necessary that steps be taken to establish and document ... primary radiometric counting standards and calibration of analytical instruments." (IAEA 1976)

The detection efficiency of any photon counting system is strongly dependant upon detector type, size and shape, source/detector geometry, and energies of the photons incident upon the detector. Consequently, measurement of absolute emission rates of gamma rays from an unknown source strength requires an 
efficiency function that is accurate, precise, and consistent with industry reporting standards (Knoll 1989; IAEA 1976). Calibration is normally accomplished through the use of radiometric counting standards that are, ideally, identical to field conditions. The calibration sources used in this study were the Department of Energy (DOE) borehole calibration sources in Grand Junction, Colorado.

\section{Description of Grand Junction Calibration Sources}

The DOE maintains a field instrument calibration facility in Grand Junction, Colorado at the Grand Junction Projects Office Technical Measurements Center. Located at this facility are calibration sources designed specifically for the calibration of in-situ gamma-ray monitoring equipment. Originally, the field calibration facilities were designed and developed for the exploration of uranium resources (Leino et al. 1994; Heistand et al. 1984). These facilities are now used for the calibration of geophysical tools used in lithology logging and high-resolution gamma spectroscopy logging systems such as the GSLS.

Three primary sources are used for the calibration of high-resolution gamma spectroscopy logging systems; designated K, U, and T (Leino et al. 1994; Randall 1994; Koizumi et al. 1994; Koizumi et al. 1993; Koizumi et al. 1991). The letter designations of the physical sources are representative of the naturally occurring radioactive material (NORM) present in elevated quantities: "K"- potassium-40, "U"uranium-238 in secular equilibrium with its daughters, and " $\mathrm{T}$ "- thorium-232 in secular equilibrium with its daughters. (Although the chemical symbol for thorium is $\mathrm{Th}$, "T" is the convention used by the Technical Measurements Center for the thorium source designation.) The borehole sources were constructed using 121.9-cm (4-ft.) ID galvanized culvert filled with concrete enriched in NORM. Figure 3 shows the construction of the $\mathrm{K}, \mathrm{U}$, and $\mathrm{T}$ sources. Through the center of each source is a 11.4-cm (4.5-in.) diameter access hole. The enriched zone of each source is composed of concrete to which uranium ore, monazite sand, and/or orthoclase sand has been added to increase the relative quantities of uranium, thorium, and potassium, respectively. Table 4 lists the measured concentrations for the enriched zones in the $K, U$, and $T$ sources (Leino et al. 1994).

A full suite of gamma-ray energies are represented by the photons emitted by the naturally occurring radioactive material in the calibration sources. The more prominent gamma-rays, parent nuclide, and absolute intensities are presented in Tables 5a through $5 \mathrm{c}$. As can be seen in Tables 5a-c, a continuum of photon energies is well represented from $186-\mathrm{keV}$ to $2,614-\mathrm{keV}$. This energy continuum is suited for performing well-logging system calibrations because most of the man-made, gamma-emitting contaminants

Table 4. Assigned concentrations for calibration of spectral gamma-ray logging systems. ${ }^{a}$

\begin{tabular}{|c|c|c|c|}
\hline \multirow[b]{2}{*}{ Source designation } & \multicolumn{3}{|c|}{ Concentration, $\mathrm{C}^{\mathrm{b}}, \mathrm{pCi} / \mathrm{g}$} \\
\hline & ${ }^{238} \mathrm{U}$ & ${ }^{232} \mathrm{Th}$ & ${ }^{40} \mathrm{~K}$ \\
\hline $\mathrm{K}$ & $0.92 \pm 0.09$ & $0.28 \pm 0.03$ & $52.24 \pm 1.67$ \\
\hline $\mathrm{U}$ & $162.9 \pm 5.34$ & $0.73 \pm 0.06$ & $10.21 \pm 0.84$ \\
\hline $\mathrm{T}$ & $8.47 \pm 0.47$ & $53.03 \pm 1.49$ & $10.38 \pm 1.17$ \\
\hline
\end{tabular}

a. Taken from Leino and others (1994).

b. Uncertainties are reported at the 95 percent confidence level. 


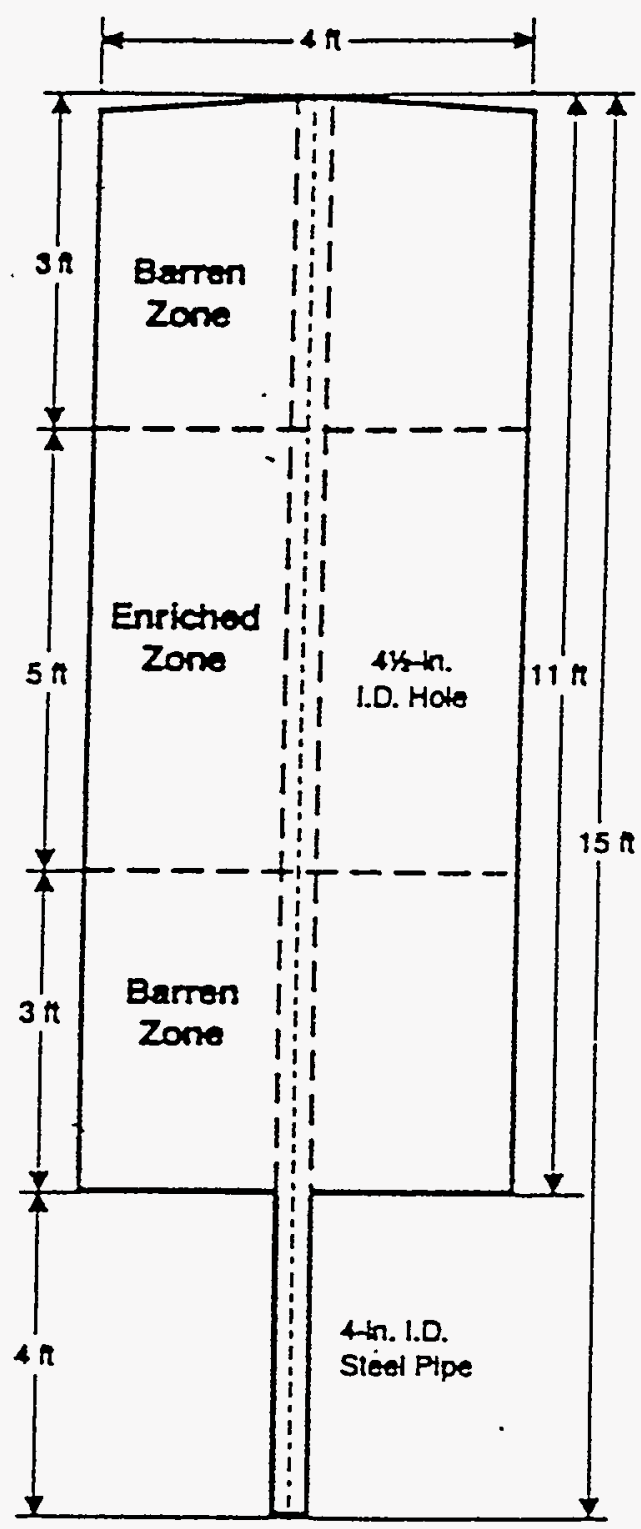

Figure 3. Typical cross section of $\mathrm{K}, \mathrm{U}$, and T calibration sources. ${ }^{\mathrm{a}}$

a. Taken from Leino et al. 1994. 
Table 5a. Potassium-40 gamma-ray and absolute peak intensity. ${ }^{\mathrm{a}}$

\begin{tabular}{ccc} 
Nuclide & $\begin{array}{c}\text { Gamma-ray energy } \\
(\mathrm{keV})\end{array}$ & $\begin{array}{c}\text { Peak intensity } \\
(\gamma \text { 's/decay })\end{array}$ \\
\hline${ }^{40} \mathrm{~K}$ & $1,460.83$ & 0.1067
\end{tabular}

a. Gamma-ray energy and absolute peak intensity values taken from EG\&G ORTEC GammaVision ${ }^{\oplus}$ software.

Table 5b. Uranium-238 series gamma-rays and absolute peak intensities. ${ }^{a}$ (Secular equilibrium assumed.)

\begin{tabular}{ccc} 
Nuclide & $\begin{array}{c}\text { Gamma-ray energy } \\
(\mathrm{keV})\end{array}$ & $\begin{array}{c}\text { Peak intensity } \\
(\gamma \text { 's/decay })\end{array}$ \\
\hline${ }^{226} \mathrm{Ra}$ & 186.10 & 0.035 \\
${ }^{214} \mathrm{~Pb}$ & 241.98 & 0.075 \\
${ }^{214} \mathrm{~Pb}$ & 295.21 & 0.185 \\
${ }^{214} \mathrm{Bi}$ & 609.31 & 0.4479 \\
${ }^{214} \mathrm{Bi}$ & $1,120.29$ & 0.148 \\
${ }^{214} \mathrm{Bi}$ & $1,509.23$ & 0.0212 \\
${ }^{214} \mathrm{Bi}$ & $2,118.55$ & 0.0114
\end{tabular}

a. Gamma-ray energy and absolute peak intensity values taken from EG\&G ORTEC GammaVision ${ }^{\star}$ software.

Table 5c. Thorium-232 series gamma-rays and absolute peak intensities. ${ }^{a}$ (Secular equilibrium assumed.)

\begin{tabular}{|c|c|c|}
\hline Nuclide & $\begin{array}{c}\text { Gamma-ray energy } \\
(\mathrm{keV})\end{array}$ & $\begin{array}{c}\text { Peak intensity } \\
\left(\gamma^{\prime} \text { s/decay }\right)\end{array}$ \\
\hline${ }^{228} \mathrm{Ac}$ & 338.32 & 0.1125 \\
\hline${ }^{228} \mathrm{Ac}$ & 463.01 & 0.0444 \\
\hline${ }^{228} \mathrm{Ac}$ & 794.95 & 0.0434 \\
\hline${ }^{228} \mathrm{Ac}$ & 911.21 & 0.266 \\
\hline${ }^{208} \mathrm{Tl}$ & $2,614.53$ & $0.3593^{b}$ \\
\hline
\end{tabular}

a. Gamma-ray energy and absolute peak intensity values taken from EG\&G ORTEC GammaVision ${ }^{\oplus}$ software unless otherwise noted.

b. Absolute peak intensity for the 2,614-keV gamma-ray from ${ }^{208} \mathrm{Tl}$ taken from The Health Physics and Radiological Health Handbook (1992). 
of concern such as ${ }^{60} \mathrm{Co},{ }^{125} \mathrm{Sb},{ }^{137} \mathrm{Cs},{ }^{152} \mathrm{Eu},{ }^{154} \mathrm{Eu},{ }^{237} \mathrm{~Np}$ (via ${ }^{233} \mathrm{~Pa}$ ), ${ }^{239} \mathrm{Pu},{ }^{240} \mathrm{Pu}$, and ${ }^{241} \mathrm{Am}$, emit gamma-rays within this 2,400-keV calibration range (Koizumi et al. 1994).

\section{Spectra Collection}

Spectra for the efficiency calibration of the INEL GSLS were collected in Grand Junction, Colorado at the Department of Energy's Grand Junction Projects Office Technical Measurements Center during the week of November 14, 1994.

Ten spectra were collected in each calibration source; $K, U$, and $T$. The center of the detector was positioned (vertically) in the center of the enriched zone, 167.6-cm (5.5-ft.) below the top of the sources. (Refer to Figure 3.) After the detector was properly positioned, ten consecutive spectra were collected with a live time of 1000-seconds. The spectra were saved to the hard disk of the GSLS computer and backed-up on 3.5-in. high-density floppy diskettes for analyses.

\section{Spectra Analysis}

Analysis of the calibration spectra files was performed with commercially available software produced by EG\&G ORTEC called GammaVision ${ }^{\otimes}$. The calibration files consisted of three sets of ten spectra from the $\mathrm{K}, \mathrm{U}$, and $\mathrm{T}$ sources.

The first step in analyzing the spectra included an energy calibration to ensure proper peak identification. After each spectrum was calibrated, a peak search was performed, and a report file generated. Each report file is formatted in ASCII text and contains information on the corresponding spectrum file such as filename, system live-time, depth of measurement, and peak search results. Included in the peak information are gross and net peak area (in terms of total counts), $1 \sigma$ peak area uncertainty, peak centroid $(\mathrm{keV})$, and peak/nuclide identification. Peak identification is accomplished through the use of an extensive nuclide library data base. EG\&G ORTEC distributes a Master Library with its spectroscopy software that contains a detailed listing of radionuclides, their gamma-rays, and associated absolute photon intensities. Information in the ORTEC library comes from several sources including the Table of Radioactive Isotopes (Browne et al. 1986), the Health Physics and Radiological Health Handbook (Schleien 1992), Die GammaLinien der Radionuklide (Erdtmann et al. 1979), and the Evaluated Nuclear Structure Data File (National Nuclear Data Center 1989). The peak information in the report files was used to develop the efficiency function of the GSLS. Special considerations had to be addressed during development of these efficiency functions including: 1) tabulation of reported absolute gamma-ray emission intensities, and 2) resolution of multiplets (Randall 1994).

\section{Special Considerations}

Absolute gamma-ray emission intensities for radioactive nuclides are tabulated and reported in a variety of references. Some of the more useful are listed above. There is some discrepancy in the tabulated values of absolute intensities among different references. Table 6 is a compilation of the absolute gamma-ray intensities from the references cited for the peaks used in the GSLS efficiency calibration. The largest discrepancy is for the $2,614-\mathrm{keV}$ photon from ${ }^{208} \mathrm{Tl}$. The photon intensities listed in the references are given as the number of photons emitted per 100 decays of the nuclide. These values are correct as photon yields; 
Table 6. Comparison of selected absolute gamma-ray intensities for gamma-rays emitted by naturally occurring radionuclides.

\begin{tabular}{cccccc}
\hline & & \multicolumn{4}{c}{ Absolute gamma-ray intensity } \\
\cline { 3 - 6 } Nuclide & $\begin{array}{c}\text { Gamma-ray energy } \\
(\mathrm{keV})\end{array}$ & $\begin{array}{c}\text { EG\&G } \\
\text { ORTEC }\end{array}$ & $\begin{array}{c}\text { Erdtmann } \\
\text { \& Soyka }\end{array}$ & $\begin{array}{c}\text { Rad. Health } \\
\text { Handbook }\end{array}$ & $\begin{array}{c}\text { Brown \& } \\
\text { Firestone }\end{array}$ \\
\hline${ }^{226} \mathrm{Ra}$ & 186.10 & 0.035 & 0.032 & 0.0328 & 0.0328 \\
${ }^{214} \mathrm{~Pb}$ & 241.98 & 0.075 & 0.074 & 0.0749 & 0.0746 \\
${ }^{214} \mathrm{~Pb}$ & 295.21 & 0.185 & 0.192 & 0.192 & 0.192 \\
${ }^{228} \mathrm{Ac}$ & 338.32 & 0.1125 & 0.12 & 0.114 & 0.124 \\
${ }^{228} \mathrm{Ac}$ & 463.01 & 0.0444 & 0.046 & $\mathrm{NL}^{\mathrm{b}}$ & 0.046 \\
${ }^{214} \mathrm{Bi}$ & 609.31 & 0.4479 & 0.46 & 0.461 & 0.461 \\
${ }^{228} \mathrm{Ac}$ & 794.95 & 0.0434 & 0.048 & $\mathrm{NL}^{\mathrm{b}}$ & 0.046 \\
${ }^{228} \mathrm{Ac}$ & 911.21 & 0.266 & 0.29 & 0.277 & 0.29 \\
${ }^{214} \mathrm{Bi}$ & $1,120.29$ & 0.148 & 0.15 & 0.15 & 0.15 \\
${ }^{40} \mathrm{~K}$ & $1,460.83$ & 0.1067 & 0.107 & $\mathrm{NL}^{\mathrm{b}}$ & 0.1067 \\
${ }^{214} \mathrm{Bi}$ & $1,509.23$ & 0.0212 & 0.03 & $\mathrm{NL}^{\mathrm{b}}$ & 0.0219 \\
${ }^{214} \mathrm{Bi}$ & $2,118.55$ & 0.0114 & 0.012 & $\mathrm{NL}^{\mathrm{b}}$ & 0.0121 \\
${ }^{208} \mathrm{Tl}$ & $2,614.53$ & 0.9916 & 1 & 0.3593 & 0.9979 \\
\hline
\end{tabular}

a. Gamma-Ray energies taken from EG\&G ORTEC GammaVision NATURAL.LIB file.

b. Absolute gamma-ray intensities for these energies not listed.

however, when considering absolute gamma-ray intensities from multiple nuclides in secular equilibrium, the decay scheme of the parent must be considered. In the case of ${ }^{208} \mathrm{Tl}$, its parent is ${ }^{212} \mathrm{Bi}$. Bismuth-212 decays by $\alpha$ and $\beta$ emission, followed by isomeric transition. Although a 2,614-keV gamma-ray is emitted each time ${ }^{203} \mathrm{Tl}$ decays, ${ }^{208} \mathrm{Tl}$ is created only $36 \%$ of the time by the $\alpha$-decay of ${ }^{212} \mathrm{Bi}$. Therefore, with a ${ }^{232} \mathrm{Th}$ source in secular equilibrium with its progeny, the percentage of time a gamma-ray is emitted by ${ }^{208} \mathrm{Tl}$ relative to the decay rate of the series is directly dependent upon the production rate of ${ }^{208} \mathrm{Tl}$. Comparing the expected gamma-ray intensities in the ${ }^{232} \mathrm{Th}$ decay scheme versus the individual yields accounts for the major discrepancy noted above. Other minor discrepancies in the absolute gamma-ray intensities are attributed to random and systematic errors in the methods used by the various authors to determine the intensities.

In addition to the tabulated values for absolute gamma-ray intensities, interference from two or more gamma-rays with identical, or nearly identical, energies, originating from different nuclei can occur. This occurs frequently when using a mixed source such as the calibration sources in Grand Junction. These sources contain more than two dozen radionuclides with over 100 different gamma-rays being emitted in their decay. Table 7 lists the multiplets used in the GSLS efficiency calibration. The total full-energy 
Table 7. Listing of complex photopeaks used in the GSLS efficiency calibration.

\begin{tabular}{cccccc}
\hline \multicolumn{2}{c}{ Primary peak } & & \multicolumn{3}{c}{ Interference peaks } \\
\cline { 5 - 6 } \cline { 5 - 6 } Nuclide & $\begin{array}{c}\text { Gamma-ray energy } \\
(\mathrm{keV})\end{array}$ & & Nuclide & $\begin{array}{c}\text { Gamma-ray energy } \\
(\mathrm{keV})\end{array}$ & $\begin{array}{c}\text { Absolute gamma-ray } \\
\text { intensity }\end{array}$ \\
\hline${ }^{226} \mathrm{Ra}$ & 186.10 & & ${ }^{235} \mathrm{U}$ & 185.72 & 0.5750 \\
${ }^{214} \mathrm{~Pb}$ & 241.98 & & ${ }^{227} \mathrm{Th}$ & 235.97 & 0.1105 \\
& & ${ }^{212} \mathrm{~Pb}$ & 238.63 & 0.4365 \\
& 295.21 & & ${ }^{224} \mathrm{Ra}$ & 240.99 & 0.0397 \\
${ }^{214} \mathrm{~Pb}$ & & ${ }^{231} \mathrm{~Pa}$ & 300.02 & 0.0239 \\
& & ${ }^{212} \mathrm{~Pb}$ & 300.09 & 0.0334 \\
& & ${ }^{231} \mathrm{~Pa}$ & 302.65 & 0.016 \\
${ }^{40} \mathrm{~K}$ & $1,460.83$ & ${ }^{228} \mathrm{Ac}$ & $1,459.19$ & 0.0104
\end{tabular}

a. Absolute gamma-ray intensities listed only for the interference photopeaks. The reader is referred to Tables 5a-c for the intensities of the primary peaks.

peak intensity resulting from the superposition of two or more gamma-rays is given by the following equation:

$$
A_{X}=\sum_{i} A_{i}
$$

where

$\mathrm{A}_{\mathrm{x}}=$ the total net counts per second at an average energy, $\mathrm{E}_{\mathrm{AVE}}$, and

$\mathrm{A}_{\mathrm{i}}=$ the individual contributions to the full energy peak (counts/s).

Prior to determining system efficiency, absolute peak intensities of complex peaks must be considered.

\section{Determination of Efficiency Function}

The efficiency for single photopeaks is represented by Equation 8:

$\epsilon(E)=\frac{A_{E}}{C \cdot N}$

where

$$
\begin{aligned}
& A_{E}=\text { observed peak intensity (cts/s) at energy } E \\
& C=\text { activity (decays/s) of the sample }
\end{aligned}
$$




$$
\mathrm{N}=\text { gamma-ray yield ( } \gamma \text { 's/decay) of the radionuclide at energy, } \mathrm{E} \text {. }
$$

In the case of complex, superimposed peaks, Equation 8 becomes

$$
\epsilon(E)=\frac{A_{X}}{\sum_{i} C_{i} \cdot N_{i}}
$$

where

$$
\begin{aligned}
& A_{X}=\text { observed peak intensity (cts/s) at an average energy, } E_{\mathrm{AVE}} \\
& \mathrm{C}_{\mathrm{i}}=\text { activity (decays/s) of the } \mathrm{i}^{\text {th }} \text { radionuclide } \\
& \mathrm{N}_{\mathrm{i}}=\text { gamma-ray yield ( } \gamma \text { 's/decay) of the } i^{\text {th }} \text { radionuclide at energy, } E .
\end{aligned}
$$

The efficiency of a detection system for any given energy can be determined by using Equations 8 and 9. However, for spectrometric measurements made in a geologic environment, it is necessary to modify the simple absolute efficiency function using constants with the proper units. Spectrometric measurements in geologic media are made in order to obtain information on the distribution of NORM and man-made radionuclides in the subsurface, and the units should have the following attributes (LAEA 1976):

- Relate as directly as possible to radioelement concentration

- Provide identical results in a direct comparison of radiometric with chemically determined values, under specified conditions

- Eliminate confusion with other units.

Because the concentrations of the standard calibration sources are given in terms of pico-Curies per gram (pCi/g), the efficiency of the detection system must be folded into a dimensionally correct equation (Koizumi et al. 1994; Koizumi et al. 1993):

$$
\epsilon(E) \cdot 100 \frac{(\text { counts } / \mathrm{s})}{(\text { gammas } / \mathrm{s} / \mathrm{g})}=\frac{\mathrm{A}(\text { counts } / \mathrm{s})}{\mathrm{N}(\text { gammas } / \text { decay })} \cdot 27.0 \frac{(\mathrm{pCi})}{(\text { decays } / \mathrm{s})} \cdot \frac{1}{\mathrm{C}(\mathrm{pCi} / \mathrm{g})}
$$

where

$$
\begin{aligned}
& \mathrm{C}=\text { concentration }(\mathrm{pCi} / \mathrm{g}) \text { of the sample } \\
& \mathrm{A}=\text { observed peak intensity (cts/s) } \\
& \mathrm{N}=\text { absolute peak intensity ( } \gamma \text { 's/decay) } \\
& 27.0=\text { a conversion factor from decays per second to picocuries }
\end{aligned}
$$


$\epsilon(E)=\quad$ energy dependent detection efficiency of the system.

The standards developed by the IAEA and adopted by the geophysics industry were the main drivers for the functional and dimensional form of Equation 10. However, to make the calculation of the efficiency function less cumbersome, Equation 10 can be re-written as:

$\epsilon(\mathrm{E}) \cdot 100=\frac{\mathrm{A}}{\mathrm{N} \cdot \mathrm{C}} \cdot 27.0$

After the spectra had been collected and the peak searches performed, values for $A, N$, and $C$ were substituted into Equation 11. These efficiency values for the gamma rays from each source, $K, U$, and $T$, were tabulated in a Microsof ${ }^{\otimes}$ Excel spreadsheet, and plotted as a function of energy.

\section{MicroShield ${ }^{\odot}$ Modeling}

\section{MicroShield ${ }^{\oplus}$ Code Description}

MicroShield ${ }^{\circ}$ is a computer modeling code developed by Getachew Worku, Phil Rhinelander, and Diane Snee of Grove Engineering. The primary purpose of MicroShield ${ }^{\circ}$ is to estimate photon fluence and exposure rates from point, line, and volume sources. MicroShield ${ }^{\circ}$ uses the point kernel technique to determine photon fluence rate, $\varphi$. The integrations are performed in the cylindrical coordinate system and may be represented by the following expression (Worku et al. 1992,1993):

$\varphi=\iint_{z,} \int_{\theta, r} \frac{S_{V} \cdot B \cdot e^{-b}}{4 \pi \cdot \rho^{2}} r d r d \theta d z$

where

$$
\begin{aligned}
& \varphi=\text { photon fluence rate (photons } / \mathrm{cm}^{2} / \mathrm{s} \text { ) } \\
& \mathrm{S}_{\mathrm{V}}=\text { source strength (photons } / \mathrm{s} / \mathrm{cm}^{3} \text { ) } \\
& \mathrm{B}=\text { buildup factor } \\
& \mathrm{e}^{-\mathrm{b}}=\text { attenuation of photons in the material } \\
& \rho=\text { distance from the source kernel to the exposure point }(\mathrm{cm}) .
\end{aligned}
$$

The numerical integration performed by MicroShield ${ }^{\circ}$ is the Gaussian quadrature with a GaussLegendre method for determining abscissas and weights. Conceptually, the point kernel technique divides an extended source into finite elements, and then treats each element as a point source. The number of finite elements is chosen by the user under the Integration Parameters menu in MicroShield ${ }^{\circ}$. For a cylindrical source, there are three integration parameters: 1) radial, 2) circumferential, and 3) axial. The minimum value for any quadrature order is eight; however, larger numbers lead to more precision in the final result. 
Additionally, larger quadratures result in a finer mesh, or smaller and more numerous kernels. If the point of interest is between the ends of a distributed source, MicroShield ${ }^{\circ}$ divides the quadrature for a given integration variable into two parts and scales each part to the ratio of the smaller to larger portion. The result is a finer integration mesh near the point of interest, and more accurate convergence in cases where the point of interest is "close" to the source (Worku et al. 1993; Press et al. 1992). The occurrence of an oscillating solution for large quadrature orders is also minimized using this technique (Worku et al. 1993). The value of this integration technique became evident during the modeling efforts.

MicroShield ${ }^{\circ}$ allows the user to build computer models considering numerous source/shield/exposure point geometries. This study considered an annular cylinder geometry with the detector positioned in the center. Input parameters required for model construction included: source and shield characteristics, and the quadrature order for integration. The source characteristics required in this application were: physical dimensions, chemical composition, and source strength. Shield characteristics included physical dimensions, chemical composition, and position relative to source. All dimensions of the source were entered including inner and outer radii of the cylinder, cylinder height, and vertical and lateral positioning of the exposure point inside the annulus. Custom materials may be generated for the source chemical composition. After the source geometry and composition were entered, parameters for source strength were entered into the code. In this study, the source strength was entered as individual photon energies in units of photons per second. MicroShield ${ }^{\circ}$ then converted the source strength to units of photons per second per $\mathrm{cm}^{3}$ for each energy. A single shield can be selected (optional) and positioned concentric to the source, inside the annulus. The casing inside a well bore is an example of a shield. If a shield was used in the model, input parameters for shield dimensions and chemical composition were entered. Quadrature orders used in this study were 20,20, and 20 for radial, circumferential, and axial coordinates, respectively. This information was employed within MicroShield ${ }^{\circ}$ to calculate the photon fluence rate at the point of interest for each photon energy group, both with and without buildup. Buildup factors for various materials were determined within MicroShield ${ }^{\circ}$ by cubic spline interpolation of tables identical to ANS 6.4.3 data (Trubey 1988); However, the photon fluence rates with buildup were not used in the development of correction factors as will be described in the results. The following are descriptions of the various computer models used in this study.

\section{The Standard Model}

The standard model for this study was designed identical to the calibration sources at Grand Junction. (See Figure 3.) The physical dimensions of these sources are 152.4-cm high, an annular wall thickness of $55.2-\mathrm{cm}, 11.4-\mathrm{cm}$ diameter holes through their centers, and total source volumes of $1.76 \times 10^{6}-\mathrm{cm}^{3}$ each. The average dry bulk density and partial density of water were computed using the parameters for the $\mathrm{K}$, $\mathrm{U}$, and $\mathrm{T}$ sources at Grand Junction. The average dry bulk density of the aggregate is $1.88-\mathrm{g} / \mathrm{cm}^{3}$, and the average partial density of water is $0.273-\mathrm{g} / \mathrm{cm}^{3}$. Partial density is determined by multiplying the density of a given material by the percent of total volume it occupies in the sample. The resultant porosity of the model is $27.3 \%$. Source strength, in terms of total number of photons emitted from the source for each energy was calculated from the data in Tables 4 and 5a-c. Table 8 lists the photon energies, source strength, and photon source density for the photons used during MicroShield ${ }^{\circ}$ modeling.

There was no internal shield present in this model. The detector was positioned in the air filled center region of the cylinder, along the center line of the cylindrical annulus at a position of $76.2-\mathrm{cm}$ below the top 
Table 8. Photon energies and source strengths used in MicroShield ${ }^{\circ}$ modeling.

\begin{tabular}{cccc}
\hline Nuclide & $\begin{array}{c}\text { Photon energy } \\
(\mathrm{keV})\end{array}$ & $\begin{array}{c}\text { Source strength } \\
\text { (photons/s) }\end{array}$ & $\begin{array}{c}\text { Source density } \\
\text { (photons/s/cm }\end{array}$ \\
\hline${ }^{226} \mathrm{Ra}$ & 186.1 & $1.24 \cdot 10^{6}$ & $7.02 \cdot 10^{-1}$ \\
${ }^{214} \mathrm{~Pb}$ & 241.98 & $1.65 \cdot 10^{6}$ & $9.37 \cdot 10^{-1}$ \\
${ }^{214} \mathrm{~Pb}$ & 295.21 & $3.76 \cdot 10^{6}$ & $2.13 \cdot 10^{0}$ \\
${ }^{228} \mathrm{Ac}$ & 338.32 & $7.33 \cdot 10^{5}$ & $4.15 \cdot 10^{-1}$ \\
${ }^{228} \mathrm{Ac}$ & 463.01 & $2.89 \cdot 10^{5}$ & $1.64 \cdot 10^{-1}$ \\
${ }^{214} \mathrm{~Pb}$ & 609.31 & $8.99 \cdot 10^{6}$ & $5.10 \cdot 10^{0}$ \\
${ }^{228} \mathrm{Ac}$ & 794.95 & $2.83 \cdot 10^{5}$ & $1.60 \cdot 10^{-1}$ \\
${ }^{228} \mathrm{Ac}$ & 911.21 & $1.73 \cdot 10^{6}$ & $9.82 \cdot 10^{-1}$ \\
${ }^{214} \mathrm{Bi}$ & $1,120.29$ & $2.97 \cdot 10^{6}$ & $1.69 \cdot 10^{0}$ \\
${ }^{40} \mathrm{~K}$ & $1,460.83$ & $1.35 \cdot 10^{5}$ & $7.67 \cdot 10^{-2}$ \\
${ }^{214} \mathrm{Bi}$ & $1,509.23$ & $4.26 \cdot 10^{5}$ & $2.42 \cdot 10^{-1}$ \\
${ }^{214} \mathrm{Bi}$ & $2,118.55$ & $2.29 \cdot 10^{5}$ & $1.30 \cdot 10^{-1}$ \\
${ }^{208} \mathrm{Tl}$ & $2,614.53$ & $2.34 \cdot 10^{6}$ & $1.33 \cdot 10^{0}$ \\
\hline
\end{tabular}

surface of the cylinder. The density of the air was taken as $0.00122-\mathrm{g} / \mathrm{cm}^{3}$. All other models developed in this study were normalized to the results from this well defined geometry, unless otherwise noted.

\section{Infinite Geometry Models}

A series of models were constructed to determine whether or not the physical sources in Grand Junction were representative of an infinite geometry, similar to that found in boreholes and monitoring wells. These models were based on the Standard model described previously, with an air filled borehole and an annular concrete source matrix. The densities of the air, and concrete/water matrix were held constant as the height of the cylinder and thickness of the annular wall were varied independently of each other to observe the effects of changing the size of the annular region on the photon fluence rate at the detector location. Additionally, the photon density in the source was held constant for all energies. Table 9 shows how the dimensions of the annulus were varied. Under normal logging conditions, the most critical dimension is the height of the annulus. The annular height is representative of the vertical distribution of lithologic layers. A study of the effects of changing the annular thickness was also necessary to demonstrate whether or not the calibration sources were representative of infinite media.

\section{Porosity and Moisture Content Models}

In order to determine the response of the GSLS detector in a borehole where the surrounding matrix has a porosity and a moisture content different from the calibration conditions, the porosity and moisture models 
Table 9. Standard model dimension variations for the purpose of infinite geometry verification.

\begin{tabular}{lrrrr}
\multicolumn{2}{c}{ Vertical } & & \multicolumn{2}{c}{ Horizontal } \\
\cline { 5 - 5 } $\begin{array}{c}\text { Height } \\
(\mathrm{cm})\end{array}$ & $\begin{array}{r}\text { Step } \\
(\mathrm{cm})\end{array}$ & & $\begin{array}{c}\text { Thickness } \\
(\mathrm{cm})\end{array}$ & $\begin{array}{r}\text { Step } \\
(\mathrm{cm})\end{array}$ \\
\hline $1-10$ & 1 & $1-10$ & 1 \\
$10-60$ & 5 & $10-50$ & 5 \\
$60-140$ & 10 & $55.2^{\mathrm{a}}$ & N/A \\
$152.4^{\mathrm{a}}$ & N/A & $65-105$ & 10 \\
$140-200$ & 20 & &
\end{tabular}

a. These are the default values for the height and thickness of the Standard model annular source.

were developed. Initially, the standard model was used to study the effects of formation porosity and moisture content on the relative photon fluence rates from the formation to the detector position, centered along the axis of the annulus. However, it became necessary to increase the size of the models and increase the quadrature order as will be described in the results. Partial densities of concrete, air and water were used as input parameters for the differing porosities and moisture contents. Table 10 lists the partial densities and material densities of the source matrices that were evaluated.

Table 10. Partial densities of materials comprising the cylindrical annular source matrix.

\begin{tabular}{|c|c|c|c|c|c|}
\hline \multirow[b]{2}{*}{ Porosity } & \multirow{2}{*}{$\begin{array}{c}\text { Saturation } \\
\text { ratio } \\
\end{array}$} & \multicolumn{4}{|c|}{ Density, $\rho, g / \mathrm{cm}^{3}$} \\
\hline & & Concrete & Air & Water & Mixture \\
\hline 5 & 0 & 2.45 & 0.00006 & 0 & 2.450 \\
\hline 5 & 1 & 2.45 & 0 & 0.05 & 2.500 \\
\hline 10 & 0 & 2.32 & 0.00012 & 0 & 2.320 \\
\hline 10 & 0.25 & 2.32 & 0.00009 & 0.025 & 2.345 \\
\hline 10 & 0.5 & 2.32 & 0.00006 & 0.05 & 2.370 \\
\hline 10 & 0.75 & 2.32 & 0.00003 & 0.075 & 2.395 \\
\hline 10 & 1 & 2.32 & 0 & 0.1 & 2.420 \\
\hline 15 & 0 & 2.19 & 0.00018 & 0 & 2.198 \\
\hline 15 & 1 & 2.19 & 0 & 0.15 & 2.340 \\
\hline 20 & 0 & 2.06 & 0.00024 & 0 & 2.060 \\
\hline 20 & 0.25 & 2.06 & 0.00018 & 0.05 & 2.110 \\
\hline 20 & 0.5 & 2.06 & 0.00012 & 0.1 & 2.160 \\
\hline 20 & 0.75 & 2.06 & 0.00006 & 0.15 & 2.210 \\
\hline 20 & 1 & 2.06 & 0 & 0.2 & 2.260 \\
\hline
\end{tabular}


Table 10. (continued).

\begin{tabular}{|c|c|c|c|c|c|}
\hline \multirow[b]{2}{*}{ Porosity } & \multirow{2}{*}{$\begin{array}{c}\text { Saturation } \\
\text { ratio }\end{array}$} & \multicolumn{4}{|c|}{ Density, $\rho, \mathrm{g} / \mathrm{cm}^{3}$} \\
\hline & & Concrete & $\mathrm{Air}$ & Water & Mixture \\
\hline 25 & 0 & 1.94 & 0.00031 & 0 & 1.940 \\
\hline 25 & 1 & 1.94 & 0 & 0.25 & 2.190 \\
\hline 30 & 0 & 1.81 & 0.00037 & 0 & 1.810 \\
\hline 30 & 0.25 & 1.81 & 0.00028 & 0.075 & 1.885 \\
\hline 30 & 0.5 & 1.81 & 0.00018 & 0.15 & 1.960 \\
\hline 30 & 0.75 & 1.81 & 0.00009 & 0.225 & 2.035 \\
\hline 30 & 1 & 1.81 & 0 & 0.3 & 2.110 \\
\hline 35 & 0 & 1.68 & 0.00043 & 0 & 1.680 \\
\hline 35 & 1 & 1.68 & 0 & 0.35 & 2.030 \\
\hline 40 & 0 & 1.55 & 0.00049 & 0 & 1.550 \\
\hline 40 & 0.25 & 1.55 & 0.00037 & 0.1 & 1.650 \\
\hline 40 & 0.5 & 1.55 & 0.00024 & 0.2 & 1.750 \\
\hline 40 & 0.75 & 1.55 & 0.00012 & 0.3 & 1.850 \\
\hline 40 & 1 & 1.55 & 0 & 0.4 & 1.950 \\
\hline 45 & 0 & 1.42 & 0.00055 & 0 & 1.421 \\
\hline 45 & 1 & 1.42 & 0 & 0.45 & 1.870 \\
\hline 50 & 0 & 1.29 & 0.00061 & 0 & 1.291 \\
\hline 50 & 0.25 & 1.29 & 0.00046 & 0.125 & 1.415 \\
\hline 50 & 0.5 & 1.29 & 0.0003 & 0.25 & 1.540 \\
\hline 50 & 0.75 & 1.29 & 0.00015 & 0.375 & 1.665 \\
\hline 50 & 1 & 1.29 & 0 & 0.5 & 1.790 \\
\hline 55 & 0 & 1.16 & 0.00067 & 0 & 1.161 \\
\hline 55 & 1 & 1.16 & 0 & 0.55 & 1.710 \\
\hline 60 & 0 & 1.03 & 0.00073 & 0 & 1.031 \\
\hline 60 & 0.25 & 1.03 & 0.00055 & 0.15 & 1.181 \\
\hline 60 & 0.5 & 1.03 & 0.00037 & 0.3 & 1.330 \\
\hline 60 & 0.75 & 1.03 & 0.00018 & 0.45 & 1.480 \\
\hline 60 & 1 & 1.03 & 0 & 0.6 & 1.630 \\
\hline
\end{tabular}




\section{Casing, Annular Fill, and Water-filled Borehole Models}

Well casing, annular fill, and water-filled boreholes can have substantial affects on the attenuation of photons originating in the surrounding matrix.

Materials most often used for well casing are PVC pipe and iron. (Although the casing is usually galvanized or low-carbon steel, the major component is iron and attenuation effects can be modeled as if the casing is pure iron.) The standard thickness of well casing is $0.635-\mathrm{cm}(0.25-\mathrm{in}$.). The effect of casing on the attenuation of photons was modeled for casing thicknesses $0.75-\mathrm{cm}$ and $1.0-\mathrm{cm}$, for both PVC and iron.

In addition to the casing, the annular region between the formation and casing is usually sealed with concrete. Depending on the size of the borehole and the outer diameter of casing, the thickness of concrete can range from $10-\mathrm{cm}$ to $15-\mathrm{cm}$. The effect of concrete on the attenuation of photons was modeled for these thicknesses.

The last set of models involved estimation of the attenuation effect of water in the borehole. Effective thicknesses of water ranging from $1-\mathrm{cm}$ to $11-\mathrm{cm}$ around the detector were constructed with MicroShield ${ }^{\circ}$.

The Standard model was used as a normalization factor for the results of this portion of the study. Results from the iron casing and water-filled borehole models were then compared to empirical results obtained by Koizumi (Koizumi et al. 1993). Based on the agreement between these studies, the results from the PVC and concrete models can be evaluated.

\section{Summary of Research Methodology}

After calibration of the GSLS in the calibration sources, simulation of various borehole conditions that may be encountered in the field were modeled with the MicroShield ${ }^{\circ}$ computer code. The first effort was to determine whether or not the calibration sources represented an infinite cylindrical geometry for the desired energy range of photons and estimate the effects of changing the vertical height of the enriched zone to simulate thin bed effects. Secondly, the effects of formation porosity and moisture content on the attenuation of photons were modeled. The last set of models were constructed to estimate the effects of various borehole parameters such as casing material and thickness, water-filled conditions, and cement seal in the annular region of the well and compare them with published, experimental results. Based on these items, the following hypotheses were developed: 1) photon fluence rates will decrease proportionally with decreasing cylinder height (representing the vertical extent of lithologic layer), if an infinite lateral geometry is maintained in the logging environment, and 2) the relative photon fluence rates for energies ranging from $186-\mathrm{keV}$ to $2,614-\mathrm{keV}$ will increase with increasing porosity, and decrease with increasing moisture content for any given porosity. 


\section{RESULTS AND DISCUSSION}

\section{Calibration and Efficiency Function}

The efficiency calibration of the Gamma Spectroscopy Logging System (GSLS) was necessary to quantify high-resolution gamma-ray spectra collected in boreholes. The result of the efficiency calibration was an energy dependant function that allows the translation of net peak area into radionuclide concentration (pCi/g), assuming the field conditions are identical to the calibratior geometry and conditions.

During collection of the calibration spectra, it became evident that there was gain shift present in the GSLS electronics. In order to resolve this problem, each spectrum was re-calibrated for energy from an energy table created in GammaVision ${ }^{\otimes}$. This re-calibration was necessary to avoid improper peak identification during the efficiency calibration. Once the spectra were properly calibrated for energy, it was possible to further analyze them for the efficiency of the detection system.

The data from the calibration spectra were entered into Microsoft ${ }^{\otimes}$ Excel as a spreadsheet. The efficiency of the system was then plotted as a function of energy as shown in Figure 4.

Included in Figure 4 is the equation of best fit for the efficiency curve and the estimated $r^{2}$ value of the curve. Excel calculates a least squares fit through the points using the generic, power law equation $y=c \cdot x^{b}$ (Microsoft $\left.^{\otimes} 1993-1994\right)$. Although it has been shown that extremely accurate and representative efficiency functions containing six and eight curve fit parameters have been developed and tested, simple two parameter relations can also be used with reasonable accuracy for photons of $100 \mathrm{keV}$ and greater (Knoll 1989). All functions studied have the same basic characteristic over the energy range of interest, and the shape of this efficiency curve is consistent with efficiency functions developed for similar logging tools employed by Westinghouse Hanford Company (Randall 1994; Koizumi et al. 1993).

The generic equation that combines the energy dependant efficiency of the detection system, $\epsilon(\mathrm{E})$, observed net count rate, $\mathrm{A}$, and absolute peak intensity, $\mathrm{N}$ to yield sample concentration is the following (Randall 1994):

$C_{x}=\frac{A_{x}}{\epsilon(E) \cdot N_{x}}$

Substituting the empirically determined function $\in(E)$ into Equation 13, and incorporating the proper units, the following equation results (Koizumi et al. 1993):

$$
\mathrm{C}(\mathrm{pCi} / \mathrm{g})=\frac{\mathrm{A}(\mathrm{cts} / \mathrm{s})}{\mathrm{N}(\gamma / \text { decay })} \cdot 27.0 \frac{(\mathrm{pCi})}{(\text { decays } / \mathrm{s})} \cdot \frac{1}{\left(3.72 \cdot \mathrm{E}^{-0.38}\right) \cdot 100 \frac{(\mathrm{cts} / \mathrm{s})}{(\gamma / \mathrm{s} / \mathrm{g})}}
$$

where $\mathrm{E}$ is entered in $\mathrm{keV}$. This equation is derived from the calibration geometry and borehole conditions; however, as stated before, ideal conditions are not always encountered in the field. Therefore correction factors need to be developed for application to spectra collected in boreholes and monitoring wells. 


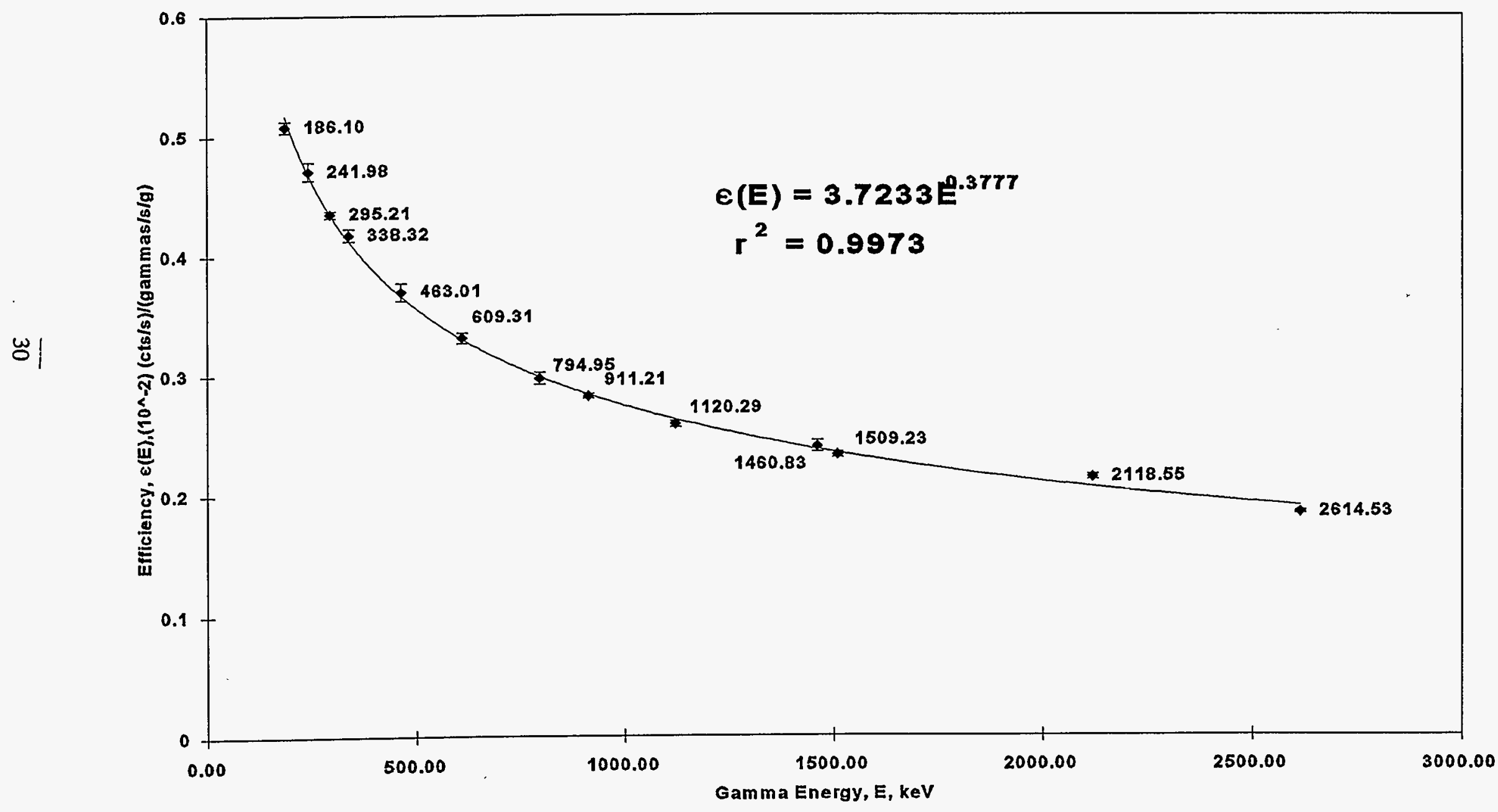

Figure 4. GSLS Efficiency curve for photons ranging from $186-\mathrm{keV}$ to $2,614-\mathrm{keV}$. 
It is important to note that the efficiency of a counting system can change. This change may be brought about by degradation of the detection medium and system electronics, and from changes or modifications to the system electronics. Therefore it is stressed that the efficiency of the system be verified and re-calibrated on a periodic basis. In addition to changes in the efficiency inherent to the system components, field conditions may adversely affect concentration calculations, resulting in erroneous concentration numbers.

\section{MicroShield ${ }^{\odot}$ Modeling}

\section{Infinite Geometry and Vertical Distribution Study}

It was assumed that the Standard model dimensions represent an infinite geometry to the detector for the energy range of photons considered in this study (186-keV to 2,614-keV), and any increase in the physical size of the source (assuming constant activity per unit volume), either vertically or laterally, would not increase the fluence rate at the center of the cylindrical annulus; however, if the dimensions of the annulus were decreased, there would be a point at which the photon fluence rate at the detector position would begin to decrease. This decrease would result in systematically low values of estimated radionuclide concentrations. The fluence rates for the standard model are listed in Table 11.

Photon fluence rates at the center of various size cylindrical annuli were modeled using MicroShield ${ }^{\circ}$. (See Table 9, Methods and Materials.) The photon fluence rates inside the annuli were normalized to the fluence rates calculated at the center of the standard model and the results displayed in Figures 5 and 6.

Table 11. Photon fluence rates for standard model conditions.

\begin{tabular}{cc}
$\begin{array}{c}\text { Photon energy } \\
(\mathrm{keV})\end{array}$ & $\begin{array}{c}\text { Photon fluence rate } \\
\left.\text { (photons/cm }{ }^{2} / \mathrm{s}\right)\end{array}$ \\
\hline 186.10 & 2.50 \\
241.98 & 3.67 \\
295.21 & 9.01 \\
338.32 & 1.85 \\
463.01 & 0.83 \\
609.31 & 28.99 \\
794.95 & 1.03 \\
911.21 & 6.71 \\
$1,120.29$ & 12.75 \\
$1,460.83$ & 0.66 \\
$1,509.23$ & 2.13 \\
$2,118.55$ & 1.36 \\
$2,614.53$ & 15.43 \\
\hline
\end{tabular}


The relative photon fluence rates converge to unity at dimensions less than or equal to the physical dimensions of the calibration sources. It is conclusive from Figures 5 and 6 that an infinite geometry is represented by the physical characteristics of the calibration sources at the Technical Measurements Center in Grand Junction. Not only does this study demonstrate infinite geometry calibration conditions, but it also demonstrates the relationship between source height and uncollided photon flux at the detector.

Correction factors for the vertical height of the formation were determined for annular heights between $15-\mathrm{cm}$ and $90-\mathrm{cm}$. Figures $7 \mathrm{a}$ and $7 \mathrm{~b}$ display the correction factors as a function of energy for different annular heights for the uncollided photons incident upon the detector. Equations representing the best fit to the data were obtained through regression analysis using the linear function:

$\mathrm{K}_{\mathrm{H}}=\mathrm{X}_{1} \cdot \mathrm{E}+\mathrm{X}_{2}$

where

$$
\begin{aligned}
& \mathrm{K}_{\mathrm{H}}=\text { the vertical correction factor } \\
& \mathrm{E}=\text { incident photon energy } \\
& \mathrm{X}_{\mathrm{i}},=\text { best fit parameters }(\mathrm{i}=1,2)
\end{aligned}
$$

Although the curves at 15,20 , and 30 -cm show some curvature, a closer look at the equation fit parameters must be made to demonstrate the linearity.

Table 12 lists the fit parameters, $X_{1}$ and $X_{2}$, and the $r^{2}$ values for each thickness depicted in Figures $7 \mathrm{a}$ and $7 \mathrm{~b}$. Values of $\mathrm{r}^{2}$ close to 1 indicate a strong linear relationship (Chase et al. 1992). As can be seen from Table 12, there is a strong linear relationship between the data points in each data set.

The rate of change of the relative photon fluence is large compared to the corresponding change in annular heights less than 15-cm (Figure 6). This could lead to large errors in the estimation of correction factors. Estimations of correction factors for thin beds less than $15-\mathrm{cm}$ thick are generally not made (Wilson et al. 1981). Additionally, annular heights greater than $90 \mathrm{~cm}$ result in less than a two or three percent decrease in the relative photon fluence rate for any energy between $186-\mathrm{keV}$ and $2,614-\mathrm{keV}$. Therefore, vertical correction factors, $\mathrm{K}_{\mathrm{H}}$, are only necessary for spectra collected in the center of very thin (15-cm to 90-cm) geologic layers.

\section{Porosity and Moisture Content Study}

Variations in the physical parameters of the formation surrounding the borehole from those of the calibration sources can cause errors in radionuclide concentration estimations. This portion of the thesis presents the results of formation porosity and saturation ratio effects on the photon fluence rates at the center of "infinite" cylindrical annuli. 

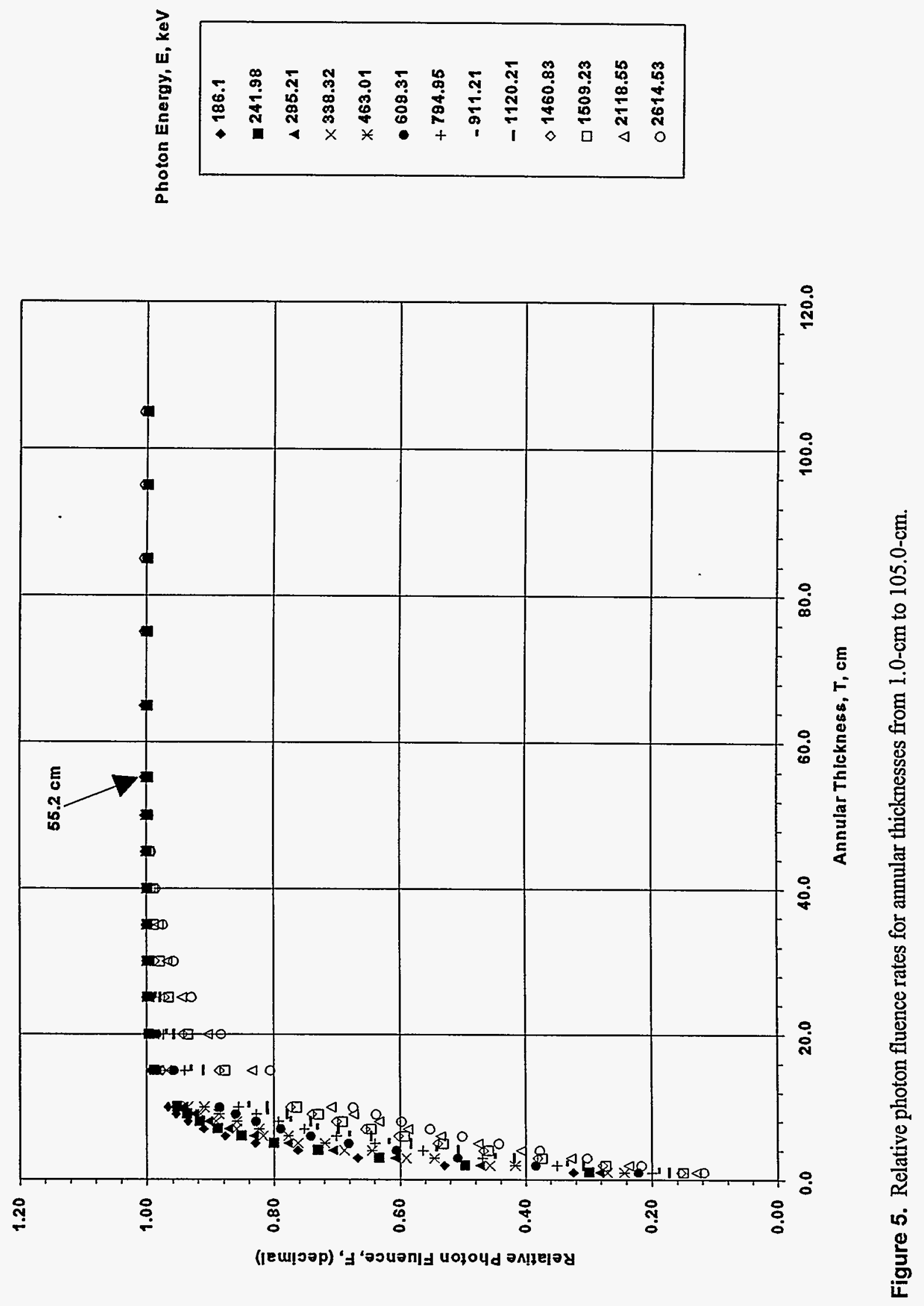


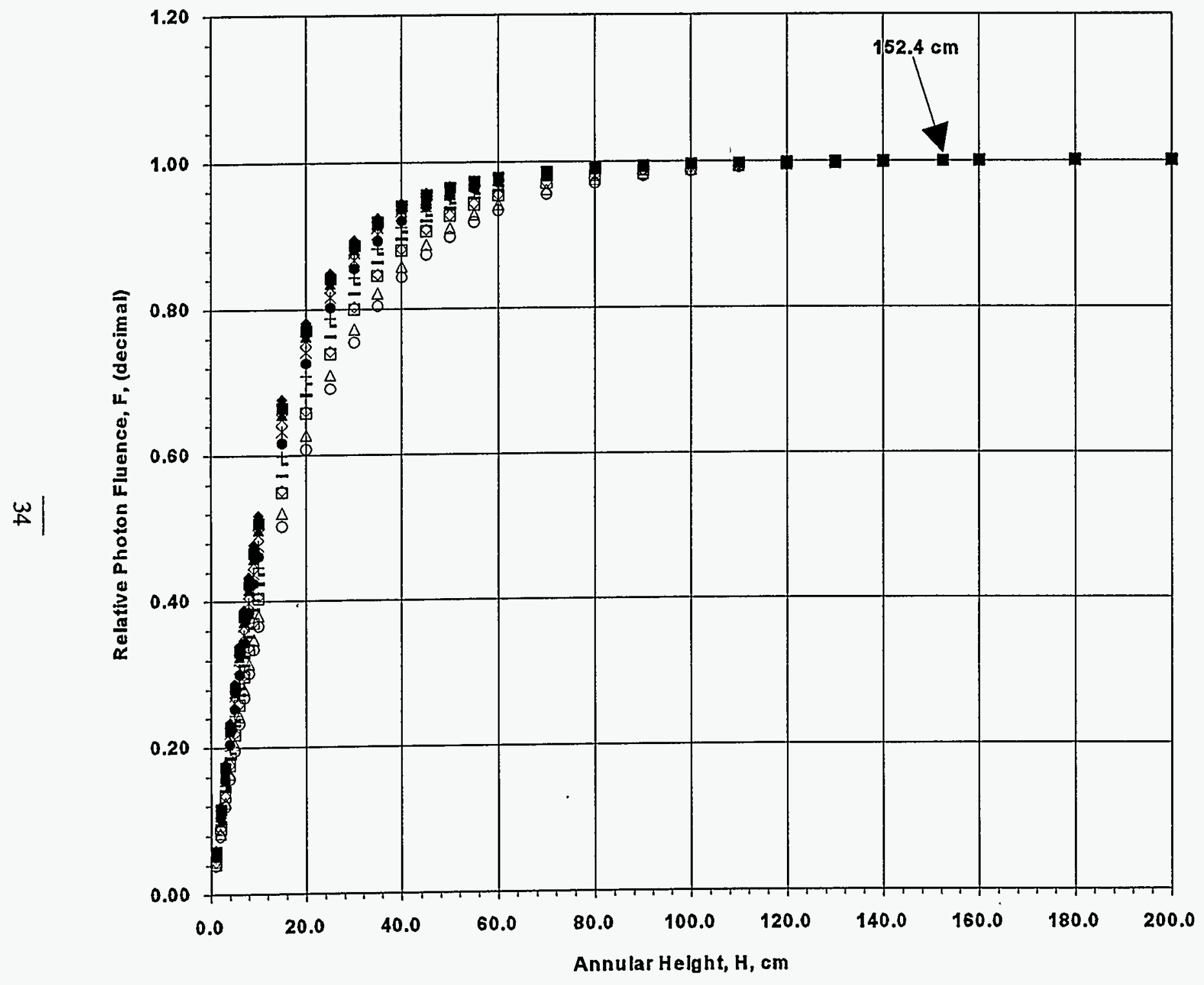

Photon Energy, E, keV

\begin{tabular}{|l|}
\hline \\
\hline 241.96 .1 \\
$\triangle 295.21$ \\
$\times 338.32$ \\
$* 463.01$ \\
-609.31 \\
+794.95 \\
-911.21 \\
-1120.21 \\
$\diamond 1460.83$ \\
$\square 1608.23$ \\
$\triangle 2118.55$ \\
02614.53 \\
\hline
\end{tabular}

Figure 6. Relative photon fluence rates for annular heights from $1.0-\mathrm{cm}$ to $200.0-\mathrm{cm}$. 


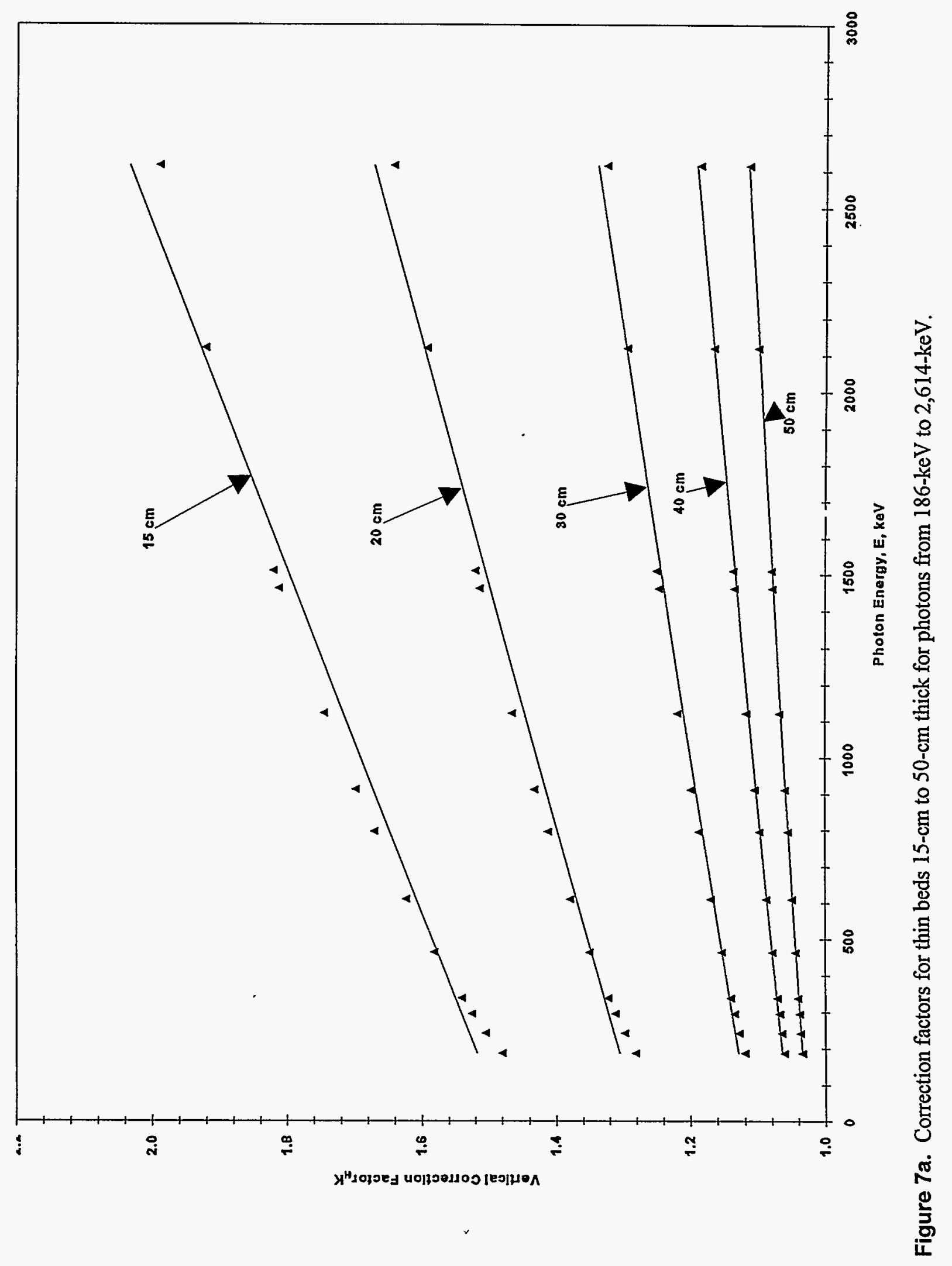




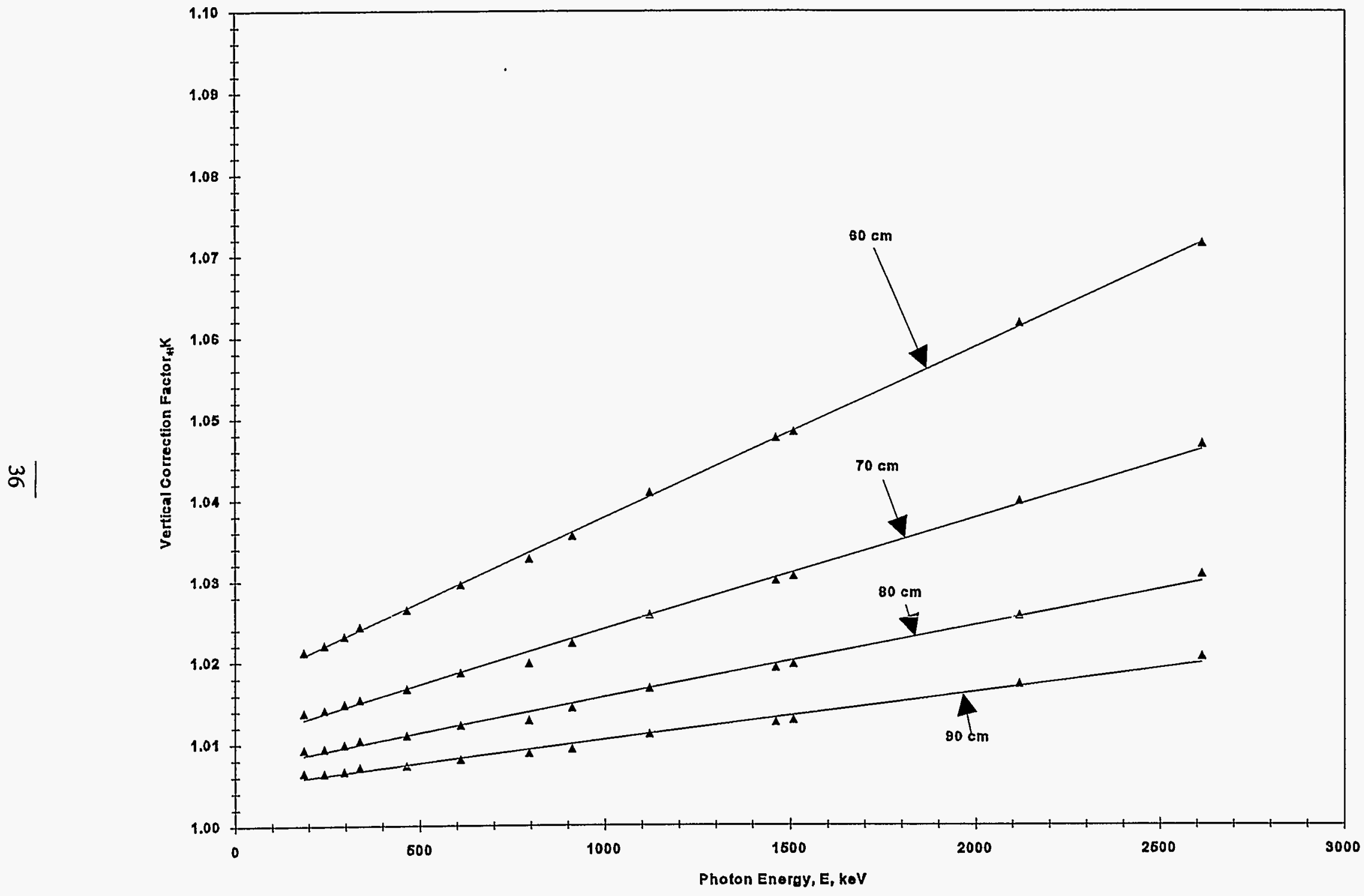

Figure $7 \mathrm{~b}$. Correction factors for thin beds $60-\mathrm{cm}$ to $90-\mathrm{cm}$ thick for photons from $186-\mathrm{keV}$ to $2,614-\mathrm{keV}$. 
Table 12. Fit parameters for vertical correction factor function.

\begin{tabular}{cccc}
\hline \multirow{2}{*}{$\begin{array}{c}\text { Annular height } \\
(\mathrm{cm})\end{array}$} & \multicolumn{2}{c}{ Fit parameters } & \multicolumn{1}{c}{$\mathrm{r}^{2}$} \\
\cline { 2 - 4 } 15 & $2.0 \cdot 10^{-4}$ & 1.4782 & 0.9765 \\
20 & $2.0 \cdot 10^{-4}$ & 1.2771 & 0.9805 \\
30 & $9.0 \cdot 10^{-5}$ & 1.1132 & 0.9884 \\
40 & $5.0 \cdot 10^{-5}$ & 1.0540 & 0.9954 \\
50 & $3.0 \cdot 10^{-5}$ & 1.0287 & 0.9990 \\
60 & $2.0 \cdot 10^{-5}$ & 1.0169 & 0.9994 \\
70 & $1.0 \cdot 10^{-5}$ & 1.0104 & 0.9965 \\
80 & $9.0 \cdot 10^{-6}$ & 1.0069 & 0.9931 \\
90 & $6.0 \cdot 10^{-6}$ & 1.0047 & 0.9890 \\
\hline
\end{tabular}

The previous results section described and verified the infinite geometry representation of the calibration sources at the Technical Measurements Center; all of the computer models were normalized to the standard geometry of the calibration sources. However, attempts to model various porosity media and various saturation ratios using the standard, or default, geometry did not yield results consistent with theoretical or intuitive predictions. The initial results from the porosity and moisture models led to the following:

1. The relative photon fluence rates decrease with increasing energy for saturation ratios, $R_{S} \geq 0.25$ in models with porosities $\geq 30 \%$.

The intuitive, or expected results are:

1. For any given porosity, the relative photon fluence rates should decrease with decreasing energy

2. The relative photon fluence rates for all energies and porosities should decrease with increasing moisture content.

Consequently, four steps were taken to investigate the nature of the output from the porosity and moisture models:

1. Verified that MicroShield ${ }^{\circ}$ input parameters and output data for Excel $^{\circledR}$ spreadsheets were correct

2. Verified quadrature orders were sufficiently large to ensure convergence of numerical integrations

3. Verified infinite geometry configuration by increasing the dimensions of the cylindrical annulus (keeping activity density constant), and compared the relative photon fluence rates for each geometry 
4. Compared the photon fluence rates at the detector with and without buildup after steps 1 through 3 were completed.

The initial bookkeeping step of verifying that numbers were entered correctly into MicroShield ${ }^{\circ}$ and Excel showed that all numbers had been entered properly, and that the output represented the input data. The second and third steps were performed concurrently because any increase in the dimensions of the model required a subsequent test of the quadrature orders to verify that the integration mesh was fine enough to ensure convergence (Negin et al. 1993). These two steps demonstrated that as the porosity of the source matrix increases, the infinite source geometry conditions disappear; therefore, the physical dimensions of the standard or reference model were increased to an annular height of $600-\mathrm{cm}$, annular thickness of $200-\mathrm{cm}$, and a detector position of $300-\mathrm{cm}$ below the top surface of the annular models. Increasing the physical dimensions of the models was necessary to maintain the "infinite" source geometry in the models with porosities greater than that of the standard $27.3 \%$. The reason for this is as follows: As the porosity of the material increased, the quantity of absorbing material (effective density) and the effective- $Z$ of the material decreased. Therefore, the size of the cylindrical annulus had to be increased to replace the "lost" material. As the size of the source matrix was increased, the number of photons originating in the source penetrated to the center of the annulus until a maximum fluence rate was reached, and the infinite geometry condition was achieved. This was verified by further increases in the source dimensions with no corresponding increase in the relative photon fluence rates. The increase in the physical size of the source also resulted in an increase in the axial integration quadrature order from 20 to 30 . The fourth step of this data check compared the results with buildup to those without buildup for all porosities and saturation ratios.

If buildup is considered, there is an increase in the relative photon fluence rates for all energies due to Compton interactions. However, when MicroShield ${ }^{\circ}$ calculates buildup, it calculates the total photon fluence rate, scattered plus uncollided photons. This technique does not separate the scattered photons into discrete energies; therefore, the fluence rate for a single energy photon group with buildup is as much as a factor of 2 greater than the fluence rate without buildup. If the calculated fluence rates with buildup were used to derive correction factors for discrete energies, the correction factors would be too low. This effect will be demonstrated in the comparisons study in the next section. The relative photon fluence rates without buildup were converted to correction factors and the results are presented next.

A set of graphs were developed from the modeling efforts to aid in the estimation of the vadose and saturated zone correction factors to be applied to spectra. Figures 8 and 9 display vadose and saturated zone correction factors as a function of formation porosity and photon energy. As can be seen in Figures 8 and 9 , the correction factors for any given porosity are constant over the energy range from $186-\mathrm{keV}$ to $2,614-\mathrm{keV}$, and the correction factors for any given energy increase smoothly and linearly with increasing porosity. If an infinite geometry is maintained for all porosities of the absorbing and source medium, more photons originating in the formation penetrate to the detector without interacting. Normalization of the data to the standard, or calibration, conditions in combination with the infinite geometry conditions removes the energy dependance of the correction factors. Therefore, the relative photon fluence rates and correction factors will remain constant for all energies considered at any porosity.

Correction factors for the vadose and saturated zones are presented in Figures 10 and 11, respectively. A linear relationship between the correction factors and formation porosity is given for both the vadose and saturated zones in the following equations: 


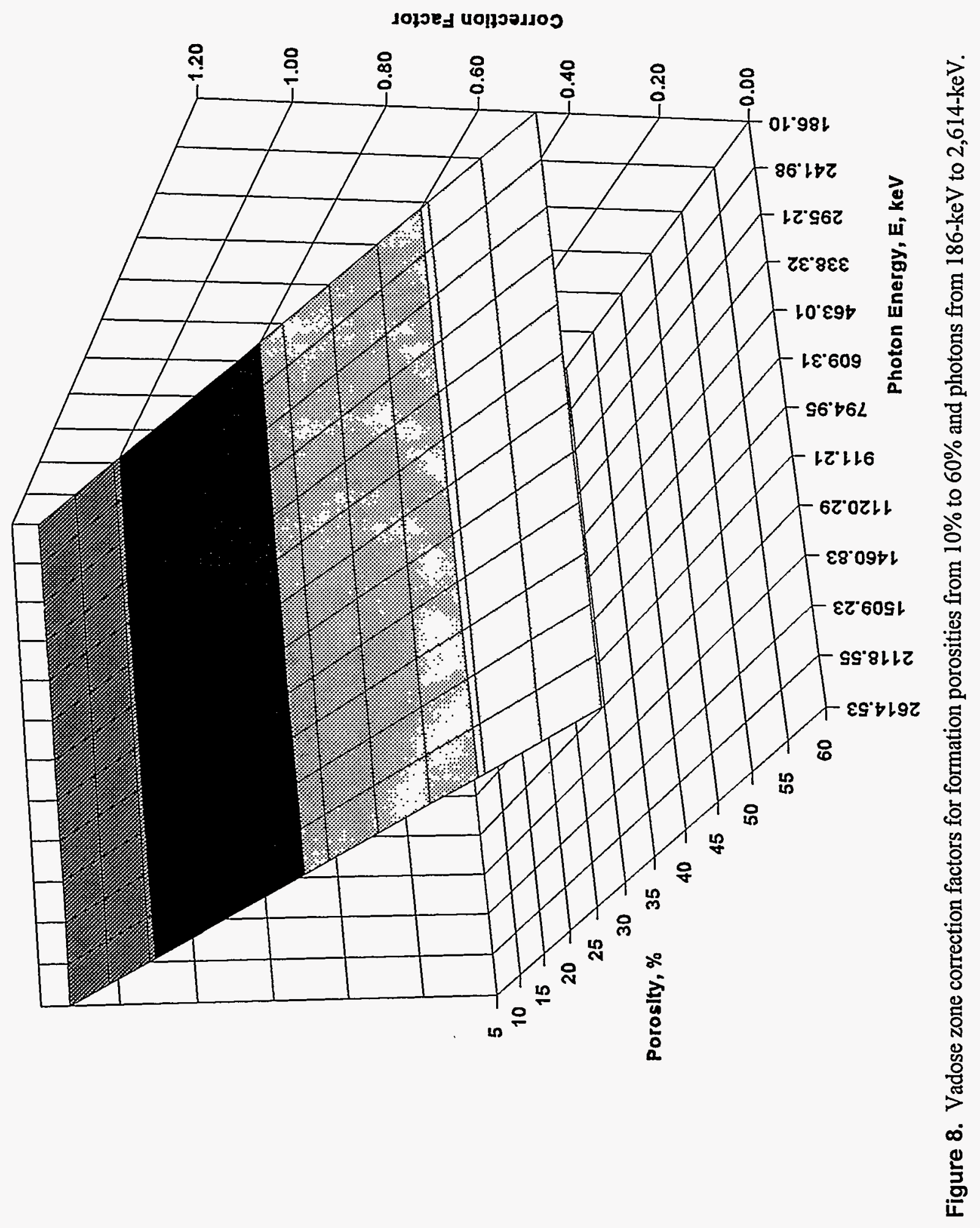




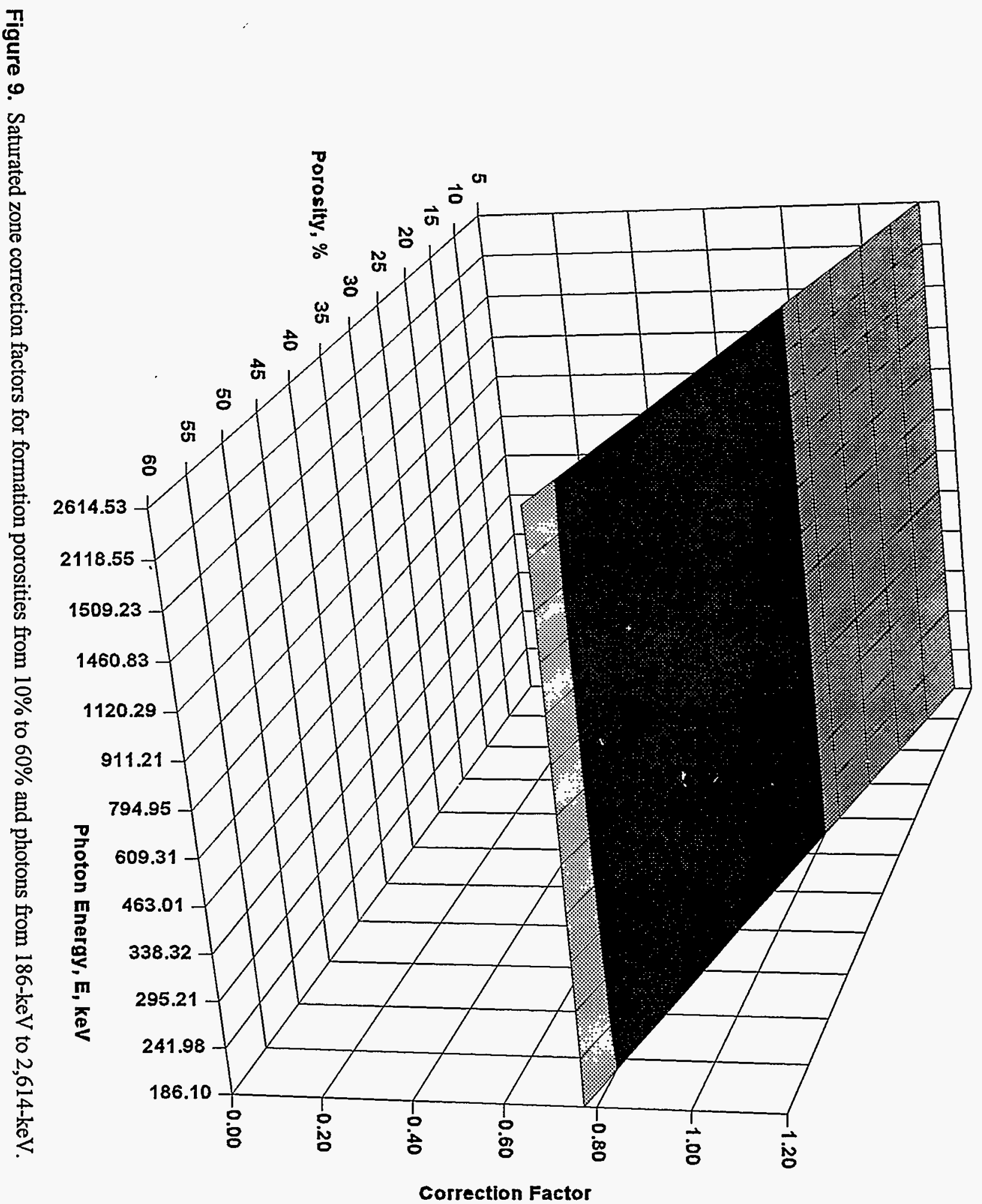




$$
\begin{aligned}
& \mathrm{K}_{\mathrm{V}}=\mathrm{X}_{3} \cdot \mathrm{n}+\mathrm{X}_{4}, \\
& \mathrm{~K}_{\mathrm{S}}=\mathrm{X}_{5} \cdot \mathrm{n}+\mathrm{X}_{6},
\end{aligned}
$$

where

$$
\begin{aligned}
& \mathrm{K}_{\mathrm{V}}=\text { vadose zone correction factor } \\
& \mathrm{K}_{\mathrm{S}}=\text { saturated zone correction factor } \\
& \mathrm{n}=\text { formation porosity }(\%) \\
& \mathrm{X}_{\mathrm{i}}=\text { best fit parameters }(\mathrm{i}=3,4,5,6)
\end{aligned}
$$

Values for the best fit parameters are listed in Table 13 for the vadose and saturated zones.

In addition to correction factors for varying formation porosities, sets of correction factors were developed for formation saturation ratios of $0.25,0.50$, and 0.75 , in media with porosities from 10 to 60 percent. Figure 12 displays the saturation ratio correction factors for porosities from 10 to 60 percent as a function of the saturation ratio. Regression analyses on the saturation ratio correction factors, $\mathrm{K}_{\mathrm{RS}}$, produced the following linear equation:

$$
\mathrm{K}_{\mathrm{RS}}=\mathrm{X}_{7} \cdot \mathrm{R}_{\mathrm{S}}+\mathrm{X}_{8}
$$

where

$$
\begin{aligned}
& \mathrm{K}_{\mathrm{RS}}=\text { saturation ratio correction factor } \\
& \mathrm{R}_{\mathrm{S}}=\text { saturation ratio (decimal) } \\
& \mathrm{X}_{\mathrm{i},}=\text { best fit parameters }(\mathrm{i}=7,8)
\end{aligned}
$$

The fit parameters, $X_{7}$ and $X_{8}$, for the saturation ratio correction factors, $K_{R S}$, are listed in Table 14 .

Table 13. Fit parameters for the vadose and saturated zone correction factors.

\begin{tabular}{ccccc}
\hline \multicolumn{4}{c}{ Correction factor fit parameters } \\
\cline { 2 - 5 } \multicolumn{3}{c}{ Vadose zone, $\mathrm{K}_{\mathrm{V}}$} & \multicolumn{2}{c}{ Saturated zone, $\mathrm{K}_{\mathrm{S}}$} \\
$\mathrm{X}_{3}$ & $\mathrm{X}_{4}$ & $\mathrm{X}_{5}$ & $\mathrm{X}_{6}$ \\
\hline-0.0119 & 1.1884 & -0.0069 & 1.1891 \\
\hline
\end{tabular}




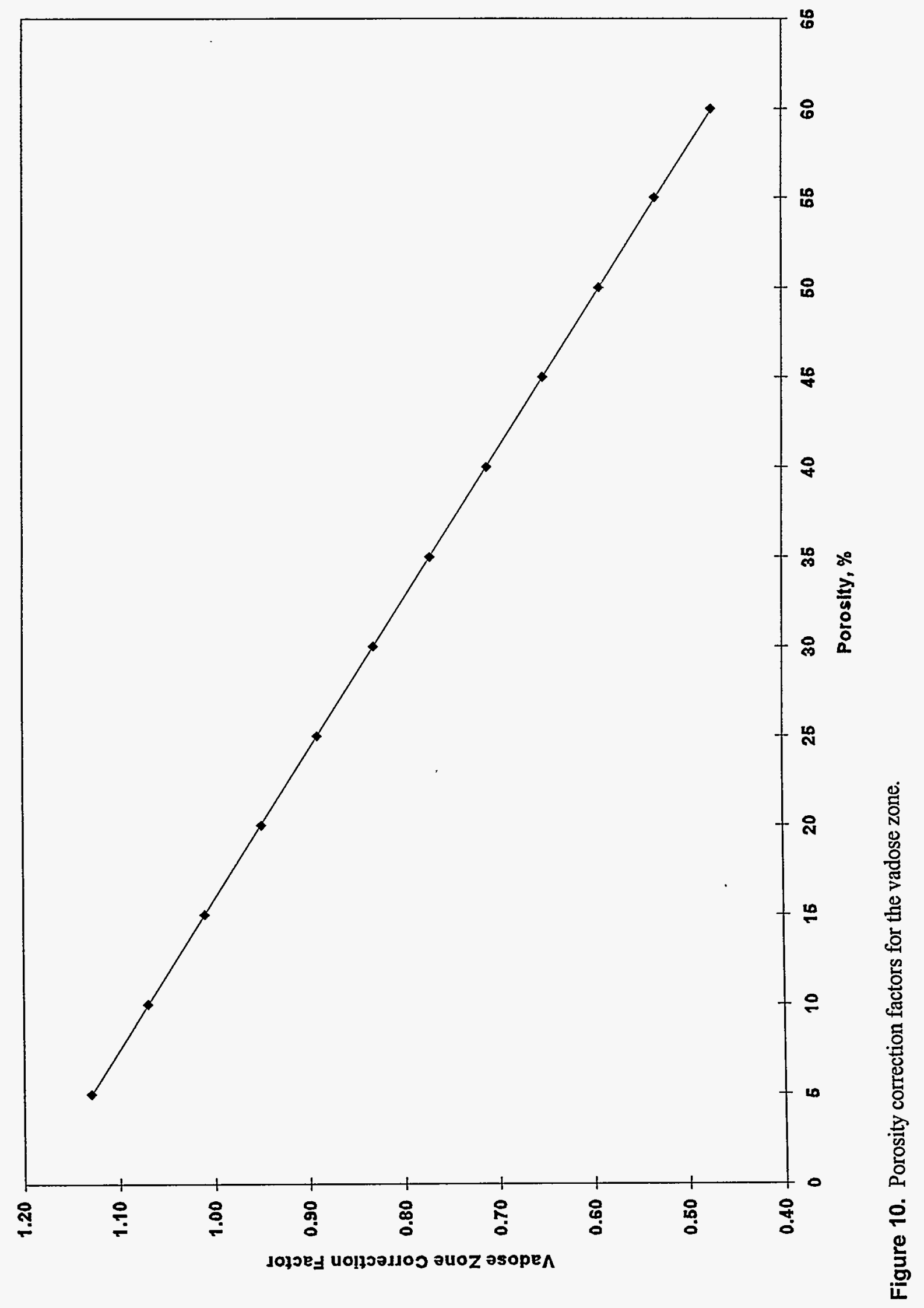




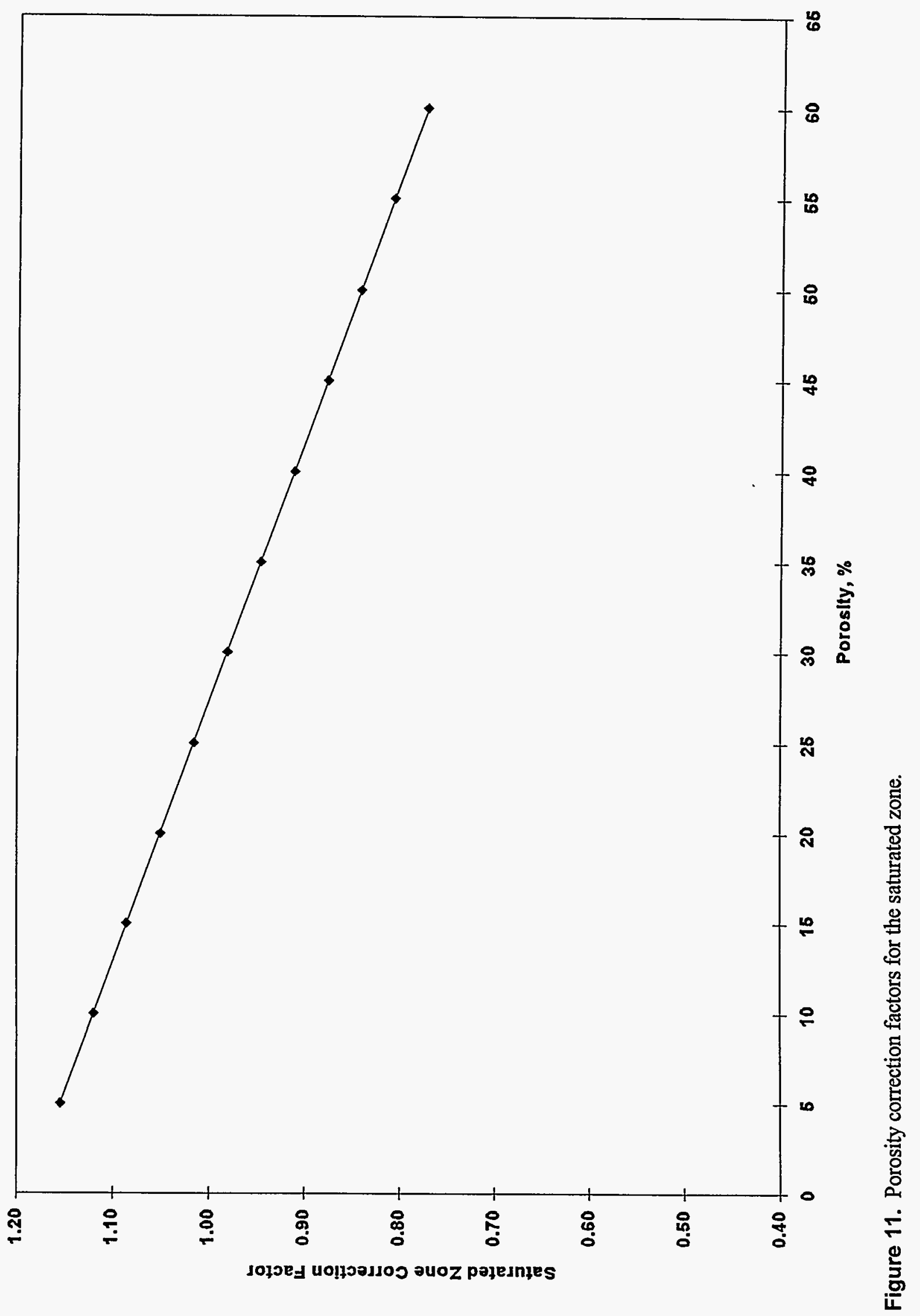


Table 14. Fit parameters for saturation ratio correction factors in formations with porosities from 10 to 60 percent.

\begin{tabular}{ccc}
$\begin{array}{c}\text { Formation porosity } \\
(\%)\end{array}$ & \multicolumn{2}{c}{ Saturation ratio fit parameters } \\
\hline 10 & $\mathrm{X}_{7}$ & $\mathrm{X}_{8}$ \\
\hline 20 & 0.0505 & 1.0695 \\
30 & 0.1008 & 0.9494 \\
40 & 0.1508 & 0.8299 \\
50 & 0.2008 & 0.7107 \\
60 & 0.2504 & 0.5917 \\
& 0.2998 & 0.4731
\end{tabular}

The correction factors for the saturation ratio show no energy dependance, as did the correction factors for the vadose and saturated zones. It can be stated then, that in an infinite cylindrical source geometry, correction factors for photon fluence rates are independent of photon energy and dependant upon the density and effective $Z$ of the formation (Wilson et al. 1979A; Wilson et al. 1981). Figure 13 shows the saturation ratio correction factor dependance on formation porosity and saturation ratio. The slope of the curve increases as the formation porosity increases. This results because at lower porosities the solid material in the formation is the primary attenuation medium for the photons, and changing the moisture content has little effect. The quantity of solid material decreases as the porosity of the formation increases. Although the solid material in the formation has a larger attenuation factor, the principle material affecting the attenuation of photons is the water/air mixture occupying the pore spaces.

It is important to note that the saturation ratio correction factors presented above also incorporate the corrections for formation porosity. Therefore, when $\mathrm{K}_{\mathrm{RS}}$ is used in correcting peak areas, $\mathrm{K}_{\mathrm{V}}$ or $\mathrm{K}_{\mathrm{W}}$ should not be used. If corrections for both porosity and saturation ratio were used concurrently, porosity would be accounted for twice, resulting in "over-correction."

\section{Casing, Annular Fill, and Water-Filled Borehole Correction Factors: A Comparison Study}

The completion materials used in the construction of monitoring wells serve as absorption and scattering media to the photons originating in the surrounding formation. As a result, correction factors must be developed and applied to the data collected with the GSLS.

Studies have been completed using computer models and empirical data to determine correction factors for iron well casing and water-filled boreholes. Carl Koizumi has been involved in both types of studies (Koizumi et al.1994; Koizumi et al. 1993; Koizumi et al. 1991; Koizumi 1988). Correction factors for iron casing and water-filled boreholes were determined using data from MicroShield ${ }^{\circ}$ models. Results both with and without buildup are presented here to demonstrate the effects of MicroShield ${ }^{\circ}$ calculated buildup factors on the accuracy of determining correction factors to be used in in-situ gamma-ray spectroscopic measurements. Correction factors for iron thicknesses of 0.75 and $1.0-\mathrm{cm}$ are presented here because they 


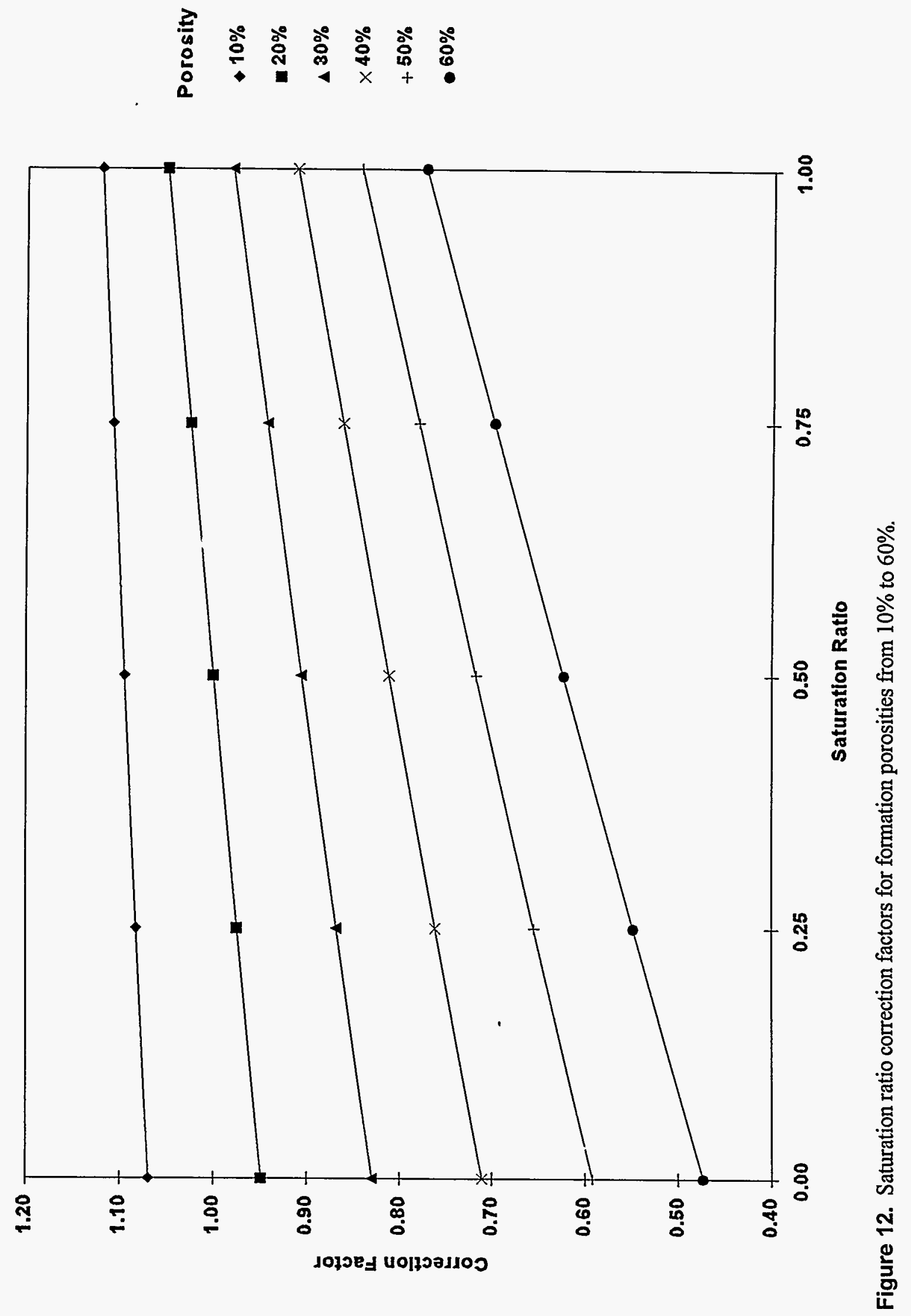




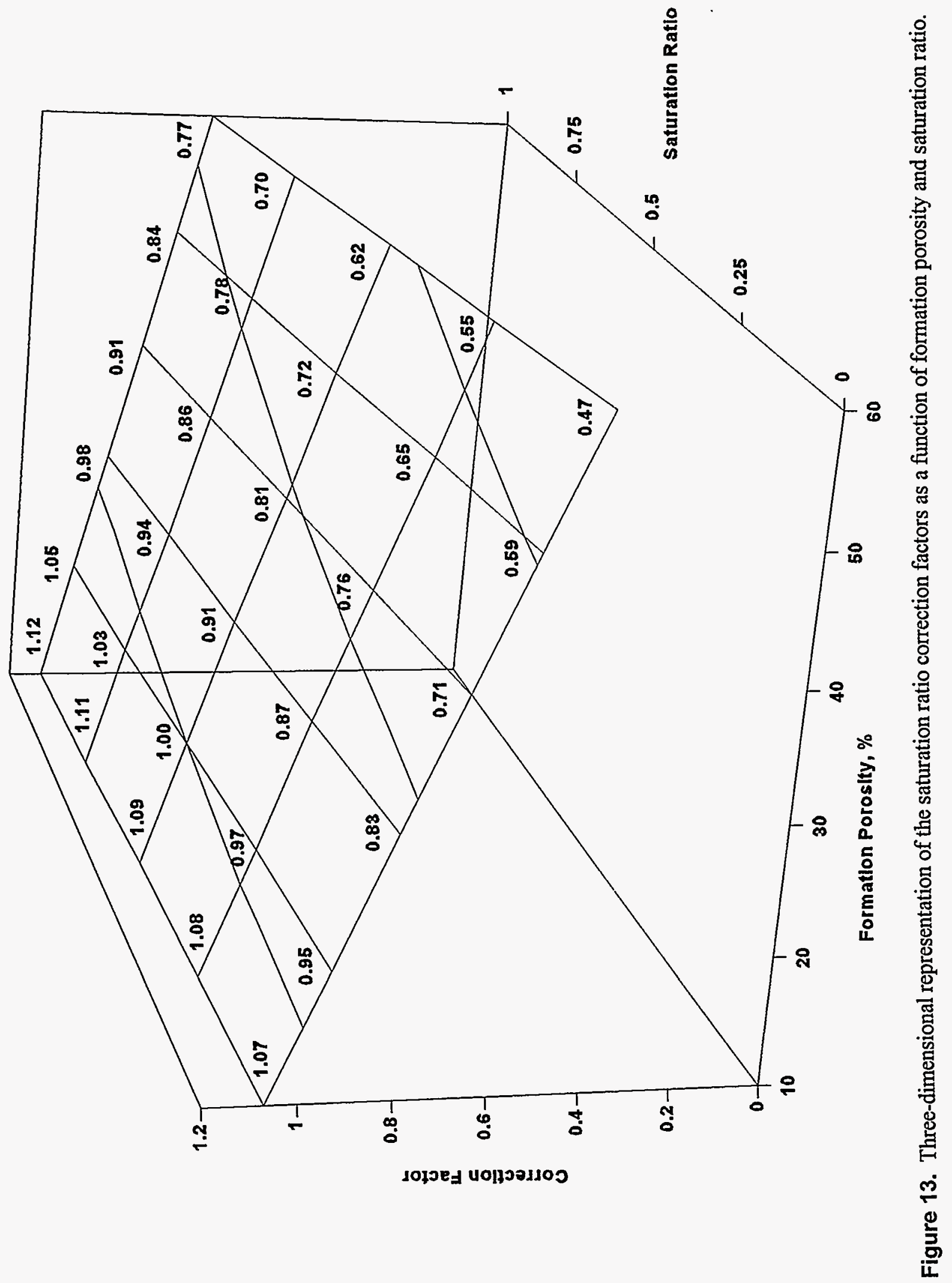


closely represent thicknesses of casing used to complete wells. Likewise, water thicknesses of 1.0, 4.0, 7.0 and 11.0-cm are used because they closely represent the quantities of water found in a borehole between the logging tool and borehole wall. Figures 14 and 15 show the correction factors for steel and water, respectively, with and without buildup.

The lines through the data points in Figure 14 are curves represented by the equation (Koizumi et al. 1993):

$$
\mathrm{K}_{\mathrm{I}}=\frac{1}{\mathrm{X}_{9}+\frac{\mathrm{X}_{10}}{\ln (E)}}
$$

where

$$
\begin{aligned}
& \mathrm{K}_{\mathrm{I}}=\text { correction factor for iron casing } \\
& \mathrm{E}=\text { photon energy }(\mathrm{keV}) \\
& \mathrm{X}_{\mathrm{i}}=\text { best-fit parameters }(\mathrm{i}=9,10) .
\end{aligned}
$$

The values for $\mathrm{X}_{9}$ and $\mathrm{X}_{10}$ without buildup, are listed in Table 15. These values are compared with those in Table 16, determined experimentally by Koizumi (Koizumi et al. 1993; Koizumi et al. 1994).
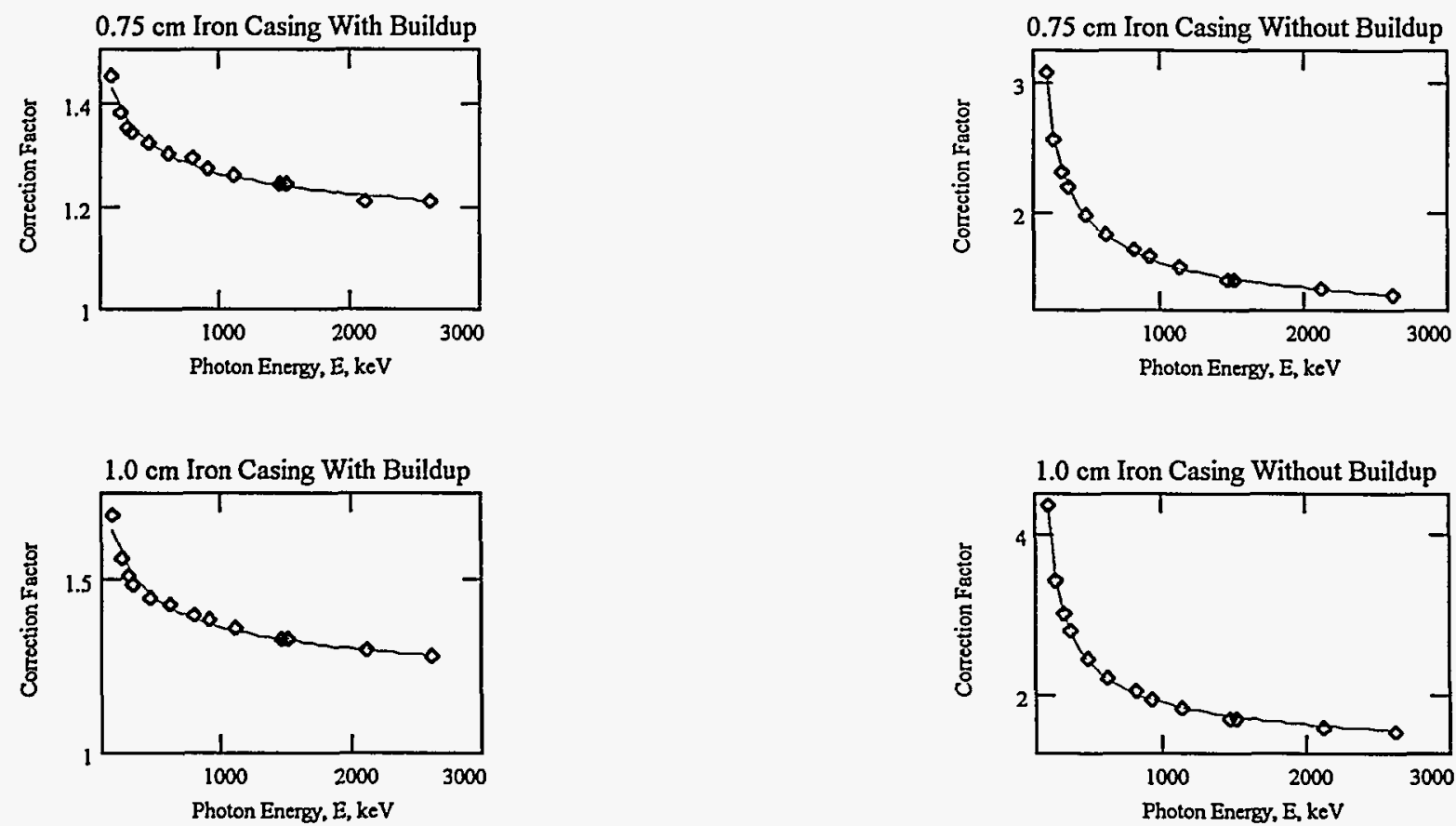

Figure 14. Iron casing correction factors, $\mathrm{K}_{\mathrm{t}}$ for casing thicknesses of $0.75 \mathrm{~cm}$ and $1.0 \mathrm{~cm}$, with and without buildup. 
Table 15. Iron casing correction factor fit parameters as determined from MicroShield ${ }^{\circ}$ output.

\begin{tabular}{ccc} 
Casing thickness & \multicolumn{2}{c}{ Fit parameters } \\
\cline { 2 - 3 }$(\mathrm{cm})$ & $\mathrm{X}_{9}$ & $\mathrm{X}_{10}$ \\
\hline 0.75 & 1.528 & -6.274 \\
1.0 & 1.476 & -6.513 \\
\hline
\end{tabular}

Table 16. Iron casing correction factor fit parameters as determined by Koizumi et al. $(1993,1994)$.

Casing thickness

(cm)

0.84

1.02

\section{Fit parameters}

$\mathrm{X}_{9} \quad \mathrm{X}_{10}$

$1.52 \pm 0.03 \quad-6.35 \pm 0.16$

$1.49 \pm 0.02 \quad-6.40 \pm 0.10$

As can be seen from the above tables, the results from MicroShield ${ }^{\circ}$ without buildup are almost identical to Koizumi's data. A similar comparison was made for water-filled borehole correction factors.

Figure 15 displays energy dependant correction factors for water-filled boreholes as determined from MicroShield ${ }^{\circ}$ modeling efforts. The curves drawn through the data points were determined through regression analysis and follow the general equation (Koizumi et al. 1993; Koizumi et al. 1994):

$$
K_{w}=\sqrt{X_{11}+\frac{X_{12}}{E}}
$$

where

$$
\begin{aligned}
& \mathrm{K}_{\mathrm{w}}=\text { water-filled borehole correction factor } \\
& \mathrm{E}=\text { photon energy }(\mathrm{keV}) \\
& \mathrm{X}_{\mathrm{i}},=\text { best-fit parameters }(\mathrm{i}=11,12)
\end{aligned}
$$

It is evident that correction factors determined using the data with buildup underscore the correction factors without buildup by as much as a factor of three. Additionally, the correction factors with buildup are not well represented by the empirically determined correction factor function.

Tables 17 and 18 list the water-filled borehole correction factor fit parameters as determined from MicroShield ${ }^{\circ}$ data and Koizumi (Koizumi et al. 1993; Koizumi et al. 1994), respectively. 

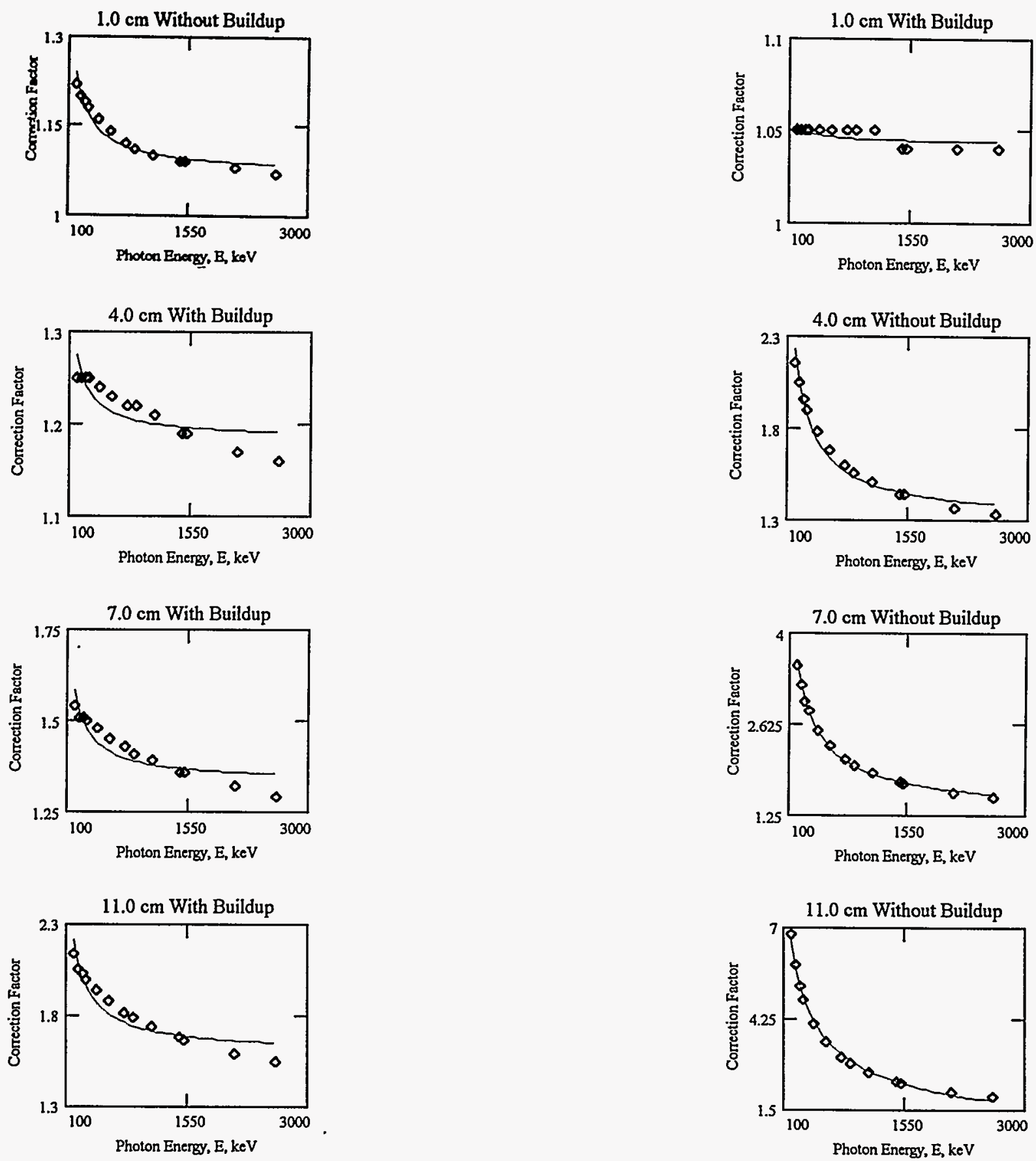

Figure 15. Water-filled borehole correction factors for water annuli of 1.0, 4.0, 7.0 and 11.0-cm thick, with and without buildup. 
Table 17. Water-filled borehole correction factor fit parameters as determined from MicroShield ${ }^{\circ}$ data.

\begin{tabular}{cccc}
\hline & $\begin{array}{c}\text { Effective borehole } \\
\text { Water thickness }\end{array}$ & \multicolumn{2}{c}{ Fit parameters } \\
\cline { 3 - 4 }$(\mathrm{cm})$ & $(\mathrm{cm})$ & $\mathrm{X}_{11}$ & $\mathrm{X}_{12}$ \\
\hline 1 & 12.2 & 1.15 & 72.26 \\
4 & 18.2 & 1.56 & 595.1 \\
7 & 24.2 & 1.653 & 2103 \\
11 & 32.2 & 0.0007 & 8178 \\
\hline
\end{tabular}

Table 18. Water-filled borehole correction factor fit parameters as determined by Koizumi et al. (1993, 1994).

\begin{tabular}{ccc}
\hline \multirow{2}{*}{$\begin{array}{c}\text { Borehole diameter } \\
(\mathrm{cm})\end{array}$} & \multicolumn{2}{c}{ Fit parameters } \\
\cline { 2 - 3 } & \multicolumn{1}{c}{$\mathrm{X}_{11}$} & \multicolumn{1}{c}{$\mathrm{X}_{12}$} \\
11.4 & $1.23 \pm 0.02$ & $83.4 \pm 7.7$ \\
17.8 & $1.73 \pm 0.06$ & $571 \pm 26$ \\
22.9 & $1.51 \pm 0.16$ & $2159 \pm 79$ \\
30.5 & $0.44 \pm 0.21$ & $6716 \pm 123$ \\
\hline
\end{tabular}

The fit parameters from the MicroShield ${ }^{\circ}$ data without buildup are close in value to Koizumi's. It is also important to note that as the borehole diameter increases, so do the uncertainties in the fit parameters; therefore, it is justifiable to state that the MicroShield ${ }^{\circ}$ fit parameters without buildup do show good agreement with Koizumi's experimental values.

A closer look at how MicroShield ${ }^{\circ}$ calculates buildup factors and a brief discussion of gamma-ray spectroscopy fundamentals is necessary here to explain the results of the MicroShield ${ }^{\circ}$ modeling. MicroShield ${ }^{\circ}$ calculates buildup factors by cubic spline interpolation of the tables in ANS 6.4.3 (Trubey 1988). These tables were developed based on Monte Carlo calculations of buildup from isotropic point sources and infinite planar sources, not cylindrical volume sources, and as mentioned previously, the photon fluence rate with buildup that is calculated and displayed by MicroShield ${ }^{\circ}$ is the total photon fluence rate. This is where MicroShield ${ }^{\circ}$ buildup results conflict with the principles of gamma-ray spectroscopy; MicroShield ${ }^{\circ}$ does not calculate and sort the individual photon fluence rates for the scattered photons. A typical gamma-ray spectrum consists of one or more full-energy peaks superimposed upon a continuum. The shape and amplitude of the continuum is due to background radiation and to buildup, or scattering, of the gamma-rays from the source. The shape and amplitude of the full-energy peak is governed by Poissan statistics; as a result, buildup does not affect the net counts under the full-energy peak. Based on this reasoning, MicroShield ${ }^{\circ}$ correction factors for photon fluence rates should be based on data without buildup.

Results from the MicroShield ${ }^{\circ}$ modeling efforts, although slightly low, did follow the same trend as the empirical data collected by Koizumi (Koizumi et al. 1993; Koizumi et al. 1994). Good agreement between 

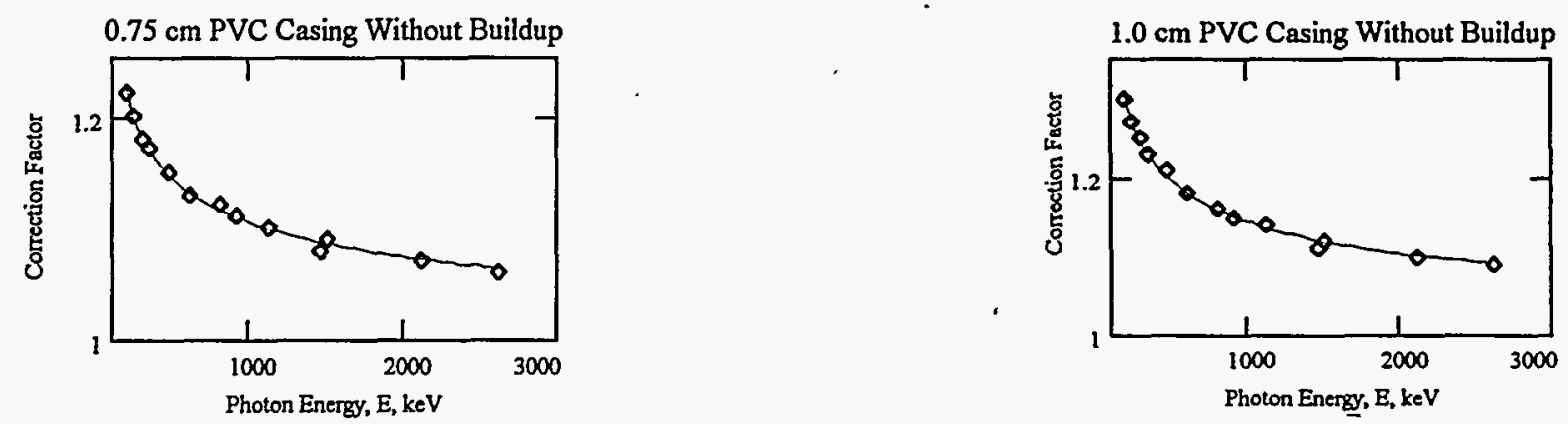

Figure 16. PVC casing correction factors for casing thicknesses of $0.75-\mathrm{cm}$ and $1.0-\mathrm{cm}$.

the two data sets allows for estimation of correction factors for other shielding materials based on MicroShield ${ }^{\circ}$ calculations.

Correction factors developed for PVC were for casing thicknesses of $0.75-\mathrm{cm}$ and $1.0-\mathrm{cm}$. These correction factors are displayed as a function of photon energy in Figure 16. The lines through the data points represent the best fit of the data for the PVC casing correction factor, $\mathrm{K}_{\mathrm{P}}$, are based on Equation 21:

$$
K_{P}=\frac{1}{X_{13}+\frac{X_{14}}{\ln (E)}}
$$

where

$$
\begin{aligned}
& \mathrm{K}_{\mathrm{P}}=\text { correction factor for } \mathrm{PVC} \text { casing } \\
& \mathrm{E}=\text { photon energy }(\mathrm{keV}) \\
& \mathrm{X}_{\mathrm{i}}=\text { best-fit parameters }(\mathrm{i}=13,14) .
\end{aligned}
$$

Fit parameters for the PVC correction factors are listed in Table 19.

The attenuation of photons through PVC, as can be expected, are quite low. This is due to the low density $\left(1.406-\mathrm{g} / \mathrm{cm}^{3}\right)$ and effective atomic number (12.0) of PVC.

Table 19. PVC casing correction factor fit parameters.

\begin{tabular}{ccc}
\hline \multirow{2}{*}{$\begin{array}{c}\text { Casing thickness } \\
(\mathrm{cm})\end{array}$} & \multicolumn{2}{c}{ Fit parameters } \\
\cline { 2 - 3 } & $\mathrm{X}_{8}$ & $\mathrm{X}_{9}$ \\
\hline 0.75 & 1.182 & -1.908 \\
1.0 & 1.214 & -2.34 \\
\hline
\end{tabular}



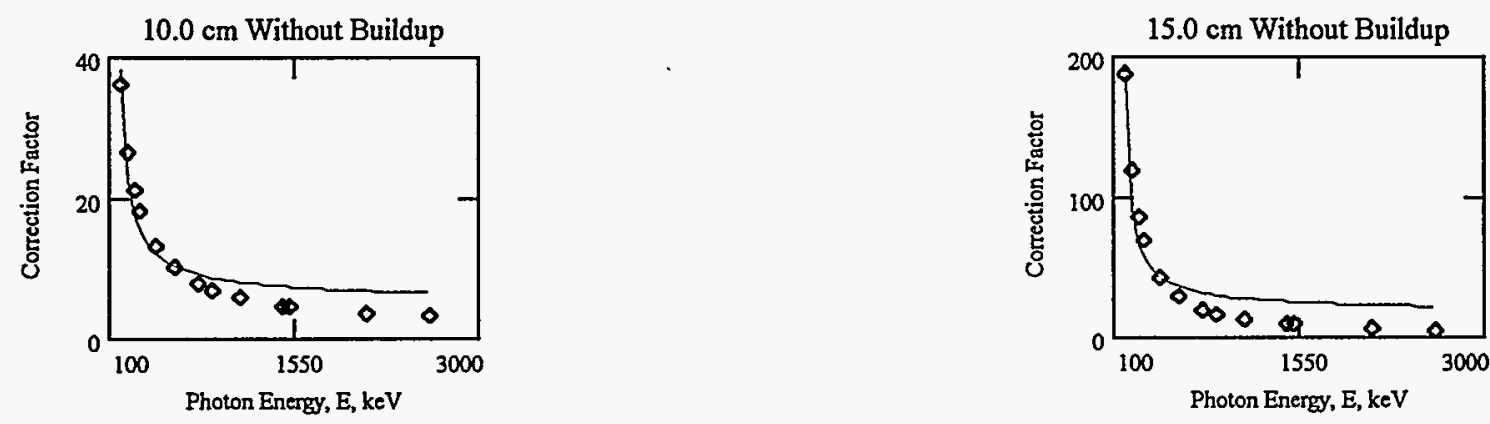

Figure 17. Concrete annular fill correction factors for fill regions $10.0-\mathrm{cm}$ and $15.0-\mathrm{cm}$ thick.

Attenuation of photons through cylindrical concrete shields was also modeled with MicroShield ${ }^{\circ}$, and a set of graphs were generated from the modeling efforts, and are shown in Figure 17. For the low energy photons, the correction factors are quite large, particularly for the lower energy photons. This is due to the relatively high interaction coefficients of low energy photons in concrete.

The concrete annular fill correction factor regression curves follow the general equation:

$$
\mathrm{K}_{\mathrm{C}}=\frac{1}{\mathrm{X}_{15}+\frac{\mathrm{X}_{16}}{\ln (\mathrm{E})}}
$$

where

$$
\begin{aligned}
& \mathrm{K}_{\mathrm{C}}=\text { correction factor for concrete annular fill } \\
& \mathrm{E}=\text { photon energy }(\mathrm{keV}) \\
& \mathrm{X}_{\mathrm{i}},=\text { best-fit parameters }(\mathrm{i}=15,16) .
\end{aligned}
$$

Table 20 lists the values for the best fit parameters for the concrete annular fill correction factors.

The MicroShield ${ }^{\circ}$ correction factors for all the above mentioned cylindrical shield applications display consistently low results when compared to experimental values. There is one obvious limitation to the MicroShield ${ }^{\circ}$ code: MicroShield ${ }^{\circ}$ models neglect the stainless steel tool casing that was present during

Table 20. Concrete annular fill correction factor function fit parameters as determined from MicroShield ${ }^{\circ}$ output.

\begin{tabular}{ccc} 
Annular thickness & \multicolumn{2}{c}{ Fit parameters } \\
\cline { 2 - 3 }$(\mathrm{cm})$ & $\mathrm{X}_{15}$ & $\mathrm{X}_{16}$ \\
\hline 10.0 & 0.401 & -1.961 \\
15.0 & 0.124 & -0.622 \\
\hline
\end{tabular}


Koizumi's measurements. However, the good agreement between the MicroShield ${ }^{\circ}$ data and the empirically determined data demonstrate the effectiveness of the use of computer models to develop correction factors for in-situ gamma-ray spectroscopy logging.

\section{Application of Correction Factors}

Applying correction factors to peaks in high-resolution gamma-ray spectra requires good knowledge of the logging environment, including well completion characteristics and information pertaining to the geologic environment surrounding the borehole. Correction factors for the varying conditions can be estimated using the graphs and regression equations presented in the previous sections.

Equation 14 is the equation used to determine radionuclide concentrations. (Shown again below):

$$
\mathrm{C}(\mathrm{pCi} / \mathrm{g})=\frac{\mathrm{A}(\mathrm{cts} / \mathrm{s})}{\mathrm{N}(\gamma / \text { decay })} \cdot 27.0 \frac{(\mathrm{pCi})}{(\text { decays } / \mathrm{s})} \cdot \frac{1}{\left(3.72 \cdot \mathrm{E}^{-0.38}\right) \cdot 100 \frac{(\mathrm{cts} / \mathrm{s})}{(\gamma / \mathrm{s} / \mathrm{g})}} .
$$

Correction factors are applied to the observed net peak area, A, prior to calculating the radionuclide concentration (Koizumi et al. 1993). The correction factors are constants; therefore they do not have any dimensions associated with them. When correction factors are used, Equation 14 is modified to account for them:

$$
\mathrm{C}(\mathrm{pCi} / \mathrm{g})=\frac{\mathrm{K}_{\mathrm{X}} \cdot \mathrm{A}(\mathrm{cts} / \mathrm{s})}{\mathrm{N}(\gamma / \text { decay })} \cdot 27.0 \frac{(\mathrm{pCi})}{(\text { decays } / \mathrm{s})} \cdot \frac{1}{\left(3.72 \cdot \mathrm{E}^{-0.38}\right) \cdot 100 \frac{(\mathrm{cts} / \mathrm{s})}{(\gamma / \mathrm{s} / \mathrm{g})}}
$$

where $\mathrm{E}$ is entered in $\mathrm{keV}$, and $\mathrm{K}_{\mathrm{X}}$ is the combined correction factor as given by Equation 23 :

$$
\mathrm{K}_{\mathrm{X}}=\left(\mathrm{K}_{\mathrm{H}} \cdot \mathrm{K}_{\mathrm{V}} \cdot \mathrm{K}_{\mathrm{S}} \cdot \mathrm{K}_{\mathrm{RS}} \cdot \mathrm{K}_{\mathrm{I}} \cdot \mathrm{K}_{\mathrm{P}} \cdot \mathrm{K}_{\mathrm{W}} \cdot \mathrm{K}_{\mathrm{C}}\right)
$$

Each individual correction factor on the right-hand side of Equation 23 will not all be used at any one time. Rules pertaining to the use of the correction factors are listed below:

1. $\mathrm{K}_{\mathrm{V}}$ and $\mathrm{K}_{\mathrm{S}}$ will never be used at the same time

2. $\mathrm{K}_{\mathrm{V}}$ and $\mathrm{K}_{\mathrm{S}}$ will never be used in conjunction with $\mathrm{K}_{\mathrm{RS}}$

3. Correction factors should be used based on available information of the logging environment, not guessing

4. If a correction factor is not used, it should be assigned a value of one.

A summary of the environmental correction factors are listed in Table 21. 
Table 21. Summary of environmental correction factors.

\begin{tabular}{|c|c|c|c|}
\hline $\begin{array}{c}\text { Correction } \\
\text { Factor } \\
\end{array}$ & Application & Equation & $\begin{array}{c}\text { List of fit } \\
\text { parameter } \\
\text { values }\end{array}$ \\
\hline $\mathrm{K}_{\mathrm{H}}$ & Thin bed & $X_{1} \cdot E+X_{2}$ & Tbl. 12, p.64 \\
\hline $\mathrm{K}_{\mathrm{v}}$ & Vadose zone & $X_{3} \cdot n+X_{4}$ & Tbl. 13, p.72 \\
\hline $\mathrm{K}_{\mathrm{S}}$ & Saturated zone & $X_{5} \cdot n+X_{6}$ & Tbl. 13, p.72 \\
\hline $\mathrm{K}_{\mathrm{RS}}$ & Partially saturated media & $\begin{array}{c}\mathrm{X}_{7} \cdot \mathrm{n}+\mathrm{X}_{8} \\
\end{array}$ & Tbl. 14, p.75 \\
\hline $\mathrm{K}_{\mathrm{I}}$ & Iron casing & $\overline{X_{9}+\frac{X_{10}}{\ln (E)}}$ & Tbl. 15, p.81 \\
\hline \multirow[t]{2}{*}{$\mathrm{K}_{\mathrm{w}}$} & Water-filled borehole & $\sqrt{x_{11}+\frac{X_{12}}{E}}$ & Tbl. 17, p.83 \\
\hline & & 1 & \\
\hline $\mathrm{K}_{\mathrm{P}}$ & PVC casing & $\begin{array}{c}X_{13}+\frac{X_{14}}{\ln (E)} \\
1\end{array}$ & Tbl. 18, p.86 \\
\hline $\mathrm{K}_{\mathrm{c}}$ & Concrete seal & $\overline{X_{15}+\frac{X_{16}}{\ln (E)}}$ & Tbl. 19, p.87 \\
\hline
\end{tabular}

The correction factors defined in the previous sections are based on regression analyses of computer generated data points, not actual experimental values. The regression equations were determined by empirical curve fitting routines, and are not based on theory. The correction factors are defined for photons ranging in energy from $186-\mathrm{keV}$ to $2,614-\mathrm{keV}$, and values for correction factors should not be extrapolated beyond these limits. The correction factors are only useful when implemented properly and with good knowledge of the logging environment.

\section{Summary of GSLS Calibration and MicroShield ${ }^{\odot}$ Modeling Results}

Calibration of the GSLS at the Technical Measurements Center in Grand Junction resulted in the development of an energy dependent efficiency function for a very simple borehole geometry. Subsequent modeling efforts employing the MicroShield ${ }^{\circ}$ computer code produced potential correction factors for a variety of borehole conditions including vadose and saturated zone, and saturation ratio correction factors, vertical height correction factors, and casing, water-filled borehole, and annular fill correction factors. The calibration efficiency function, in conjunction with the appropriate correction factors, may be applied to net peak areas in spectra collected in regions of unknown quantities of gamma-emitting radionuclides to yield accurate concentration estimations. 


\section{CONCLUSION}

\section{Efficiency Calibration}

Calibration of the Gamma Spectroscopy Logging System in Grand Junction, Colorado allowed the development of an efficiency function for photons ranging in energy from $186-\mathrm{keV}$ to $2,614-\mathrm{keV}$ for simple, uncased borehole geometry. Although the efficiency calibration is accurate for the simple borehole geometry, it has been recognized that the conditions encountered in the field are far different from the calibration conditions, and corrections must be made to peak areas in spectra collected under non-standard conditions.

\section{MicroShield ${ }^{\odot}$ Correction Factors}

Computer modeling of the various conditions that may be encountered in the field is one method for the development of correction factors (Koizumi 1988; Wilson et al. 1979A; Conaway 1991; Wilson et al. 1991; Gadeken et al. 1991; Wilson et al. 1993). The best approach for determining the effect of various conditions that may be encountered is to consider each condition separately, and methodically.

The first set of MicroShield ${ }^{\circ}$ models were necessary to confirm that the calibration sources at the Technical Measurements Center represented an infinite cylindrical, volume source. The results from this test were conclusive of that fact. This study also produced a set of correction factors for measurements taken in thin lithologic beds. It was shown that the relative photon fluence rates decrease linearly with decreasing bed thickness, supporting the first hypothesis.

The second set of computer models were developed to determine the effects of changing the porosity and the moisture content of the geologic environment surrounding the borehole from that of the standard calibration conditions. The second hypothesis was supported by the vadose and saturated zone, and saturation ratio correction factors. It was demonstrated that the photon fluence rates increase linearly with increasing porosities for all energies for any given moisture content. Additionally, it was shown that under conditions of an infinite source geometry, there is no energy dependance of the vadose and saturated zone, and saturation ratio correction factors.

The final portion of this thesis involved the comparison of MicroShield ${ }^{\circ}$ correction factors for iron casing and water-filled boreholes to correction factors determined experimentally by Koizumi (Koizumi et al. 1993). The results showed good agreement between correction factor values and the empirically determined curves. Based on the good agreement between these two data sets, correction factors were estimated for PVC casing and annular regions filled with cement to simulate other types of well completion environments.

The calibration sources in Grand Junction allowed the development of counting efficiencies for a specific set of conditions. Computer modeling of various other conditions that may be encountered in the borehole environment will allow for extrapolation between the calibration conditions and the actual logging conditions. However, in order for the correction factors to improve the accuracy of the estimations of radionuclide concentrations, the logging conditions must be well understood so the appropriate correction factors are applied. This provides a rational method to estimate the efficiencies for the broad continuum of possible field conditions. The end result of a good efficiency function and proper correction factors is a systematic, accurate method for estimating gamma-emitting radionuclide concentrations in-situ. 


\section{REFERENCES}

Bertozzi, W., D. V. Ellis, J. S. Wahl, 1981, "The Physical Foundation of Formation Lithology Logging with Gamma Rays," Geophysics 46:1439-1455.

Bevington, P. R. and D. K. Robinson, 1992, Data Reduction and Error Analysis for the Physical Sciences, New York: McGraw-Hill, Inc.

Blizard, E. P., A. Foderaro, N. G. Goussev, E. E. Kovalev, 1968, Extended radiation sources (point kernel integrations). In: Engineering Compendium on Radiation Shielding, Volume 1: Shielding Fundamentals and Methods, Berlin: Springer-Verlag.

Bohn, H. L., B. L. McNeal, G. A. O'Connor, 1985, Soil Chemistry, Jolnn Wiley \& Sons, Inc.

Browne, E. Firestone, R. B., 1986, Table of Radioactive Isotopes, New York: John Wiley \& Sons, Inc.

Cember, H., 1989, Introduction to Health Physics, New York: Pergamon Press, 1989.

Chase, W. Brown, F., 1992, General Statistics, New York: John Wiley \& Sons, Inc.

Conaway, J. G., 1991, Identification of Artificial Gamma-emitting Nuclides Using a Scintillator-based Gamma-ray Spectral Logging System, Los Alamos, NM: Los Alamos National Laboratory; Report LA-UR-91-2590.

Czubek, J. A., 1969, "Influence of Borehole Construction on the Results of Spectral Gamma-logging," In: Proceedings of the Symposium on the Use of Nuclear Techniques in the Prospecting and Development of Mineral Resources, International Atomic Energy Agency, Vienna, pp. 37-53.

EG\&G ORTEC, 1994, GammaVision software, version 1.05.

EG\&G ORTEC, 1994, Maestro II emulation software, version 1.70.

Erdtmann, G. and W. Soyka, 1979, Die Gamma-linien der Radionuklide, Weinheim, Deutschland: Verlag Chemie GmbH.

Fertl, W. H., 1979, "Gamma Ray Spectral Data Assists in Complex Formation Evaluation," The Log Analyst 20:3-37.

Fetter, C. W., 1994, Applied Hydrogeology, New York: Macmillan College Publishing Company.

Gadeken, L. L. and H. D. Smith, Jr., 1987, "TracerScan: A Spectroscopy Technique for Determining the Distribution of Multiple Radioactive Tracers in Downhole Operations." The Log Analyst 28:27-36. 
Gadeken, L. L., H. D. Smith, Jr., D. J. Seifert, 1988a, "Calibration and Analysis of Borehole and Formation Sensitivities for Gamma Ray Spectroscopy Measurements with Multiple Radioactive Tracers," The Log Analyst 29:159-176; 1988A.

Gadeken, L. L., H. D. Smith, Jr., D. M. Arnold, C. A. Robbins, 1988b, "Natural Gamma Ray Spectroscopy Applied to Borehole Measurements," In: Institute of Electrical and Electronic Engineers Transactions on Nuclear Science, 1987 Nuclear Science Symposium, 1987 Symposium on Nuclear Power Systems, Volume 35, IEEE Nuclear and Plasma Sciences Society, San Francisco, CA 1988B: 822-826.

Gadeken, L. L., M. L. Gartner, D. E. Sharbak, D. F. Wyatt, 1991, "The Interpretation of Radioactive-tracer Logs using Gamma-ray Spectroscopy Measurements," The Log Analyst 32:25-34.

Giles, J. R., 1995, Gamma spectroscopy logging system, Poster presentation, “Environmental Restoration 1995" Conference: INEL Technology Forum, Denver, 1995.

Glasstone, S. and A. Sesonske, 1981, "Nuclear Reactor Engineering," New York: Van Nostrand.

Griffith, G., R. P. Gardner, K. Verghese, 1992, "The NaI Gamma-ray Detector Response Functions Using Semiempirical Monte Carlo Modeling," In: Transactions of the American Nuclear Society Conference on Industrial Radiation and Radioisotope Measurement Applications, Volume II, Editor I. O. Macke. American Nuclear Society, La Grange Park, IL 1992: 10-11.

Heistand, B. E. and E. F. Novak, 1984, Parameter Assignments for Spectral Gamma-ray Borehole Calibration Models, Grand Junction, CO: Grand Junction Projects Office, Report GJBX--2(84).

Hyman, S. C., B. Minushkin, J. Certaine, 1955, "How Drill-hole Diameter Affects Gamma-ray Intensity," Nucleonics 13:49-50.

International Atomic Energy Agency, 1976, "Radiometric Reporting Methods and Calibration in Uranium Exploration," Technical Reports Series No. 174, Vienna: IAEA.

International Atomic Energy Agency, 1979, "Gamma-ray Surveys in Uranium Exploration," Technical Reports Series No. 18, Vienna: IAEA.

Killeen, P. G., K. A. Pflug, C. J. Mwenifumbo, R. L. Zelmer, B. A. McCallum, 1993, “Application of Spectral Gamma-ray Logging to Low-level Radioactive Waste Management Studies at Port Hope, Ontario, Canada," Nucl. Geophys. 7:501-514.

Knoll, G. F., 1989, Radiation Detection and Measurement, New York: John Wiley \& Sons, Inc.

Koizumi, C. J., 1988, Computer Determination of Calibration and Environmental Corrections for a Natural Spectral Gamma-ray Logging System, Richland, WA: Hanford, Report WHC-SA-0229. 
Koizumi, C. J., J. R. Brodeur, W. H. Ulbricht, R. Price, 1991, Calibration of the RLS HPGe Spectral Gamma Ray Logging System, Richland, WA: Hanford, Report WHC-EP-0464.

Koizumi, C. J. and R. K. Price, 1993, Calibration of the Radionuclide Logging System Germanium Detector, Richland, WA: Hanford; Report WHC-SD-EN-TRP-004.

Koizumi, C. J., J. R. Brodeur, R. K. Price, J. E. Meisner, D. C. Stromswold, D. C., 1994, "High-resolution Gamma-ray Spectrometry Logging for Contamination Assessment." Nucl. Geophys. 8:149-164.

Lauber, A. and O. Landström, 1972, "A Ge(Li) Bore Hole Probe for In Situ Gamma ray Spectrometry," Geophysical Prospecting 20:800-813.

Leino, R, D. C. George, B. N. Key, L. Knight, W. Steele, 1994, Field Calibration Facilities for Environmental Measurement of Radium, Thorium, and Potassium, Grand Junction, CO: Grand Junction Projects Office; Report DOE/ID/12584-179 GJ/TMC-01(Third Edition) UC-902.

Mathews, M. A., H. R. Bowman, H. Long-ji, M. J. Lavelle, M. J., Smith, J. R. Hearst, H. A. Wollenberg, Jr., S. Flexser, 1986, Low Radioactivity Spectral Gamma Calibration Facility, Los Alamos, NM: Los Alamos National Laboratory; Report LA-UR--86-980.

MathSoft, Incorporated, Mathcad 5.0 Plus for Windows \& User's Guide, Cambridge, MA: MathSoft, Inc., 1991-1994.

Microsoft Corporation, Microsoft $_{\circledast}$ Excel Version $5.0 \&$ User's Guide, U.S.A.: Microsoft $_{\circledast}$ Corporation, 1993-1994.

National Institute of Standards and Technology, 1988, NIST Standard Reference Database 8, X-ray and Gamma-ray Attenuation Coefficients and Cross Sections Database Version 2.0, Programmer Berger, M. J. Gaithersburg: Standard Reference Data NIST.

National Standard Reference Data System, 1969, Photon Cross Sections, Attenuation Coefficients, and Energy Absorption Coefficients from $10 \mathrm{keV}$ to $100 \mathrm{GeV}$, NSRDS-NBS 29, Washington, D.C., NBS.

Nuclear Data Sheets, 1989, produced by the National Nuclear Data Center for The International Network for Nuclear Structure Data Evaluation, Edited by Martin, M. J.; Tuli, J. K. New York: Academic Press.

Negin, C. A. and G. Worku, MicroShield Version 4 Verification \& Validation Report, Part I, Test Plan and Test Results, Grove Engineering: 1992, 1993A.

Negin, C. A. and G. Worku, MicroShield version 4.10 user's manual, Grove Engineering; 1992, $1993 \mathrm{~B}$.

Paton, T. R., 1978, The Formation of Soil Material, London: George Allen \& Unwin Ltd.

Press, W. H., S. A. Teukolsky, W. T. Vetterling, B. P. Flannery, 1992, Numerical Recipes in FORTRAN, the Art of Scientific Computing, New York: Cambridge University Press. 
Randall, R., 1994, Calibration of the Radionuclide Logging System Germanium Detector, Richland, WA: Hanford, Draft.

Rhodes, D. F., R. A. Stallwood, W. E. Mott, 1961, "Intensity of Unscattered Gamma rays Inside Cylindrical Self-absorbing Sources." Nucl. Sci. and Engr. 9:41-46.

Rhodes, D. F. and W. E. Mott, 1966, "Quantitative Interpretation of Gamma-ray Spectral Logs," Geophysics 31:410-418; 1966.

Schleien, B, 1992, The Health Physics and Radiological Health Handbook, Scinta, Inc., Silver Spring 1992: 152, 281-285.

Sposito, G., 1989, The Chemistry of Soils, New York: John Wiley \& Sons, Inc.

Truby, D. K., 1988, New Gamma-ray Buildup Factor Data for Point-kernel Calculations, ANS 6.4.3 Standard Reference Data, Oak Ridge, TN: Oak Ridge National Laboratory; Report ORNL/RSIC-49/R-1; 1988.

Truman, R. B., D. K. Davies, W. E. Howard, R. K. Vessell, 1986, "Utilization of Rock Characterization Data to Improve Well Log Interpretation," In: Proceedings of the 27th Annual Logging Symposium on the Society of Professional Well Log Analysts, Society of Professional Well Log Analysts, Houston, TX 1986: V 1-21.

Turner, J. E., 1986, Atoms, Radiation, and Radiation Protection, New York: Pergamon Press.

Wilson, R. D., D. C. Stromswold, M. L. Evans, M. Jain, D. A. Close, D. A., 1979a, "Spectral Gamma-ray Logging II: Formation and Thin Bed Effects," In: Transactions of the Society of Professional Well Log Analysts Twentieth Annual Logging Symposium Volume II, Society of Professional Well Log Analysts, Houston, TX 1979A: FF 1-17.

Wilson, R. D., D. C. Stromswold, M. L. Evans, M. Jain, D. A. Close, 1979b, "Spectral Gamma-ray Logging III: Borehole Correction Factors," In: Transactions of the Society of Professional Well Log Analysts Twentieth Annual Logging Symposium Volume II, Society of Professional Well Log Analysts, Houston, TX 1979B: EE 1-16.

Wilson, R. D., D. C. Stromswold, 1981, Spectral Gamma-ray Logging Studies, Grand Junction, CO: Grand Junction Projects Office; Report GJBX-21(81).

Wilson, R. D., J. G. Conaway, 1993, "Simulations of Spectral Gamma-ray Logging Tool Response to Formation and Borehole Wall Source Distributions," Nucl. Geophys. 7:35-53.

Worku, G., C. A. Negin, MicroShield Version 4 Verification \& Validation Report, Part II, Technical Bases Document, Grove Engineering: 1992, 1993. 
Worku, G., P. Rhinelander, D. Snee, 1992, MicroShield Version 4.10, Rockville, MD: Grove Engineering, 1992.

Young, J. H., 1980, "Spectral Gamma-ray (KUT) Borehole Logging," Paper presented at: 55th Annual Fall Technical Conference and Exhibition of the Society of Petroleum Engineers of ALME, American Institute of Mining, Metallurgical, and Petroleum Engineers, Inc., Dallas, TX 1980: Paper No. 9465, p. 12.

Zhao, J., J. Liu, R. Zhang, H. Ni, S. Wu, 1991, "High Resolution Borehole Logging Techniques to Analyze Elements in Formations,." In: Proceedings of an International Symposium on Nuclear Techniques in the Exploration and Exploitation of Energy and Mir eral Resources, International Atomic Energy Agency, Vienna 1991: 289-297. 